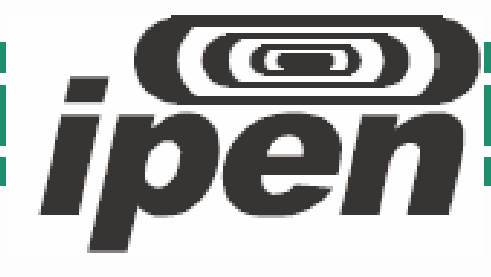

AUTARQUIA ASSOCIADA À UNIVERSIDADE DE SÃO PAULO

\title{
MEDIDAS DO PRIMEIRO COEFICIENTE DE TOWNSEND DE IONIZAÇÃO NO ISOBUTANO PURO SUBMETIDO A CAMPOS ELÉTRICOS UNIFORMES
}

ANNA RAQUEL PETRI

Dissertação apresentada como parte dos requisitos para obtenção do Grau de Mestre em Ciências na Área de Tecnologia Nuclear - Aplicações

Orientadora:

Profa. Dra. Carmen Cecília Bueno 
INSTITUTO DE PESQUISAS ENERGÉTICAS E NUCLEARES

Autarquia associada à Universidade de São Paulo

\begin{abstract}
MEDIDAS DO PRIMEIRO COEFICIENTE DE TOWNSEND DE IONIZAÇÃO NO ISOBUTANO PURO SUBMETIDO A CAMPOS ELÉTRICOS UNIFORMES
\end{abstract}

ANNA RAQUEL PETRI

Dissertação apresentada como parte dos requisitos para obtenção do Grau de Mestre em Ciências na Área de Tecnologia Nuclear - Aplicações

Orientadora:

Profa. Dra. Carmen Cecília Bueno

São Paulo 
À minha família, 


\section{AGRADECIMENTOS}

À orientadora Profa. Dra. Carmen Cecília Bueno, pela confiança, incentivo e pelos conhecimentos e experiência transmitidos ao longo destes anos.

À Profa. Dra. Josemary A. C. Gonçalves, pelas importantes sugestões, apoio e imprescindível contribuição a este trabalho.

Ao Dr. Aléssio Mangiarotti, do Laboratório de Instrumentação e Física Experimental de Partículas (LIP) da Universidade de Coimbra, pelas valiosas discussões acerca dos processos físicos envolvidos em nosso sistema e pelas simulações realizadas utilizando o programa Magboltz 2.

Aos colegas Me. Iara Batista de Lima e Me. Túlio Cearamicoli Vivaldini, que pacientemente explicaram a técnica utilizada e por todo auxilio prestado durante o desenvolvimento deste projeto.

Ao Prof. Dr. Jiro Takahashi, do Laboratório do Acelerador Linear da Universidade de São Paulo, responsável pelo projeto e supervisão da construção da câmara.

Ao Eng. Jair S. do Nascimento-Singer, da Semikron Nuremberg/ Alemanha, pela inestimável contribuição no projeto e montagem dos eletrodos e do circuito eletrônico de aquisição dos sinais elétricos.

Ao Eng. José Carlos de Souza, chefe da Oficina Mecânica do Departamento de Física Experimental do Instituto de Física da Universidade de São Paulo pela cuidadosa construção da câmara.

Ao Dr. Wilson Aparecido Parejo Calvo, diretor do Centro de Tecnologia Nuclear (CTR) do IPEN-CNEN, por disponibilizar a infraestrutura e as instalações do CTR para a realização deste trabalho.

Ao Conselho Nacional de Desenvolvimento Científico e Tecnológico (CNPq), pela concessão da bolsa de estudos. 


\title{
MEDIDAS DO PRIMEIRO COEFICIENTE DE TOWNSEND DE IONIZAÇÃO NO ISOBUTANO PURO SUBMETIDO A CAMPOS ELÉTRICOS UNIFORMES
}

\author{
Anna Raquel Petri
}

\section{RESUMO}

Neste trabalho são apresentados os valores do primeiro coeficiente de Townsend de ionização, $\alpha$, para o isobutano puro, obtidos com uma câmara de placas paralelas de anodo resistivo no intervalo de campo elétrico reduzido de $140 \mathrm{Td}$ a $230 \mathrm{Td}$. O método empregado baseia-se em uma nova versão da técnica de Townsend pulsada, onde a ionização primária é produzida pela incidência de um feixe de laser pulsado de nitrogênio em um eletrodo (catodo) de alumínio. O anodo de vidro de alta resistividade $\left(\rho=2 \times 10^{12} \Omega . \mathrm{cm}\right)$ protege o detector contra descargas disruptivas. Para validação inicial do método, a comparação entre as correntes elétricas medidas nos regimes de ionização e de avalanche foi usada na determinação dos valores de $\alpha$ no nitrogênio, gás amplamente estudado com dados bem estabelecidos na literatura. Esta técnica foi estendida com sucesso para obtenção do parâmetro $\alpha$ para o isobutano puro. A presença de efeitos relativos à carga espacial, recombinação e à queda ôhmica através do anodo resistivo foi investigada mediante variação da taxa de repetição do feixe de laser, de sua intensidade e do campo elétrico aplicado. Destes processos secundários, somente a queda ôhmica mostrou-se relevante e os valores de campo elétrico reduzido foram corrigidos para este efeito. Os primeiros coeficientes de Townsend obtidos são compatíveis, dentro do erro experimental, com os determinados com o programa Magboltz 2 versões 7.1 e 8.6. 


\title{
MEASUREMENTS OF TOWNSEND FIRST IONIZATION COEFFICIENT IN PURE ISOBUTANE UNDER UNIFORM ELECTRIC FIELDS
}

\author{
Anna Raquel Petri
}

\begin{abstract}
In this work are presented data of Townsend first ionization coefficient, $\alpha$, in pure isobutane, obtained with a parallel plate chamber of resistive anode, for the reduced electric field range of $140 \mathrm{Td}$ up to $230 \mathrm{Td}$. The adopted method is based on a new version of the Pulsed Townsend Technique, where the primary ionization is produced by the incidence of nitrogen pulsed laser beam in an aluminum electrode (cathode). The glass anode of high resistivity $\left(\rho=2 \times 10^{12} \Omega . \mathrm{cm}\right)$ protects the detector against sparks. To validate the method, the $\alpha$ values were determined by comparing the ionization and avalanche electric currents in nitrogen, gas widely studied with well-established data in literature. This technique was successfully extended to obtain $\alpha$ parameters in pure isobutane. The presence of effects related to spatial charge, recombination and ohmic drop across the resistive anode was investigated by varying laser pulse repetition rate, its intensity and applied electric field. Of these secondary processes, only the ohmic drop was relevant and the reduced electric field values were corrected for it. The first Townsend coefficients obtained are compatible, within the experimental errors, with those determined with Magboltz 2 program versions 7.1 e 8.6.
\end{abstract}




\section{SUMÁRIO}

Página

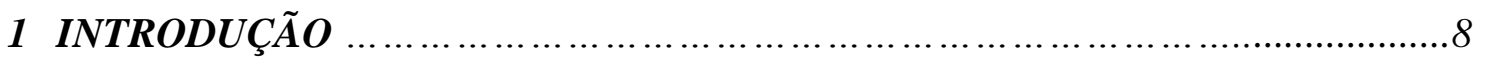

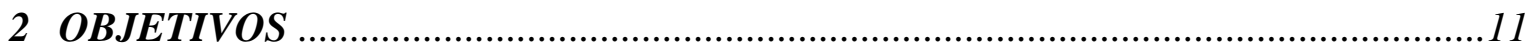

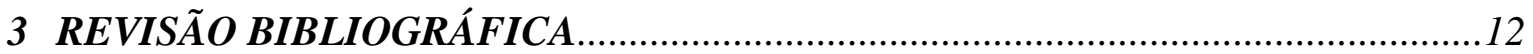

3.1 Processos colisionais mais importantes em detectores gasosos...................................12

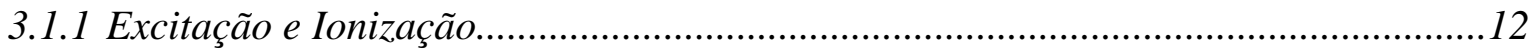

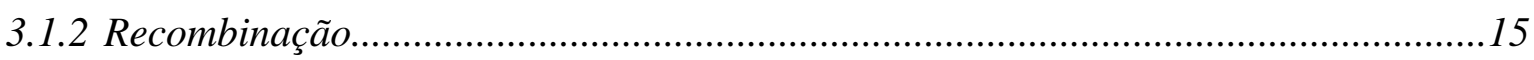

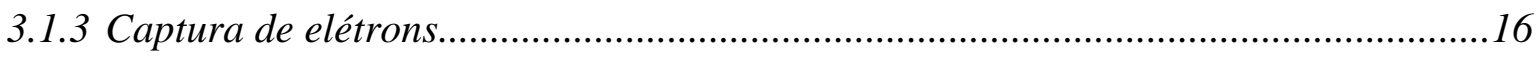

3.2 Fenômenos de Transporte em gases.......................................................................... 17

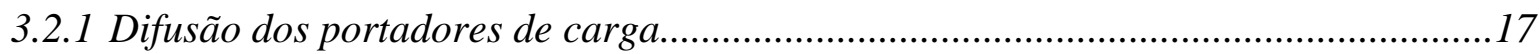

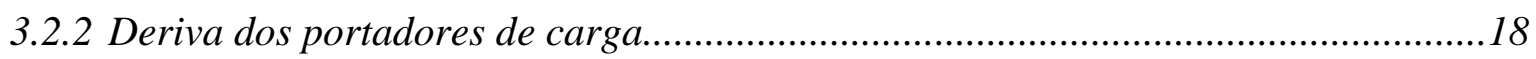

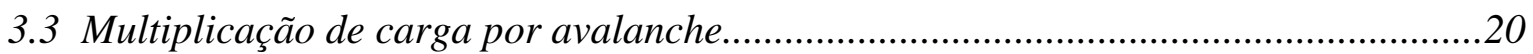

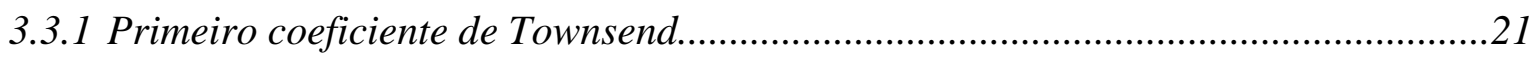

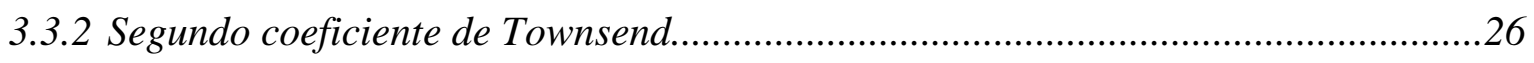

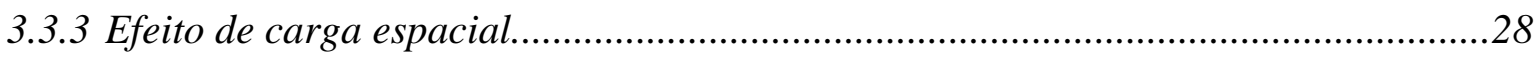

3.3.4 Disruptura gasosa em campos elétricos uniformes...................................................30

3.3.5 Métodos para a determinação do parâmetro $\alpha$.............................................................

3.3.5.1 Método pulsado ou técnica de Townsend pulsada (Pulsed Townsend Technique)..32

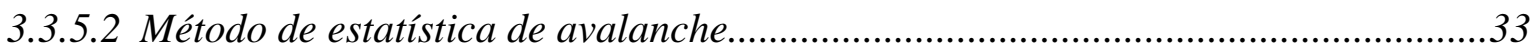

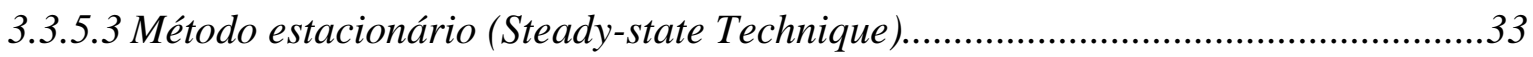

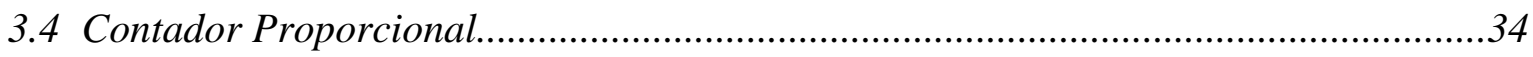

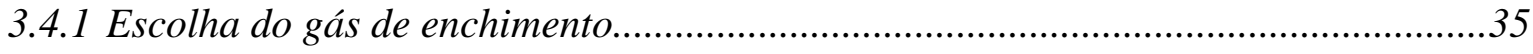

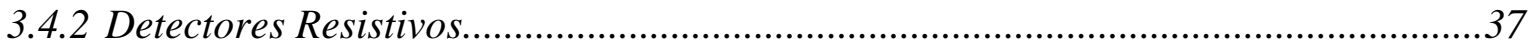

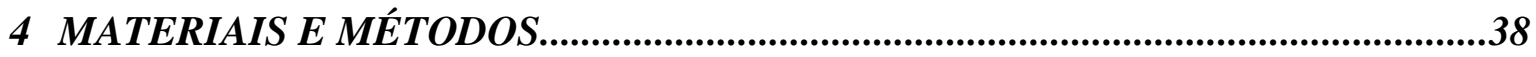

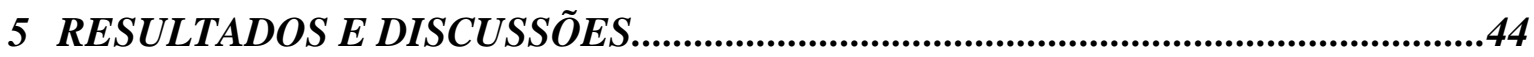

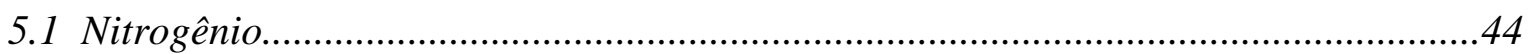

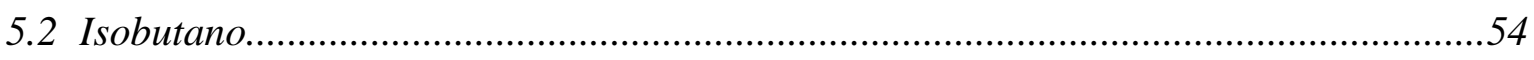

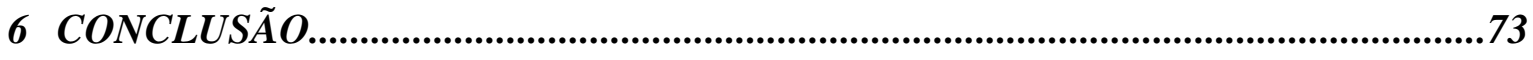

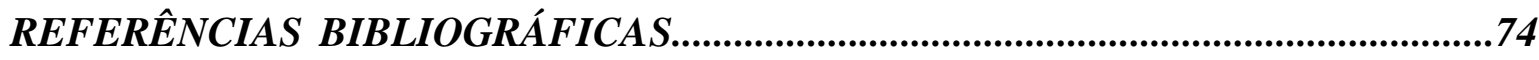




\section{INTRODUÇÃO}

Os avanços nos experimentos de Física de Altas Energias têm sido a principal motivação para a otimização e desenvolvimento de detectores de radiação [1]. As câmaras de placas paralelas resistivas (Resistive Plate Chambers - RPCs) foram propostas em 1981 por Santonico e Cardarelli [2] e seus principais atrativos são: custo relativamente baixo, simplicidade de construção, alta eficiência de detecção [3], excelentes resoluções temporal (até 50 ps) e espacial (até $30 \mu \mathrm{m}$ ) [4-6]. Devido a estas características, as RPCs são empregadas no Large Hadron Collider (LHC) como trigger nos experimentos Compact Muon Solenoid (CMS) e A large Toroidal LHC ApparatuS (ATLAS) e em medidas de tempo de vôo no experimento A Large Ion Collider Experiment (ALICE) [5, 7]. Para uma completa compreensão do comportamento destes dispositivos é necessário o conhecimento dos parâmetros de transporte de elétrons nas misturas gasosas utilizadas, em particular do primeiro coeficiente de Townsend de ionização e da velocidade de deriva dos elétrons [8].

O primeiro coeficiente de Townsend de ionização, $\alpha$, representa o número de elétrons secundários produzidos pelo elétron primário por unidade de trajetória na direção do campo elétrico [9]. Este parâmetro de transporte é fundamental para modelar a formação de descargas elétricas em gases [10-12], pois é utilizado para descrever a multiplicação de cargas e o crescimento da corrente elétrica.

Foi desenvolvido um aparato dedicado à investigação dos parâmetros de transporte de elétrons em gases [11] por meio de uma nova versão da Técnica de Townsend Pulsada [13] no Laboratório de Desenvolvimento de Detectores Gasosos, localizado no Centro de Tecnologia das Radiações (IPEN/CNEN-SP). No arranjo empregado, a ionização primária é gerada pela fotoemissão de elétrons produzida pela incidência de um feixe de laser pulsado de nitrogênio em um eletrodo metálico (catodo). Os sinais elétricos decorrentes do movimento dos elétrons em direção a um eletrodo resistivo (anodo) podem ser adquiridos individualmente, por meio de amplificadores e osciloscópios de elevada largura de banda $(\approx \mathrm{GHz})$ ou através da medição da corrente elétrica, utilizando um eletrômetro. 
O parâmetro $\alpha$ depende da intensidade do campo elétrico e da natureza, da temperatura e pressão do gás. Apesar de sua importância, há poucos dados na literatura para gases de estrutura molecular complexa [9]. Um exemplo é o isobutano $\left(\mathrm{iC}_{4} \mathrm{H}_{10}\right)$, gás comumente empregado em detectores de radiação, cujas principais aplicações são enumeradas a seguir:

- em microdosímetros, devido a sua densidade equivalente a dos tecidos humanos moles $[14,15]$;

- em detectores operando de regime de descarga auto-limitada (streamers), tanto puro [16, 17] como em misturas gasosas com argônio $\left(\leq 60 \% \mathrm{Ar}+\geq 40 \% \mathrm{iC}_{4} \mathrm{H}_{10}\right)[18]$

- como inibidor em misturas com gases nobres nos detectores que operam em regime de avalanche $[6,19,20]$. Um exemplo é o denominado "gás mágico", composto de $70 \% \mathrm{Ar}+29,6 \% \mathrm{iC}_{4} \mathrm{H}_{10}+$ 0,4\% freon 13B1, utilizado em câmaras multi-fios (Multiwire Proportional Chamber-MWPC) [21].

Os estudos do primeiro coeficiente de Townsend para o isobutano são escassos, especialmente para campos elétricos reduzidos, E/N, abaixo de $500 \mathrm{Td}\left(1 \mathrm{Td}=10^{-21} \mathrm{~V} \cdot \mathrm{m}^{2}\right)$. Deste modo, esta dissertação contribui com dados do primeiro coeficiente de Townsend no isobutano puro em um intervalo de campo elétrico reduzido (143 Td - $230 \mathrm{Td}$ ) no qual os únicos valores experimentais presentes na literatura do parâmetro $\alpha$ foram obtidos para uma taxa de repetição dos pulsos laser de $15 \mathrm{~Hz}$ por Lima $[22,23]$ em seu projeto de mestrado no Laboratório de Desenvolvimento de Detectores Gasosos. Investigou-se também a presença dos efeitos secundários associados ao arranjo experimental, como carga espacial, queda ôhmica e recombinação, mediante a variação da taxa de repetição $(10 \mathrm{~Hz}$, $15 \mathrm{~Hz}$ e $20 \mathrm{~Hz})$ dos pulsos laser e a intensidade do feixe (66\% - 100\%), além do aumento do campo elétrico aplicado. É importante ressaltar que alguns resultados aqui apresentados foram publicados recentemente por Mangiarotti et. al. [24], em uma colaboração do Laboratório de Desenvolvimento de Detectores Gasosos com o Laboratório de Instrumentação e Física Experimental de Partículas (LIP), da Universidade de Coimbra. 
Esta dissertação é dividida em seis capítulos. No Capítulo 2 são apresentados os objetivos deste trabalho. No Capítulo 3 são discutidos os principais processos físicos envolvidos no funcionamento de um detector de radiação gasoso de elevado ganho, como a multiplicação de cargas e os movimentos de deriva e difusão, e a influência de um eletrodo resistivo em seu comportamento. $\mathrm{O}$ aparato experimental e a metodologia adotada são detalhados no Capítulo 4.

O Capítulo 5 é dividido em duas partes. A primeira é dedicada à validação inicial do método utilizando o nitrogênio, adotado devido à grande quantidade de dados bem estabelecidos disponíveis na literatura [25-27]. A segunda parte refere-se aos valores do primeiro coeficiente de Townsend obtidos para o isobutano puro. No Capítulo 6 são apresentadas as discussões finais sobre os resultados desta dissertação. 


\section{OBJETIVOS}

Determinação do primeiro coeficiente de Townsend para o isobutano puro em função do campo elétrico reduzido no intervalo de $140 \mathrm{Td}$ a $230 \mathrm{Td}\left(1 \mathrm{Td}=10^{-21} \mathrm{~V} \cdot \mathrm{m}^{2}\right)$. Estudo da influência dos efeitos de carga espacial, queda ôhmica e recombinação nos coeficientes de Townsend mediante a variação da taxa de repetição dos pulsos e da intensidade do feixe de laser de nitrogênio. 


\section{REVISÃO BIBLIOGRÁFICA}

Em um gás ordinário, as dimensões de suas moléculas são muito menores que a distância média entre elas. Como essas partículas são eletricamente neutras, elas só interagem entre si através de frequentes colisões elásticas, i.e., suas energias internas permanecem inalteradas. Quando uma radiação ionizante atravessa o gás, ela deposita energia no meio, podendo ionizar as partículas neutras do gás, produzindo pares de íons (elétrons livres e íons positivos). Em detectores de radiação que contém um gás em seu volume sensível, a interação entre as partículas ocorre majoritariamente por processos colisionais. A natureza desses processos depende do tipo de gás (ou da composição da mistura gasosa), sua densidade e da presença de campos elétricos e/ou magnéticos externos e de suas intensidades. A seguir são apresentados os processos colisionais mais relevantes para a operação de detectores gasosos.

\subsection{Processos colisionais mais importantes em detectores gasosos}

Para que a passagem de uma radiação ionizante seja detectada, é necessário que esta deposite energia no volume sensível do detector. Portanto, os processos colisionais relevantes são aqueles que envolvem alteração da energia interna, ou seja, as interações inelásticas (dissociação de uma molécula, recombinação, excitação e ionização de átomos, formação de íons negativos, etc). Para a representação dos processos, consideremos que $A$ e $B$ representam átomos neutros do gás, $e$ é um elétron livre, $h v$ um fóton e os símbolos $*{ }^{+} \mathrm{e}^{-}$indicam, respectivamente, que o átomo está em estado excitado, ionizado positivamente e ionizado negativamente.

\subsubsection{Excitação e Ionização}

Quando um elétron livre colide com um átomo neutro, ele pode transferir parte de sua energia cinética na forma de energia de excitação, como representado abaixo:

$\rightarrow$ Excitação por impacto eletrônico: $e+A \rightarrow e+A^{*}$ 
A probabilidade de excitação por impacto eletrônico é nula no potencial de excitação e cresce até um valor máximo para uma energia ligeiramente acima do potencial de excitação, diminuindo gradualmente depois. O processo inverso é conhecido como desexcitação por impacto eletrônico e o elétron transporta, após a colisão, a energia de excitação do átomo na forma de energia cinética.

A excitação de um átomo também pode ocorrer por:

$\rightarrow$ Excitação por fotoabsorção: $h v+A \rightarrow A^{*}$

Este é um processo pouco provável, a menos que a energia do fóton seja numericamente próxima ao potencial de excitação. Uma molécula pode ter vários modos de excitação, crescendo em número e complexidade para moléculas poliatômicas. Por exemplo, os gases nobres possuem somente transições radiativas, enquanto moléculas poliatômicas fracamente ligadas, como os hidrocarbonetos, apresentam transições não radiativas de natureza rotacional e vibracional. Neste caso também há o processo inverso, a desexcitação radiativa, na qual um fóton é emitido com a energia de excitação do átomo. Uma alternativa à desexcitação radiativa é a ejeção de um elétron orbital com energia cinética correspondente a diferença entre a energia de excitação do átomo e sua energia de ligação, denominado de elétron Auger.

O processo de excitação por impacto eletrônico é importante em detectores gasosos, pois comumente seu volume sensível é composto prioritariamente de átomos de gases nobres, que podem atingir estados metaestáveis como resultado da colisão inelástica com elétrons. Devido à longa meia-vida dos átomos metaestáveis, sua concentração pode ser comparável a das partículas carregadas. Por isso, o efeito Penning, descrito a seguir, é também responsável pela geração de carga elétrica nas misturas gasosas empregadas nos detectores de radiação que serão discutidas no item 3.4.1.

Se ocorrer a colisão do átomo excitado da espécie $A$ com um átomo no estado fundamental da espécie $B, A$ pode se desexcitar transferindo sua energia excedente para o átomo $B$. Esse fenômeno é um processo relevante particularmente se a energia de excitação de $A$ for superior ao potencial de ionização de $B$ e é denominado:

$\rightarrow$ Ionização por Efeito Penning: $A^{*}+B \rightarrow A+B^{+}+e$ 
Em gases monoatômicos como o hélio e o neônio, esse é um efeito de grande importância, já que eles possuem estados metaestáveis com energias $\left(E_{m} \sim 20 \mathrm{eV}\right.$ para o He e 16 eV para o $\mathrm{Ne}$ ) ligeiramente acima do potencial de ionização dos gases moleculares comuns, como o oxigênio e o nitrogênio, que é aproximadamente de $15 \mathrm{eV}$ [28]. Por isso, mesmo a presença de pequenas quantidades de gases moleculares resultam no aumento da ionização [28].

No impacto eletrônico, se a energia do elétron incidente for acima do primeiro potencial de ionização do átomo, um par de íons poderá ser formado:

$\rightarrow$ Ionização por impacto eletrônico: $e+A \rightarrow 2 e+A^{+}$

Este processo é fundamental nos detectores que operam com multiplicação de cargas (contadores proporcional e Geiger-Muller) e sua probabilidade cresce acima do limiar até atingir um valor máximo, que para a maioria dos gases, é de $100 \mathrm{eV}$ [21]. As transições radiativas dos gases nobres produzem fótons com energias que podem ser superiores à energia de ligação de elétrons no átomo. Consequentemente, a absorção desse fóton pelo átomo pode resultar em sua ionização, denominada também de:

$\rightarrow$ Fotoionização: $h v+A \rightarrow e+A^{+}$

Se o gás for composto por moléculas, a absorção de um fóton pode resultar em sua fragmentação:

$\rightarrow$ Processo Fotodissociativo: $h v+A B \rightarrow A^{*}+B$

A dissociação de uma molécula neutra pode ser causada também por impacto eletrônico e excitação e, em geral, os fragmentos são formados em estados excitados. Este processo é a base do funcionamento dos gases inibidores de descargas (quenching), que serão discutidos no item 3.4.1. 


\subsubsection{Recombinação}

A colisão entre um íon positivo e um elétron livre pode resultar na recombinação, que é o fenômeno no qual o íon positivo torna-se neutro pela captura de um elétron livre.

$\rightarrow$ Recombinação radiativa íon-elétron: $e+A^{+} \rightarrow A+h v$

A recombinação radiativa íon-elétron é o tipo mais frequente e pode produzir radiação de curtíssimo comprimento de onda [29]. Alternativamente, em uma colisão entre um íon positivo e um negativo, um elétron pode ser transferido, tornando os dois átomos neutros.

$\rightarrow$ Recombinação radiativa mútua: $B^{-}+A^{+} \rightarrow A+B+h v$

Em ambos os casos, uma terceira partícula pode estar envolvida. Neste caso, não é necessária a emissão de fóton, pois a energia excedente pode ser transportada como energia cinética da terceira partícula. A recombinação é particularmente importante nas regiões onde há grande concentração de portadores, como por exemplo, em uma avalanche de Townsend e ao longo da trajetória de radiações com alto poder de ionização, como a partícula alfa.

No caso de uma molécula positivamente carregada, ela pode ser neutralizada pela recombinação com um elétron livre e subsequente dissociação:

$\rightarrow$ Recombinação dissociativa: $e+A B^{+} \rightarrow A^{*}+B$

O íon positivo pode ser neutralizado também através da transferência de carga por colisão com uma molécula (ou átomo) neutra.

$\rightarrow$ Transferência de carga: $A^{+}+B \rightarrow A+B^{+}$

Esse processo é mais significativo quando há uma mistura gasosa com diferentes tipos de moléculas, pois há uma tendência de transferir a carga positiva para a molécula com menor poder de ionização. 


\subsubsection{Captura de elétrons}

A captura de elétrons ocorre quando um elétron colide com uma molécula, resultando em um íon negativo. O modo mais simples de formação de íons negativos está representado abaixo:

$\rightarrow$ Captura de elétron: $e+A B \rightarrow A B^{-}$

O elétron, ao colidir com uma molécula, pode causar sua dissociação, sendo este capturado por um dos fragmentos:

$\rightarrow$ Captura de elétron dissociativa: $e+A B \rightarrow A+B^{-}$

A energia de ligação do elétron adicional à molécula (ou átomo) é conhecida como afinidade eletrônica, ou eletroafinidade, e é definida como a diferença de energia entre o estado fundamental da molécula neutra e o estado de menor energia do íon negativo correspondente. Uma afinidade eletrônica positiva significa que o íon negativo resultante é estável. A eletroafinidade é diferente para átomos e moléculas do mesmo elemento químico; por exemplo, para o átomo de oxigênio seu valor é $1,46 \mathrm{eV}$ e para as moléculas $\mathrm{O}_{2}$ e $\mathrm{O}_{3}$ é $0,44 \mathrm{eV}$ e $2,10 \mathrm{eV}$, respectivamente.

A tendência de um átomo de atrair elétrons em uma ligação química recebe o nome de eletronegatividade. Átomos com níveis eletrônicos quase completos terão eletronegatividade maior do que átomos com níveis eletrônicos escassamente preenchidos. Quanto maiores forem os valores de afinidade eletrônica e de energia de ionização, maior será a eletronegatividade. Na FIG. 1 é possível observar que os elementos mais eletronegativos são os átomos halogênios, o oxigênio, o nitrogênio e o enxofre, sendo quatro o valor máximo de eletronegatividade na escala de Pauling, correspondente ao flúor. 


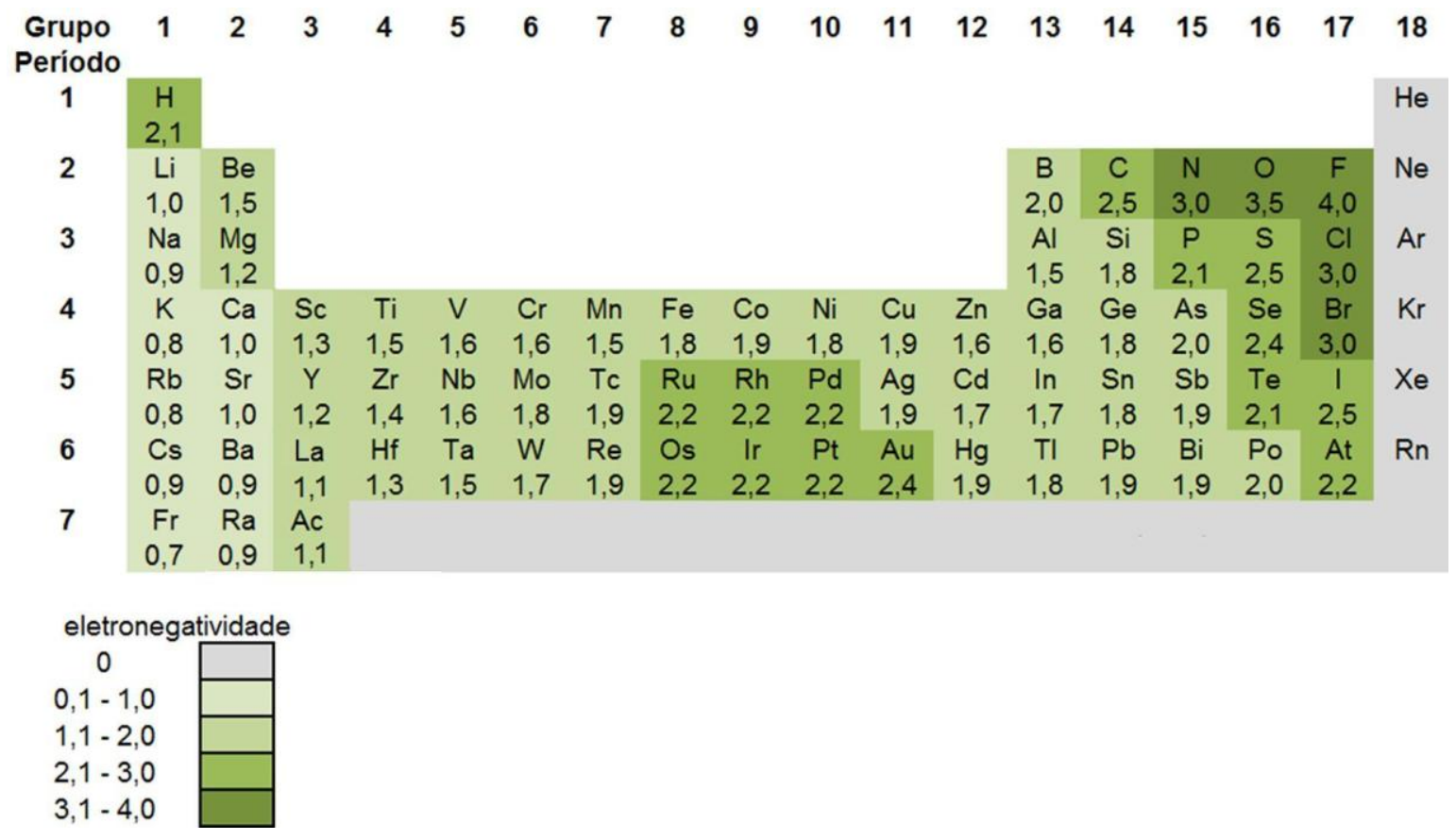

FIGURA 1 - Escala de eletronegatividade de Pauling [30].

\subsection{Fenômenos de Transporte em gases}

Em geral, nos detectores gasosos a coleta nos respectivos eletrodos dos pares de íons formados no gás em decorrência da perda de energia da radiação incidente produz um sinal elétrico de corrente ou tensão. Considerando um detector hipotético, cujo volume sensível é composto por um dado gás a uma pressão constante, seu modo de operação dependeria somente da tensão elétrica aplicada ou da intensidade do campo elétrico [31]. Porém, em condições reais, a operação de um detector depende dos processos colisionais que ocorrem no gás, dos parâmetros de transporte e da distribuição energética dos portadores de carga, além do campo elétrico.

\subsubsection{Difusão dos portadores de carga}

Ao atravessar um meio gasoso, a radiação causa ionização de suas moléculas, produzindo íons positivos e elétrons livres. Na ausência de campo elétrico, as cargas produzidas tendem a se movimentar aleatoriamente para regiões de menor concentração de carga, devido à alta densidade de portadores, sendo esse movimento denominado difusão. Durante seu deslocamento, perdem energia através de múltiplas colisões com as moléculas do gás, até atingirem o equilíbrio térmico.

A distância média entre duas colisões é definida como livre caminho médio $\lambda \mathrm{e}$ depende da mistura gasosa, variando diretamente com a temperatura e inversamente com a 
pressão. Para os elétrons, o livre caminho médio é aproximadamente quatro vezes o dos íons em um gás a uma dada pressão e temperatura, devido a sua pequena massa e dimensão. Em condições normais, a velocidade dos íons varia entre $10^{3}-10^{4} \mathrm{~cm} / \mathrm{s}$, enquanto a do elétron é cerca de $10^{7} \mathrm{~cm} / \mathrm{s}$ [21]. Por isso, o processo de difusão é mais significativo para os elétrons.

Quanto maior for o gradiente de concentração $\nabla n$, maior será o fluxo de partículas $\boldsymbol{J}$, conforme a relação:

$$
J=-D . \nabla n
$$

O sinal negativo representa o movimento das partículas de uma região de alta densidade de concentração para uma região de baixa densidade e a constante de proporcionalidade $D$ é denominada de coeficiente de difusão. Podemos estimar aproximadamente $D$ através da relação $[32,33]$ :

$$
D \approx v_{c} \cdot \lambda^{2}
$$

sendo $v_{c}$ a frequência das colisões, que está relacionada com a velocidade média dos portadores $\bar{v}$ :

$$
\bar{v}=v_{c} \cdot \lambda
$$

Se a densidade dos portadores de carga é $10^{14} \mathrm{~m}^{-3}$ ou maior, a interação entre os portadores de carga não é desprezível [32]. Neste caso, ocorrerá a separação das cargas geradas na ionização primária e, devido à diferença nas suas velocidades de difusão, os elétrons irão mover-se para regiões de menor concentração mais rapidamente. Essa separação resultará no retardo dos elétrons e aceleração dos íons positivos.

\subsubsection{Deriva dos portadores de carga}

Ao aplicar um campo elétrico externo, $E$, no volume do gás, surgirá um movimento líquido dos portadores de carga. A velocidade média deste movimento é denominada de velocidade de deriva. Para íons em um gás, a velocidade de deriva, $W$, pode ser prevista com razoável exatidão pela relação: 


$$
W=\mu \cdot \frac{E}{N}
$$

sendo $\mu$ a mobilidade específica do íon que está movendo-se no gás.

A velocidade de deriva é linearmente proporcional à razão do campo elétrico e da densidade do gás, $E / N$, denominada de campo elétrico reduzido. A densidade do gás é dada por:

$$
N=N_{0} \frac{P(\text { Torr })}{760} \frac{273,15}{T(K)}
$$

sendo $N_{O}$ o número de Loschmidt $\left(N_{O}=2,687 \times 10^{15} \mathrm{~m}^{-3}\right), P$ é a pressão do gás e $T$ sua temperatura. Em homenagem a um dos pioneiros no estudo de transporte de elétrons em gases, John S. Townsend, o campo elétrico reduzido é comumente expresso em townsend $\left(1 \mathrm{Td}=10^{-21} \mathrm{~V} \cdot \mathrm{m}^{2}\right)$.

A mobilidade $\mu$ é aproximadamente constante ao longo de uma faixa de campo elétrico e pressão do gás e não diferencia muito para íons positivos e negativos no mesmo gás. Com pressão de uma atmosfera e campo elétrico de $10^{4} \mathrm{~V} / \mathrm{m}$, a velocidade de deriva dos íons é de $1 \mathrm{~m} / \mathrm{s}$. Considerando detectores de dimensão de centímetros, isso resulta em um tempo de trânsito de aproximadamente $10 \mathrm{~ms}$.

Devido à massa muito menor, os elétrons atingem grande aceleração entre colisões com moléculas neutras de gás, e o valor da mobilidade é tipicamente 1000 vezes maior do que a dos íons. Tempo de coleção dos elétrons são da ordem de $\mu$ s. Em alguns gases, por exemplo, os hidrocarbonetos e as misturas de hidrocarbonetos com argônio, ocorrem um efeito de saturação na velocidade de deriva. Ela atinge um valor máximo para altos valores de campo elétrico e pode até decrescer se a intensidade do campo continuar a aumentar. Em vários outros gases, como o nitrogênio, o hidrogênio e o argônio puros, a velocidade de deriva cresce continuamente para grandes valores de $E / N$ [32]. 


\subsection{Multiplicação de carga por avalanche}

Para valores baixos de campo elétrico, os elétrons e os íons criados pela radiação incidente possuem energia suficiente apenas para realizar o movimento de deriva até os eletrodos correspondentes. Durante a migração desses portadores de carga, ocorrem várias colisões com moléculas neutras. Devido à baixa mobilidade dos íons, eles adquirem pouquíssima energia entre as colisões, mesmo para valores maiores de campo elétrico.

Por outro lado, os elétrons livres, por terem massa pequena, são facilmente acelerados pelo campo e podem atingir valores significativos de energia cinética antes de uma colisão. Aumentando o campo elétrico acima de alguns $\mathrm{kV} / \mathrm{cm}$, os elétrons podem receber energia suficiente entre duas colisões para produzir excitação e ionização.

Se essa energia é maior do que o potencial de ionização de uma molécula neutra do gás, é possível a criação de um par de íons adicional. Como a energia média adquirida pelos elétrons entre as colisões cresce com o aumento do campo elétrico, há um valor limiar de campo acima do qual essa ionização secundária pode ocorrer.

Os elétrons secundários, gerados pelo elétron primário, produzem ionizações terciárias, e assim por diante. O processo de multiplicação de cargas termina quando todos os elétrons livres são coletados no anodo. Esse efeito é conhecido como avalanche Townsend. Devido à grande diferença entre a velocidade de deriva de íons e elétrons, da ordem de mil, e a difusão de cargas no gás, a avalanche de Townsend adquire o formato de uma gota (FIG. 2).
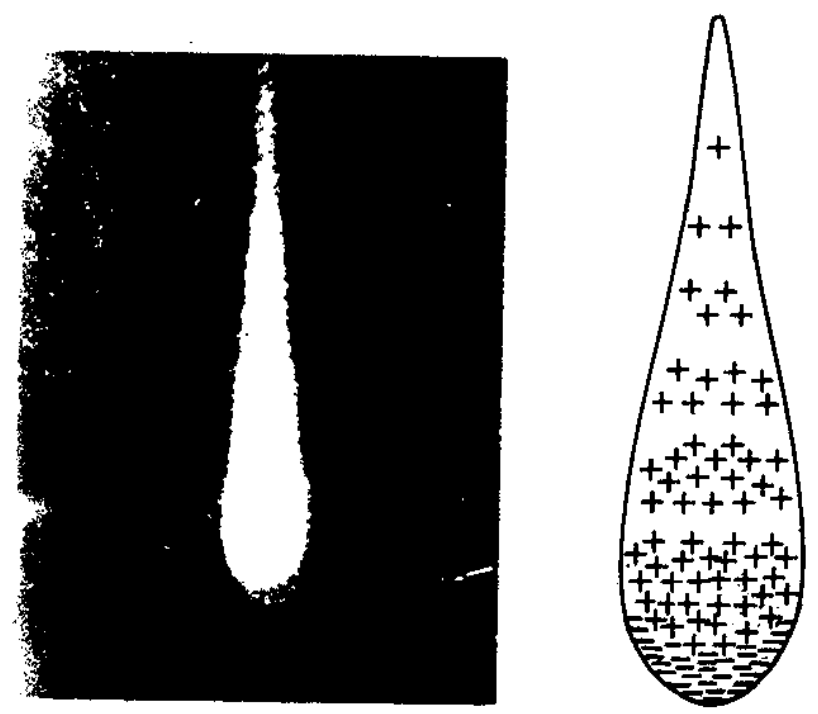

FIGURA 2 - Formato de gota de uma avalanche mostrando os íons positivos deixando atrás os elétrons. A fotografia mostra um formato de avalanche real, obtida com uma câmara de nuvens [21]. 


\subsubsection{Primeiro coeficiente de Townsend}

O livre caminho médio para ionização é definido como a distância média que o elétron tem que percorrer antes de ter uma colisão ionizante. $\mathrm{O}$ inverso do livre caminho médio é denominado de primeiro coeficiente de Townsend de ionização, $\alpha_{i}$, e representa o número de pares de íons produzidos por unidade de comprimento de deriva. $\mathrm{O}$ aumento do número de elétrons, $d n$, por unidade de caminho percorrido, $d x$, é dado pela Equação de Townsend:

$$
d n=n \alpha_{i} d x
$$

Para gases cuja eletronegatividade é significativa, considera-se o coeficiente de ionização efetivo, representado pelo parâmetro $\alpha$. O número de elétrons que são capturados pelas moléculas neutras do gás por comprimento de deriva é denominado de coeficiente de captura de elétrons, simbolizado usualmente por $\eta$. Sendo o primeiro coeficiente de ionização de Townsend $\alpha_{i}$, temos que $\alpha=\alpha_{i}-\eta$. Por conveniência, o coeficiente de ionização efetivo é denominado na literatura somente de coeficiente de ionização.

Para geometria de placas paralelas (campo elétrico constante e uniforme), considerando que não há variações significativas de pressão e temperatura do gás, o primeiro coeficiente de Townsend é constante e, por integração, temos que:

$$
n=n_{o} \cdot e^{\alpha x}
$$

sendo $n_{o} \mathrm{o} \mathrm{n}^{\circ}$ de elétrons primários e $x$ o comprimento da avalanche.

Considerando que todos os elétrons primários são emitidos do catodo, sendo produzidos, por exemplo, pela incidência de um feixe de radiação ultravioleta (FIG. 3), então $x$ será igual à distância entre os eletrodos, $d$. 


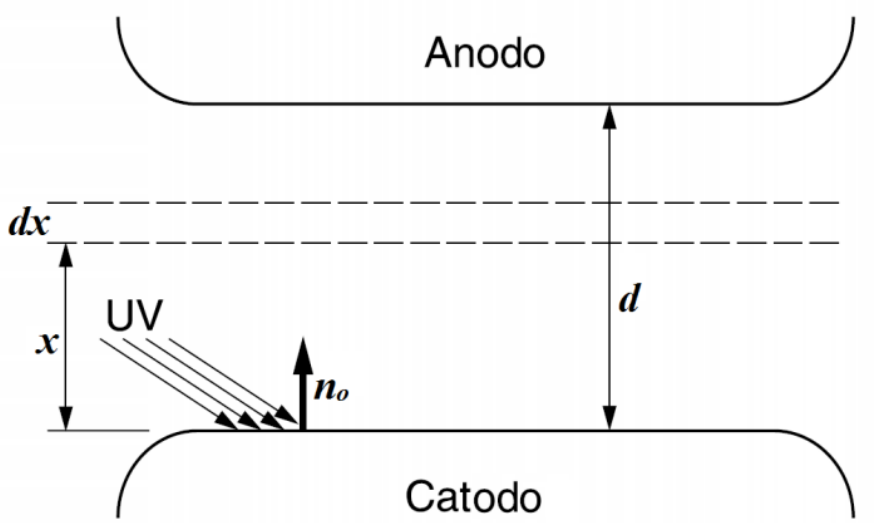

FIGURA 3 - Elétrons primários produzidos por efeito fotoemissivo devido à incidência no catodo de radiação ultravioleta [32].

A multiplicação de cargas pode ser descrita quantitativamente pelo fator de multiplicação, $M$, dado pela relação:

$$
M=\frac{n}{n_{0}}=e^{\alpha d}
$$

A partir da equação (7), temos que a relação entre a corrente elétrica no regime de avalanche e o espaçamento dos eletrodos é:

$$
I=I_{0} e^{\alpha d}
$$

sendo $I_{o}$ a corrente elétrica devido à ionização primária.

Os processos secundários, como a emissão de fótons de desexcitação, que induzem novas avalanches, e a deformação do campo elétrico devido ao efeito de carga espacial, resultam na ruptura gasosa e transição para o regime de faíscas. Fisicamente, há um limite para a multiplicação antes da ruptura do gás, dado pela condição de Raether [21]:

$$
\alpha x \sim 20 \text { ou } M \sim 10^{8}
$$

Com o aumento da distância $x$, a condição de Raether será atingida para menores valores de $\alpha x$, ou seja, para uma dada intensidade de campo elétrico, a probabilidade de ruptura cresce $\operatorname{com} x$. Na prática, a distribuição estatística da energia dos 
elétrons, e, portanto o $M$, em geral, não permite operar o detector com um ganho médio acima de $\sim 10^{6}$ para evitar faíscas.

A razão do primeiro coeficiente de ionização de Townsend e da densidade de moléculas (EQ. 5) é comumente denominada de coeficiente de ionização reduzido ou primeiro coeficiente de ionização de Townsend reduzido. Experimentalmente, obtém-se que o parâmetro $\alpha / N$ é função somente do campo elétrico reduzido (FIG. 4).
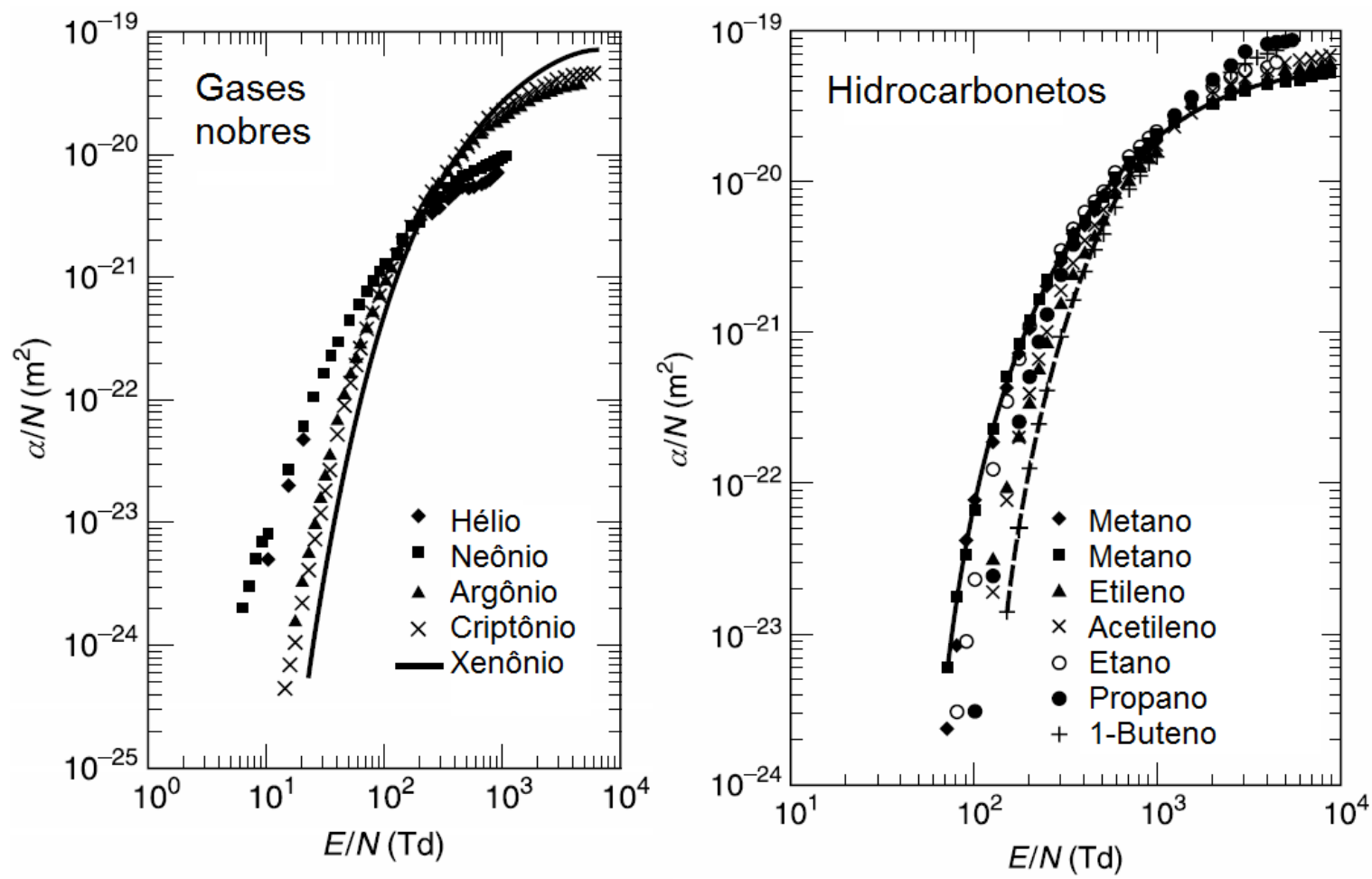

FIGURA 4 - Coeficiente $\alpha / N$ em função do campo elétrico reduzido para gases nobres (esquerda) e hidrocarbonetos (direita) [32].

Em geral, para campos elétricos reduzidos baixos, os hidrocarbonetos complexos e pesados são melhores isolantes. Para E/N intenso eles são melhores condutores, alcançando maiores valores de $\alpha / N$ [32]. Na TAB. 1 são apresentadas algumas das expressões analíticas para $\alpha / N=f(E / N)$ propostas na literatura. 
TABELA 1 - Parametrizações principais presentes na literatura para a relação $\alpha / N=f(S)$, na qual $S=E / N[34,35]$.

\begin{tabular}{ccc}
\hline Autores & $\alpha / N$ & Ano \\
\hline Rose e Korff & $C \sqrt{S}$ & 1941 \\
Diethorn & $\mathrm{FS}$ & 1956 \\
Williams e Sara & $A \exp (-B / S)$ & 1962 \\
Zastawny & $\mathrm{G}\left(\mathrm{S}-\mathrm{S}_{0}\right)$ & 1967 \\
Charles & $H \exp (-K / \sqrt{S})$ & 1971 \\
Aoyama & $A S^{m} \exp \left(-B S^{m-1}\right)$ & 1985 \\
Kowalski & $L S^{3 / 2}$ & 1986 \\
\hline
\end{tabular}

A parametrização mais conhecida foi proposta por Williams e Sara [36] e é válida para pequenos valores do primeiro coeficiente de Townsend [21]:

$$
\frac{\alpha}{N}=A e^{-B \frac{N}{E}}
$$

sendo $A$ e $B$ constantes que dependem da natureza do gás. Na TAB. 2 são apresentados os resultados obtidos para estes parâmetros em gases nobres e hidrocarbonetos.

TABELA 2 - Valores das constantes $A$ e $B$ da parametrização de Williams e Sara e a região de campo elétrico reduzido na qual eles são válidos para gases nobres [33] e hidrocarbonetos [32].

\begin{tabular}{cccc}
\hline Gás & $\mathbf{A}\left(\mathbf{1 0} \mathbf{- 1 6}^{\mathbf{1 6}} \mathbf{c m}^{\mathbf{2}}\right)$ & $\mathbf{B} \mathbf{( T d )}$ & Região de E/N $(\mathbf{T d})$ \\
\hline $\mathrm{He}$ & 0,85 & 96 & $60-420$ \\
$\mathrm{Ne}$ & 1,1 & 280 & $280-1100$ \\
$\mathrm{Ar}$ & 4,0 & 510 & $280-1700$ \\
$\mathrm{Kr}$ & 4,8 & 680 & $280-2800$ \\
$\mathrm{Xe}$ & 7,3 & 990 & $280-2300$ \\
Metano & 2,28 & 599 & $82-405$ \\
Etano & 3,5 & 677 & $141-532$ \\
Etileno & 2,7 & 840 & $121-434$ \\
Acetileno & 4,2 & 939 & $132-804$ \\
Propano & 6,5 & 973 & $100-1889$ \\
Butano & 7,6 & 1136 & $166-1889$ \\
1-Buteno & 5,4 & 1198 & $149-1120$ \\
\hline
\end{tabular}


Não há regra simples para o comportamento do primeiro coeficiente de Townsend para misturas gasosas. Como uma tendência geral, adicionar a um gás nobre um vapor ou gás poliatômico resulta no crescimento da intensidade de campo elétrico necessária para obter um dado valor do primeiro coeficiente de Townsend. Porém, uma aproximação exponencial ainda é possível para pequenos valores de $\alpha$.

Consideremos que cada elétron possui pouca energia ao iniciar um livre caminho médio $\lambda$. Para que sua próxima colisão inelástica seja ionizante, ele deve adquirir do campo elétrico energia superior a $e V_{i}$, sendo $V_{i}$ o primeiro potencial de ionização do gás e $e$ é a carga elétrica fundamental. Assim, a distância mínima que o elétron deve percorrer para ionizar uma molécula do gás é:

$$
l=\frac{V_{i}}{E}
$$

Pela distribuição estatística de livres caminhos, temos que a fração de colisões que excede o livre caminho médio é:

$$
\frac{z_{l}}{z_{0}}=e^{-l / \lambda}
$$

A partir da equação (13) e assumindo que o número total de colisões por unidade de trajetória na direção do campo é $\lambda^{-1}$, podemos determinar o número de colisões ionizantes por unidade de comprimento de deriva, $\alpha$ :

$$
\alpha=\frac{1}{\lambda} e^{-l / \lambda}
$$

Das equações (12) e (14), utilizando $\lambda=\lambda_{1} / N$, pois o livre caminho médio depende da densidade numérica do gás, obtemos:

$$
\frac{\alpha}{N}=\frac{1}{\lambda_{1}} e^{-\frac{V_{i}}{\lambda_{1}} \frac{N}{E}}
$$


Comparando as equações (11) e (15), termos que as constantes $A$ e $B$ da parametrização de Williams e Sara estão relacionadas a grandezas características do gás, sendo:

$$
\begin{aligned}
& A=\frac{1}{\lambda_{1}} \\
& B=\frac{V_{i}}{\lambda_{1}}
\end{aligned}
$$

Entretanto, os valores dados por $A$ e $\quad B$ discordam dos obtidos experimentalmente. As razões para estas divergências são as considerações utilizadas para obter a equação (15). Assumiu-se que os elétrons iniciam sua trajetória após uma colisão com pouca energia cinética e, na prática, um grande número possui energia acima da energia de ionização. Além disso, apenas uma fração dos elétrons com energia acima de $e V_{i}$ irão ionizar ao colidirem. Parte da energia dos elétrons será dispersa em colisões elásticas e processos de excitação. Assim, o significado físico de $A$ é o de um valor de saturação para o qual o coeficiente $\alpha / N$ tende para grandes valores de $E / N$, enquanto $B$ é proporcional a um potencial de ionização efetivo, $V_{e f}$, que inclui as perdas de energia por excitação. Deste modo, o potencial de ionização efetivo, que deve variar entre o primeiro potencial de ionização e a energia média necessária para um elétron ionizar uma molécula do gás, pode ser estimado pela razão das equações (17) e (16):

$$
\frac{B}{A}=V_{e f}
$$

\subsubsection{Segundo Coeficiente de Townsend}

Como descrito no item 2.1.1, a colisão inelástica de elétrons com as moléculas do gás pode, além da produção de carga elétrica por ionização, resultar na excitação destas moléculas e na criação de átomos metaestáveis. Os fótons emitidos na desexcitação das moléculas, dos átomos metaestáveis e dos íons positivos podem produzir elétrons, que iniciarão novas avalanches. Assume-se que esses processos secundários ocorrem predominantemente no catodo devido à ação dos íons positivos e fótons, sendo responsáveis pelo aumento da corrente elétrica acima do previsto pela equação (9). Assim, 
define-se o segundo coeficiente de Townsend de ionização, $\gamma$, como o número de elétrons secundários produzidos pelo elétron primário.

Consideremos $n_{0}$ o número de elétrons liberados do catodo por uma fonte externa, como representado na FIG. 3. O número de elétrons produzidos por todas as fontes no catodo é $n_{0}{ }^{\prime}$, de modo que $\left(n_{0}{ }^{\prime}-n_{0}\right)$ elétrons devem-se somente aos efeitos secundários. O número de elétrons que chegam ao anodo é $n$ e, portanto, são gerados por colisões ionizantes no gás $\left(n-n_{0}{ }^{\prime}\right)$ elétrons. Consequentemente:

$$
\left(n_{0}^{\prime}-n_{0}\right)=\left(n-n_{0}{ }^{\prime}\right) \gamma
$$

Sendo:

$$
n=n_{0}{ }^{\prime \alpha d}
$$

Isolando $n_{0}$ 'na equação (19) e substituindo na equação (20), temos:

$$
n=\frac{n_{0}+\gamma n}{1+\gamma} e^{\alpha d}
$$

Rearranjando a equação (21) e convertendo o número de elétrons em corrente elétrica, obtemos:

$$
I=\frac{I_{0} e^{\alpha d}}{1-\gamma\left(e^{\alpha d}-1\right)}
$$

A equação (22) se reduz a equação (9) quando os processos secundários forem desprezíveis, i. e., para $\gamma \rightarrow 0$ e é válida para gases não eletronegativos à baixa pressão.

O parâmetro $\gamma$ depende do campo elétrico aplicado, do gás e sua densidade, do material constituinte do catodo e também das condições de sua superfície, como oxidação, uniformidade e ocorrências de descargas. Mesmo em condições de alta pureza e vácuo, uma única descarga altera consideravelmente a superfície do catodo, como pode ser observado na FIG. 5. Por isso, $\gamma$ não é uma grandeza reprodutível. 


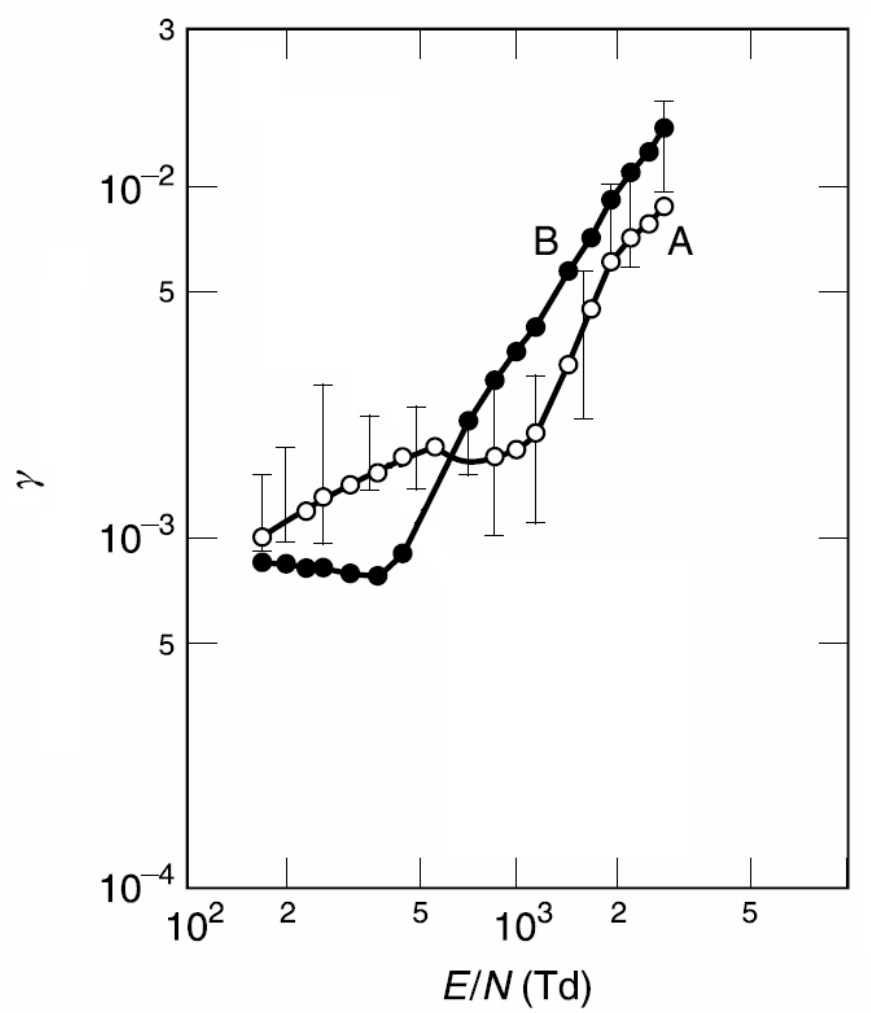

FIGURA 5 - Segundo coeficiente de Townsend no ar seco para um catodo de banhado a ouro. As curvas A e B foram obtidas antes e depois de uma descarga, respectivamente [32].

Em hidrocarbonetos, o segundo coeficiente de Townsend é pequeno $\left(\gamma<10^{-4}\right)$ e ele pode ser adicionado a outros gases para suprir esse coeficiente, permitindo medições de corrente elétrica para fatores de multiplicação grandes $\left(e^{\alpha d}>10^{6}\right)$ para investigar efeitos de carga espacial [32].

\subsubsection{Efeito de carga espacial}

Cada elétron primário irá gerar uma avalanche, criando pares de íons secundários. Os elétrons rapidamente atingem o anodo, por causa de sua alta velocidade de deriva. Mesmo após a coleta dos elétrons gerados em todas as avalanches, os íons positivos permanecem no gás, por possuírem baixa mobilidade. Essa concentração de carga positiva irá alterar localmente o campo elétrico e afeta a multiplicação de carga, sendo esse processo denominado de efeito de carga espacial. Em gases eletronegativos, os íons negativos também contribuirão para a criação de carga espacial. A intensidade e configuração normal do campo elétrico são restauradas quando todos os íons são neutralizados. 
$O$ efeito de carga espacial torna-se significativo no caso de uma intensa ionização primária ou para grandes fatores de multiplicação. Para que não ocorra redução significativa da eficiência do detector, isto implica no compromisso entre a taxa de contagens e a tensão aplicada [37, 38], de modo que os campos elétricos reduzidos sejam menores para taxas de contagens maiores.

Para grandes fatores de multiplicação, a densidade de íons em uma avalanche individual pode ser tão grande que os fotoelétrons gerados próximo à avalanche conseguem adquirir energia suficiente do campo gerado pela carga espacial para iniciar novas avalanches ao redor da avalanche principal. Nesta condição, o campo elétrico entre a carga espacial e o catodo é tão intenso que os elétrons secundários nesta região também iniciarão novas avalanches. Como resultado, uma faísca irá se propagar do anodo para o catodo, caracterizando a transição da avalanche de elétrons (FIG. 6-a) para um streamer (FIG. 6-b).

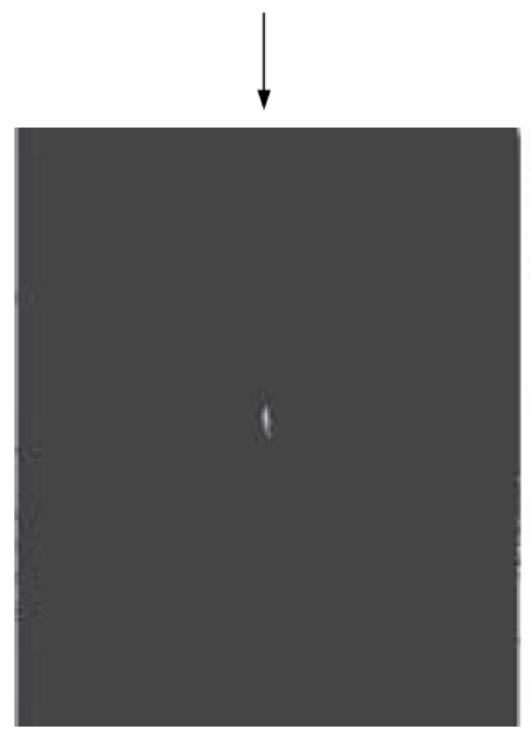

a)

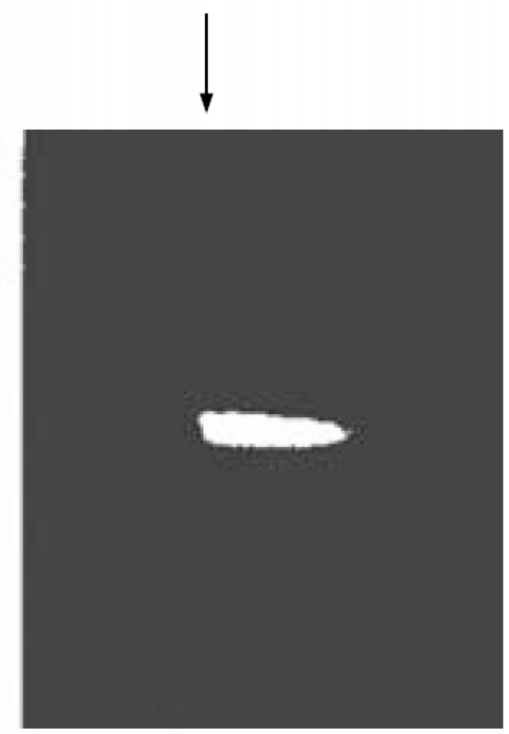

b)

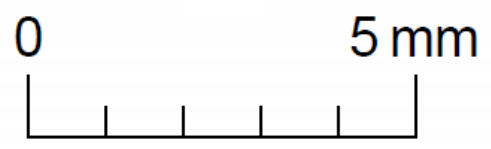

FIGURA 6 - Fotografias de descargas gasosas em contadores cilíndricos operando nos regimes: a) proporcional (ou de avalanche) e b) de streamers. As setas indicam a posição do fio anodo [18]. 


\subsubsection{Disruptura gasosa em campos elétricos uniformes}

A partir de um dado valor de campo elétrico reduzido, a corrente elétrica que flui no gás tende ao infinito, devido à ionização intensa, e o gás torna-se condutor. Nesta condição, o número de elétrons primários e secundários gerados no catodo serão iguais, resultando na realimentação da avalanche e no aparecimento da corrente auto-mantida. O crescimento da corrente é limitado somente pela resistência no circuito e pela fonte de alta tensão. Utilizando a equação (22), obtemos que a condição para a disruptura gasosa é:

$$
\gamma\left(e^{\alpha d}-1\right)=1
$$

Como discutido no item 2.3.1, o primeiro coeficiente de Townsend reduzido é função do campo elétrico reduzido, $\alpha / N=f(E / N)$. Se assumirmos que o segundo coeficiente de Townsend também é função do campo elétrico reduzido, $\gamma=\phi(E / N)$, podemos reescrevendo a equação (23) para um campo elétrico uniforme, $E_{S}=V_{S} d$, sendo $V_{s}$ a tensão de disruptura:

$$
N d=\frac{1}{f\left(V_{s} / N d\right)} \ln \left[1+\frac{1}{\phi\left(V_{s} / N d\right)}\right]
$$

A partir da equação (24), temos que a tensão de disruptura é função somente do produto do número de moléculas por unidade de volume e do espaçamento dos eletrodos, $V_{s}=\psi(N d)$, e esse resultado é conhecido como lei de Paschen. Utilizando a parametrização de Williams e Sara (equação 11) na equação (24), a tensão de disruptura será:

$$
V_{s}=\frac{B N d}{\ln \left[\frac{A N d}{\ln \left(1+\frac{1}{\gamma}\right)}\right]}
$$

Nas curvas da tensão em função de $N d$, denominadas de curvas de Paschen (FIG. 7), podem ser observados um mínimo, característico da lei de Paschen. 


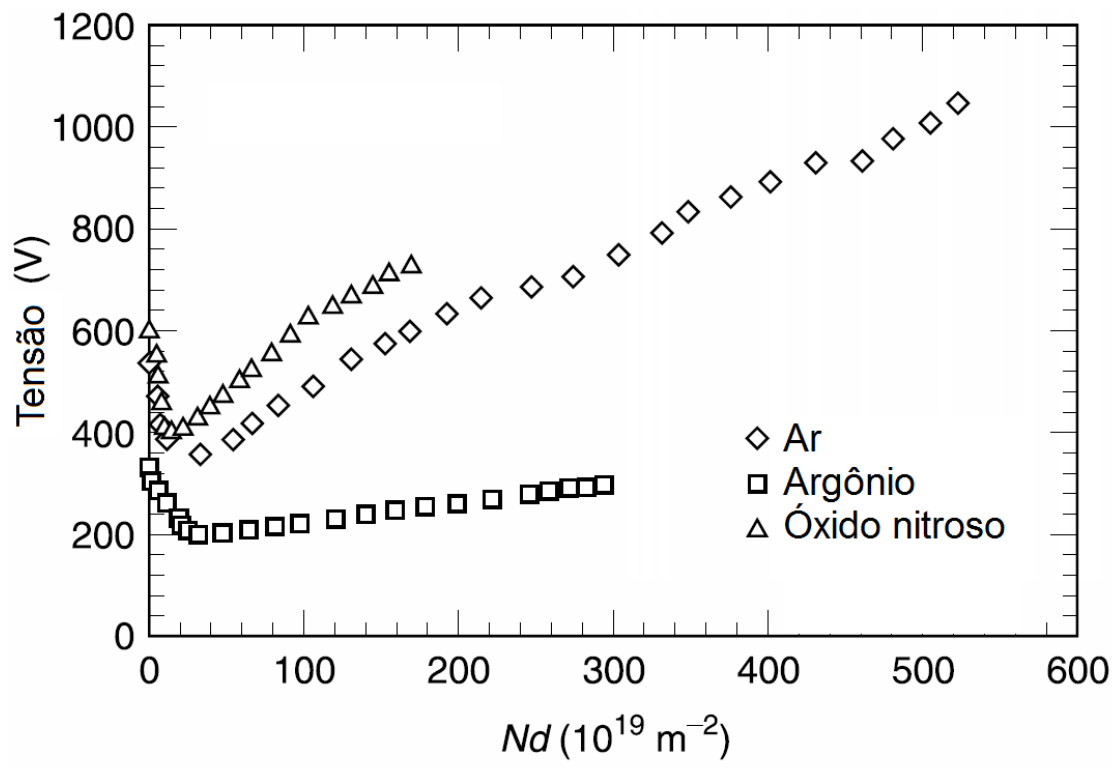

FIGURA 7 - Curvas de Paschen para diferentes gases. A Lei de Paschen possui um mínimo, obtido para todos os gases. [32]

Para determinar a tensão de disruptura mínima, a equação (25) foi derivada e igualada a zero:

$$
N d_{\text {min }}=\frac{2,718}{A} \ln \left[1+\frac{1}{\gamma}\right]
$$

A FIG. 8 apresenta as curvas resultantes das equações (25) e (26) em função do segundo coeficiente de Townsend para o ar seco.

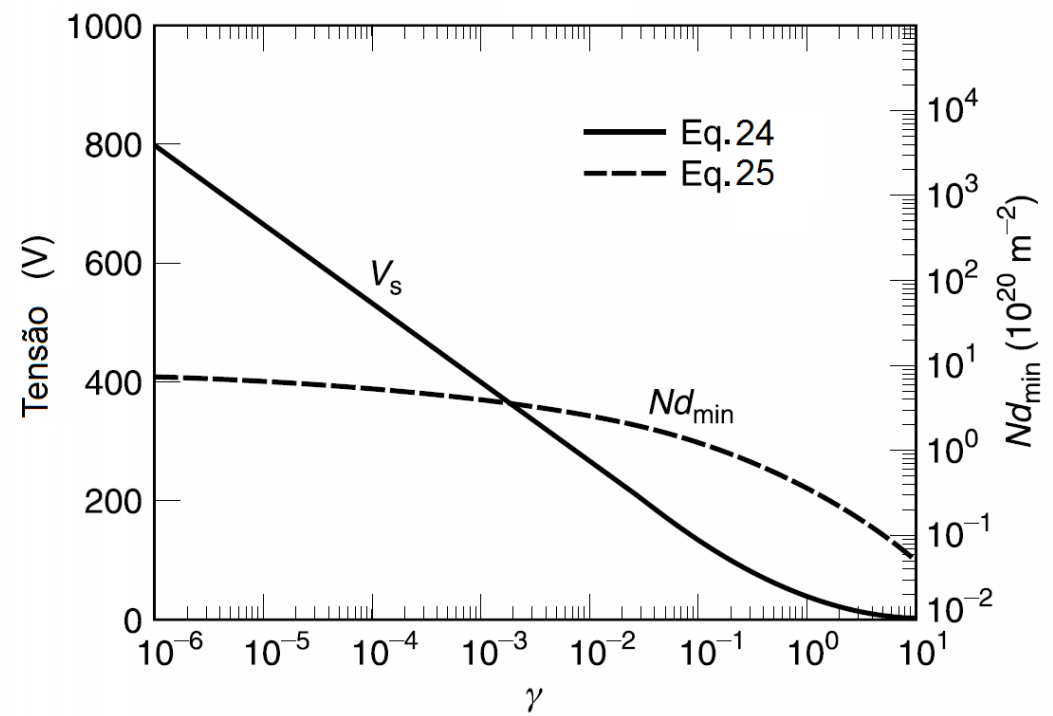

FIGURA 8 - Comportamento da tensão e do produto $\mathrm{Nd}_{\min }$ em função do ar seco[32]. 
Substituindo (26) em (25), temos que a tensão de disruptura mínima será:

$$
V_{s, \min }=2,718 \frac{B}{A} \ln \left[1+\frac{1}{\gamma}\right]
$$

e, portanto, depende do gás e do catodo empregados.

Consequentemente, para a disruptura gasosa, o valor mínimo de E/N pode ser estimado pela razão de (27) e (26):

$$
\left(\frac{E}{N}\right)_{s, \min }=B
$$

Como os parâmetros do modelo de Williams e Sara dependem somente das características do gás, obtém-se que o campo elétrico mínimo para a disruptura independe do catodo utilizado.

\subsubsection{Métodos para a determinação do parâmetro $\alpha$}

Os valores experimentais do primeiro coeficiente de Townsend podem divergir entre si por causa da metodologia adotada em sua obtenção, como foi observado por Sakai et al [39, 40], Tagashira et al [41] e Gallagher et al [42]. São descritos neste capítulo os três métodos mais difundidos para a medição do coeficiente de ionização: o método pulsado, a estatística de avalanches e o método estacionário. Porém, motivados pelos avanços na eletrônica de aquisição e análise do sinal, novas técnicas estão sendo propostas, além de versões dos métodos aqui discutidos.

\subsubsection{Método pulsado ou técnica de Townsend pulsada (Pulsed Townsend Technique)}

A principal vantagem deste método é permitir a determinação simultânea da velocidade de deriva, do coeficiente de difusão longitudinal e do primeiro coeficiente de Townsend. A ionização primária é produzida no catodo por um pulso de radiação ultravioleta.

Os dados podem ser obtidos de dois modos, dependendo da escolha da constante de tempo, $\tau$, do circuito empregado para extração do sinal em relação aos tempo de trânsito dos elétrons $\left(T_{e} \sim 10^{-7}\right.$ a $\left.10^{-5} \mathrm{~s}\right)$ ou dos íons positivos e negativos $\left(T_{i o n} \sim 10^{4}\right.$ a $\left.10^{-2} \mathrm{~s}\right)$. 
No modo integral, $\tau>T_{e}$ ou $T_{i o n}$ e no modo diferencial, $\tau<T_{e}$ ou $T_{i o n}$. A descrição do aparato experimental e a análise teórica utilizada para cada modo encontra-se nos trabalhos de Hunter et al [43] no modo integral e Urquijo et al [44] no modo diferencial.

\subsubsection{Método de estatística de avalanche}

Este método é baseado na natureza estatística do processo de multiplicação de cargas. As considerações teóricas deste método e o aparato experimental empregado são apresentados no trabalho de Cookson et al [45]. A probabilidade $q(n, d) \delta n$ de que a avalanche iniciada por um elétron originário do catodo gere um número de elétrons que atingem o anodo entre $n$ e $n+1$ é dada por:

$$
q(n, d)=\frac{1}{\bar{n}} \exp \left(-\frac{n}{\bar{n}}\right)
$$

sendo o tamanho médio da avalanche, $\bar{n}$ :

$$
\bar{n}=e^{\alpha d}
$$

A aquisição da função de distribuição $q(n, d)$ pode ser obtida por meio de um analisador de amplitudes de pulsos, sendo o coeficiente de ionização determinado pelo valor médio da distribuição, pelo coeficiente angular da curva $\ln q \times n$ ou por extrapolação para $n \rightarrow 0$.

\subsubsection{Método estacionário (Steady-state Technique)}

Neste método, assume-se que a nuvem de elétrons encontra-se numa região de equilíbrio sob um campo elétrico uniforme. Há basicamente duas versões deste método: variação da distância entre os eletrodos e variação da pressão do gás.

$\mathrm{Na}$ técnica de variação da distância entre os eletrodos, o campo elétrico reduzido é mantido constante e a corrente é medida para diversos espaçamentos dos eletrodos, $d$. Como o crescimento da corrente é descrito pela equação (9), o primeiro coeficiente de Townsend é obtido através do coeficiente angular da curva $\ln I \times d$. Esta técnica é adotada por Sugawara et al [46]. 
A variação da pressão altera o número de moléculas por unidade de volume, $N$. Para determinar o coeficiente de ionização, o espaçamento dos eletrodos é constante e a equação (9) é reescrita como:

$$
I=I_{0} \exp \left(\frac{\alpha}{N} \times N d\right)
$$

\subsection{Contador Proporcional}

Os contadores proporcionais operam com intensidade de campo elétrico superior à das câmaras de ionização, para que possa ocorrer o processo de avalanche de Townsend e a carga coletada seja maior do que a gerada somente pela ionização primária. Para uma dada tensão de polarização, a carga total ainda é proporcional à energia depositada no meio pela radiação. Devido à multiplicação gasosa, o pulso gerado é consideravelmente maior do que os obtidos na câmara de ionização sob as mesmas condições de uso e o detector proporcional pode ser aplicado em situações nas quais o número de pares de íons gerados pela radiação é muito pequeno.

Um detector de placas paralelas é formado de dois eletrodos metálicos planos espaçados a uma distância $d$ (FIG. 9). Ao aplicar uma diferença de potencial entre os eletrodos, $V$, obtém-se um campo elétrico uniforme:

$$
E=\frac{V}{d}
$$

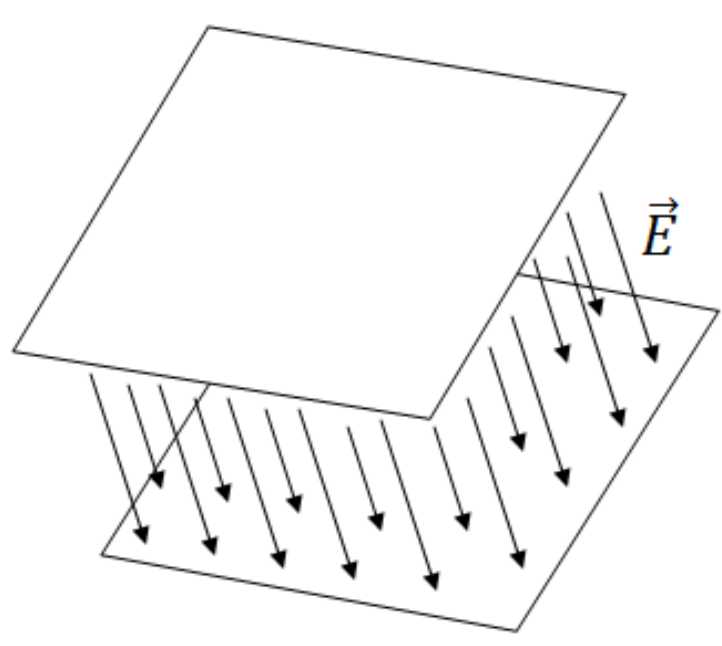

FIGURA 9 - Linhas de Campo de um detector de geometria planar. 
A amplitude do sinal gerada devido à coleção de cargas, $n$, em um dos eletrodos é:

$$
V_{\text {sinal }}=\frac{n e}{C}
$$

sendo $e$ a carga elétrica fundamental e $C$ é a capacitância do sistema. Utilizando a equação (8), podemos reescrever a equação (33) em função do fator de multiplicação e do número de pares de íons gerados pela ionização primária:

$$
V_{\text {sinal }}=M \times \frac{n_{0} e}{C}
$$

A quantidade $\frac{n_{0} e}{C}$ é praticamente constante para uma dada energia de um tipo de radiação, a menos de flutuações estatísticas. O fator de multiplicação, $M$, dado pela equação (8) depende do coeficiente de ionização e da extensão da avalanche, ou seja, da distância entre o ponto onde ocorreu a ionização primária e o anodo. Consequentemente, além da energia depositada pela radiação ionizante incidente no gás, $V_{\text {sinal }}$ também dependerá da extensão da avalanche. Por isso, para a medição do coeficiente de multiplicação em gases com detectores de eletrodos paralelos e planares, usualmente a ionização primária é produzida por efeito fotoemissivo resultante da incidência de luz ultravioleta no catodo [11, 26, 44, 47].

\subsubsection{Escolha do gás de enchimento}

Alguns fatores são considerados para a escolha do gás de enchimento: pequena eletronegatividade, baixa tensão de operação, ganho elevado e boa resolução energética, temporal e espacial. Os gases nobres são frequentemente escolhidos, pois possuem eletronegatividade praticamente nula e, por possuírem um potencial de ionização menor, necessitam de um campo elétrico menos intenso para formação da avalanche.

A multiplicação gasosa é baseada nas ionizações secundárias criadas pelas colisões entre elétrons livres e moléculas neutras. Além da ionização, essas colisões podem produzir excitação da molécula, sem a criação do elétron secundário. Gases nobres se desexcitam somente pela emissão de fótons com espectro predominantemente situado na 
região do ultravioleta. Esses fótons podem possuir energia suficiente para arrancar, por absorção fotoelétrica, elétrons do catodo e iniciar uma nova avalanche, que resultará em um pulso espúrio, mesmo para ganhos moderados, podendo causar perda da proporcionalidade. Além disso, esses fótons de desexcitação reduzem a resolução espacial e aumentam o tempo morto.

A quantidade de estados não radiativos (rotacionais e vibracionais), presentes nas moléculas poliatômicas, permite a absorção de fótons numa vasta faixa de energia: para o metano, por exemplo, a absorção é muito eficiente no intervalo de 7,9-14,5 eV, que inclui a faixa de energia de emissão do argônio. Essa é uma propriedade comum da maioria das composições orgânicas com hidrocarboneto e álcool, e de vários componentes inorgânicos como fréons, $\mathrm{CO}_{2}, \mathrm{BF}_{3}$ e outros. A molécula dissipa a energia excessiva por colisões elásticas ou dissociação em radicais mais simples. O mesmo ocorre quando a molécula poliatômica ionizada é neutralizada no catodo. Na neutralização, pode ocorrer a dissociação ou a formação de grandes complexos, chamada de polimerização. A introdução destes gases, denominados de inibidores de descargas ou quenching, mesmo em pequenas quantidades, alteram as condições operacionais do contador, porque o potencial de ionização baixo resulta numa grande eficiência de troca de carga. A eficiência do quenching de um gás poliatômico cresce com o número de átomos na molécula. Por isso, o isobutano $\left(\mathrm{iC}_{4} \mathrm{H}_{10}\right)$ é muito usado para operações estáveis com ganho elevado [21].

Infelizmente, o uso de gases orgânicos poliatômicos, mesmo em pequenas concentrações, pode diminuir o tempo de vida dos contadores selados, quando utilizados para a detecção de grandes fluxos de radiação. O processo de dissociação rapidamente consome as moléculas disponíveis em contadores proporcionais selados. A recombinação de moléculas pode produzir polímeros. Esses produtos são depositados no catodo e no anodo, dependendo de sua afinidade química, e modificam significativamente a operação do contador após fluxos integrais de radiação ao torno de $10^{7}-10^{8}$ contagens por $\mathrm{cm}^{2}$, resultando no envelhecimento do detector. Para evitar perda da eficiência de detecção e comprometimento da operação do contador, pode-se utilizar um sistema de fluxo contínuo de gás. Detectores de fluxo contínuo permitem a variação do gás de enchimento, quando desejável. O gás, após passar pelo contador, pode ser liberado diretamente na atmosfera ou ser reciclado, utilizando um filtro. 


\subsubsection{Detectores Resistivos}

Os detectores resistivos são caracterizados por possuírem pelo menos um dos eletrodos constituído de material de alta resistividade, da ordem de $10^{12} \Omega . \mathrm{cm}$. Uma camada condutora é aplicada externamente, para permitir a polarização desse material. A principal vantagem desse contador é a maior estabilidade de resposta, porque a presença do eletrodo resistivo protege o detector do aparecimento de faíscas.

Quando é aplicada uma diferença de potencial entre o anodo e a superfície condutora, após um intervalo de tempo necessário para o equilíbrio, não haverá diferença de potencial entre as duas superfícies do vidro. Ao incidir no volume sensível do contador, a radiação forma pares de íons. Os íons positivos e os elétrons movimentam-se, sob a ação de um campo elétrico, em direção do catodo e do anodo, respectivamente, resultando na passagem de uma corrente $I$ através do dielétrico de resistência $R$. Como consequência, tem-se uma queda de potencial, denominado de queda ôhmica, dada pela expressão:

$$
\Delta V=R I
$$

Esta queda ôhmica reduz o potencial efetivo no gás $\left(V_{e f}=V_{\text {aplicado }}-\Delta V\right)$ e a intensidade do campo elétrico na região entre os eletrodos. Deste modo, o campo elétrico reduzido efetivo no gás será:

$$
\frac{E_{e f}}{N}=\frac{V_{\text {aplicado }}-R I}{N d}
$$

Como o ganho do detector depende do campo elétrico, o efeito da queda de potencial no eletrodo resistivo é a redução da carga total gerada na avalanche e a diminuição da amplitude do pulso de saída. É importante ressaltar que a queda ôhmica não ocorre nos detectores metálicos, por possuírem resistência desprezível. O ganho também depende da taxa de irradiação. Experimentalmente, observa-se uma queda da eficiência de detecção com o aumento da taxa de irradiação, particularmente quando o intervalo entre a incidência de duas partículas subsequentes não é desprezível em relação à constante de tempo do eletrodo, sendo esse fenômeno observado em detectores resistivos de geometria planar [48] e cilíndrica [37]. 


\section{MATERIAIS E MÉTODOS}

A câmara de aço inox (FIG. 10) utilizada possui dois eletrodos paralelos em configuração semelhante a uma RPC e duas janelas de sílica fundida sintética diametralmente opostas, uma para possibilitar a incidência do feixe de laser de nitrogênio no catodo e a outra para monitorá-lo. As janelas de sílica fundida possuem revestimento apropriado para melhorar suas propriedades de transmissão na região do ultravioleta. Foram utilizados os gases nitrogênio, $\mathrm{N}_{2}$, com pureza de 99,999\% e isobutano, $\mathrm{iC}_{4} \mathrm{H}_{10}$, de 99,9\%, em regime de fluxo contínuo de gás, à pressão ligeiramente acima da atmosférica. Como a densidade dos gases é influenciada pela temperatura e pressão, elas foram monitoradas em todas as medições.

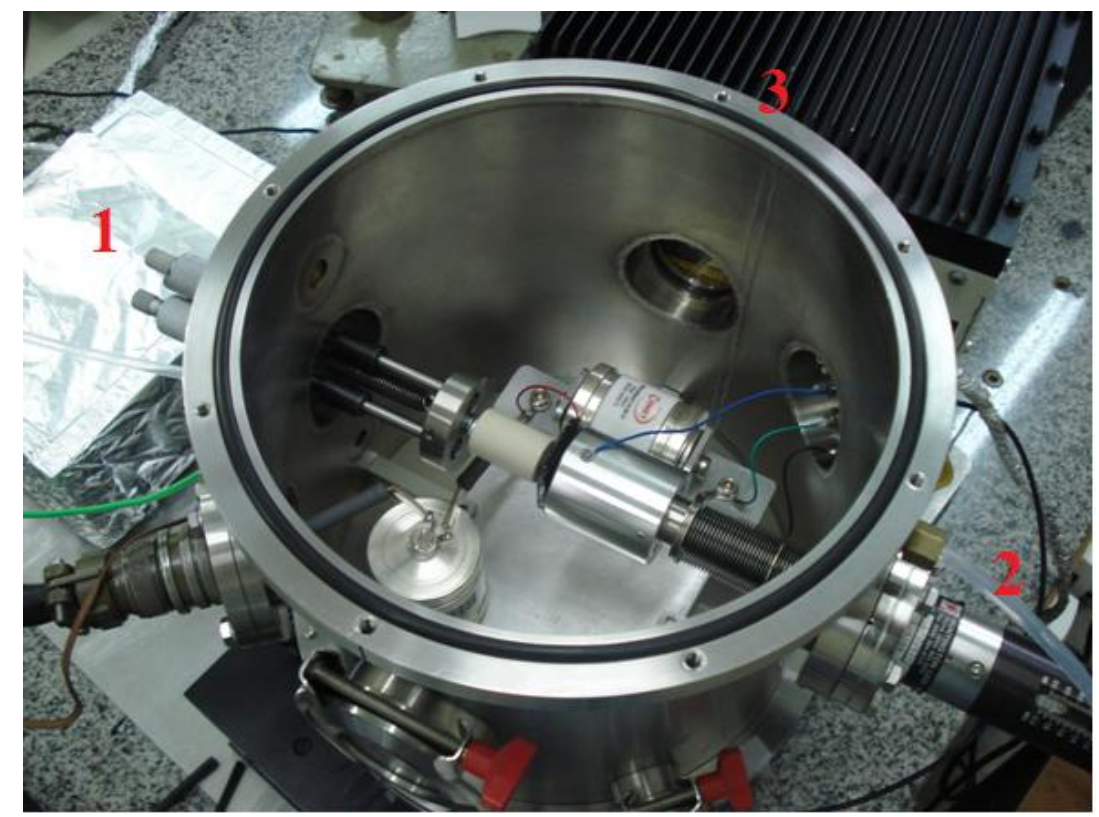

FIGURA 10 - Visão interna da câmara, onde é possível observar à esquerda os três micrômetros

(1) ligados ao anodo, à direita o parafuso micrométrico (2), que serve de suporte ao catodo e acima o laser (3).

O catodo é constituído de uma placa de alumínio polida com $40 \mathrm{~mm}$ de diâmetro e o anodo é uma placa de vidro de $32,5 \times 32,5 \mathrm{~mm}^{2}$ de alta resistividade $\left(2 \times 10^{10} \Omega \mathrm{m}\right)$ com $3,5 \mathrm{~mm}$ de espessura (FIG. 11). 


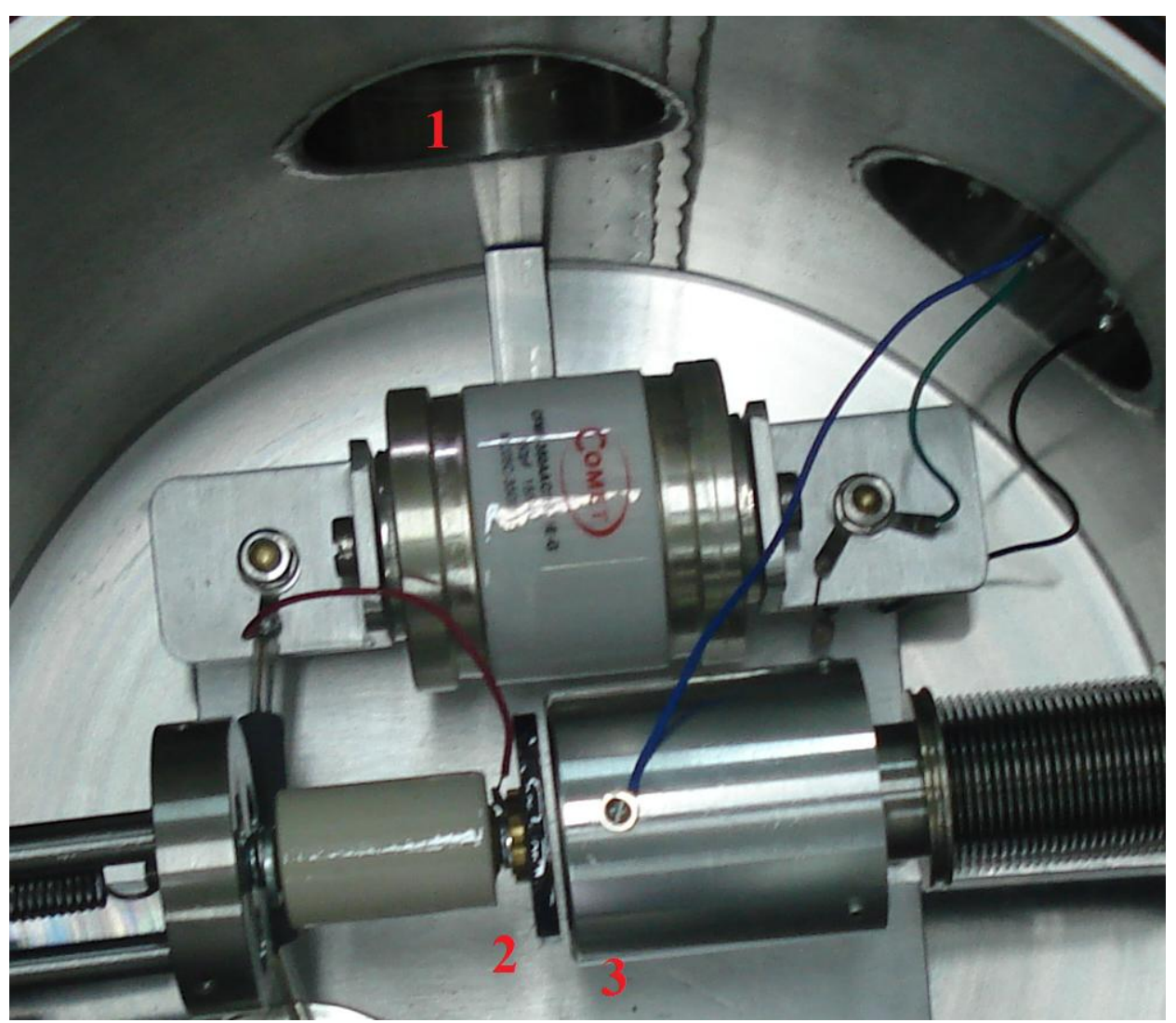

FIGURA 11 - Detalhe da janela de sílica fundida sintética (1) e dos eletrodos $(2$ - anodo e 3 - catodo). A janela de sílica fundida sintética, que serve de entrada para o feixe de laser, é transparente à radiação ultravioleta.

Os elétrons primários são produzidos por efeito fotoemissivo pela incidência de um feixe de laser de nitrogênio pulsado no catodo metálico. A área de projeção do feixe no catodo é de $3 \times 5 \mathrm{~mm}^{2}$ e foi determinada posicionando-se um papel milimetrado na frente deste eletrodo.

Cada disparo do laser de nitrogênio (LTB ${ }^{\circledR}$ modelo MNL200-LD) produz um sinal elétrico com duração média de 700 ps. O feixe de laser possui baixa divergência, $1 \times$ $2 \mathrm{~mm}^{2}$ de área e comprimento de onda na região do ultravioleta $(337,1 \mathrm{~nm})$. Por meio de uma interface com o computador e utilizando o software fornecido pelo fabricante, é possível selecionar a taxa de repetição do pulso desejada $(10,15$ ou $20 \mathrm{~Hz})$ e monitorar a temperatura, energia do feixe e pressão do nitrogênio.

Os fotoelétrons são acelerados em direção ao anodo resistivo sob a ação do campo elétrico uniforme (FIG.12) obtido através da polarização de uma placa de latão de $40 \mathrm{~mm}$ de diâmetro, onde o vidro foi fixado com uma fita dupla-face de cobre. Para obter os campos elétricos reduzidos empregados neste trabalho (de $28 \mathrm{Td}$ a $230 \mathrm{Td}$ ), foi utilizada 
uma fonte de alta tensão (225-30R Bertan ${ }^{\circledR}$ ) estabilizada e de baixo ruído (ripple de até $400 \mathrm{mV}$ para a faixa de $0 \mathrm{a} 30 \mathrm{kV}$ ).

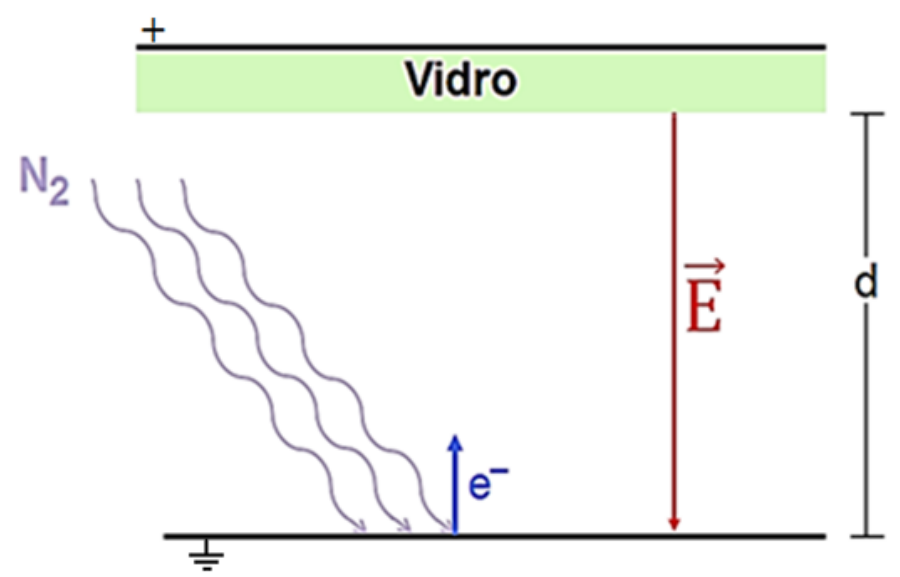

FIGURA 12 - Produção da ionização primária pela incidência do feixe de laser de nitrogênio no catodo metálico. Os fotoelétrons são acelerados em direção ao anodo resistivo pelo campo elétrico uniforme $\vec{E}$. A distância entre os eletrodos é representada pord.

O movimento de cargas entre os eletrodos produz uma corrente elétrica, que foi medida com os eletrômetros Keithley ${ }^{\circledR}$ modelos 610C e 6517B, diretamente conectados ao catodo, conforme o circuito representado na FIG. 13.

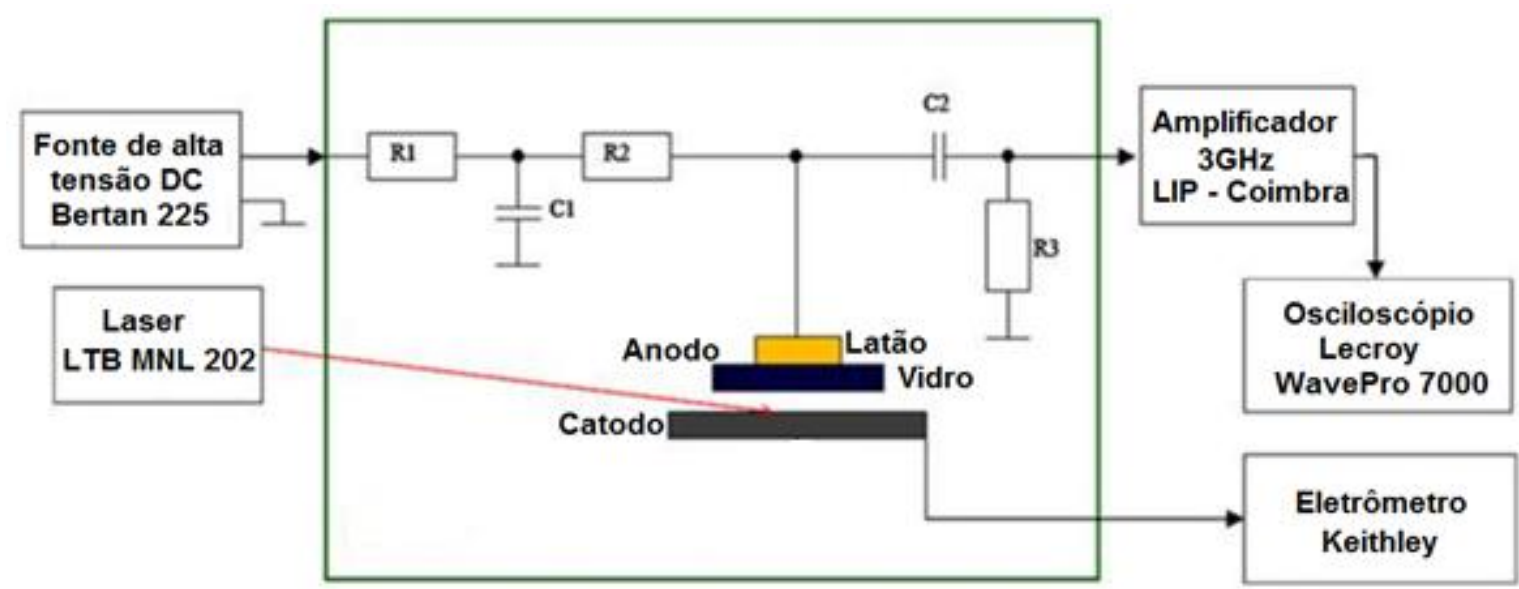

FIGURA 13 - Esquema do circuito eletrônico de extração dos sinais dos eletrodos [23]. Foram utilizados dois capacitores da Comet de $350 \mathrm{pF} / 15 \mathrm{kV}(\mathrm{Cl}$ e C2) e três resistores $(R 1=10 \mathrm{M} \Omega, R 2=100 \mathrm{M} \Omega$ e $R 3=1 \mathrm{M} \Omega)$.

Primeiramente, alinhou-se a altura da janela de saída do feixe de laser e da janela da câmara, para garantir a incidência do feixe de laser em sua região central do 
catodo. Foi adotado o ângulo de entrada do feixe, em relação ao catodo, que tornava máxima a amplitude do sinal elétrico obtido na saída do amplificador (FIG. 13).

Posicionando-se lâmpadas de luz branca na base e na lateral da câmara, ajustou-se visualmente o paralelismo dos eletrodos através dos três micrômetros (189 Mitutoyo $^{\circledR}$ ), apresentados na FIG. 14, conectados ao anodo. Como as medidas são sensíveis ao alinhamento do arranjo experimental e à focalização do laser, este foi mantido sobre uma bancada ótica, projetada para este fim. O catodo foi fixado a um parafuso micrométrico de $2 \mu \mathrm{m}$ de resolução de escala (L2241-2 Huntington®), que permite variar o espaçamento entre os eletrodos até $50 \mathrm{~mm}$ (FIG. 15).

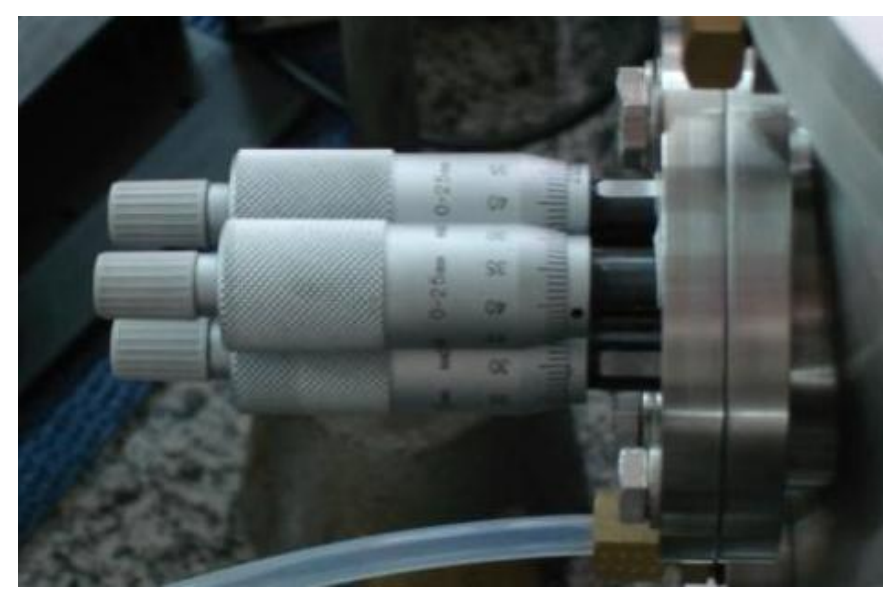

FIGURA 14 - Detalhe dos três micrômetros (189 Mitutoyo ${ }^{\circledR)}$ conectados ao anodo e utilizados para ao ajuste do paralelismo entre os eletrodos.

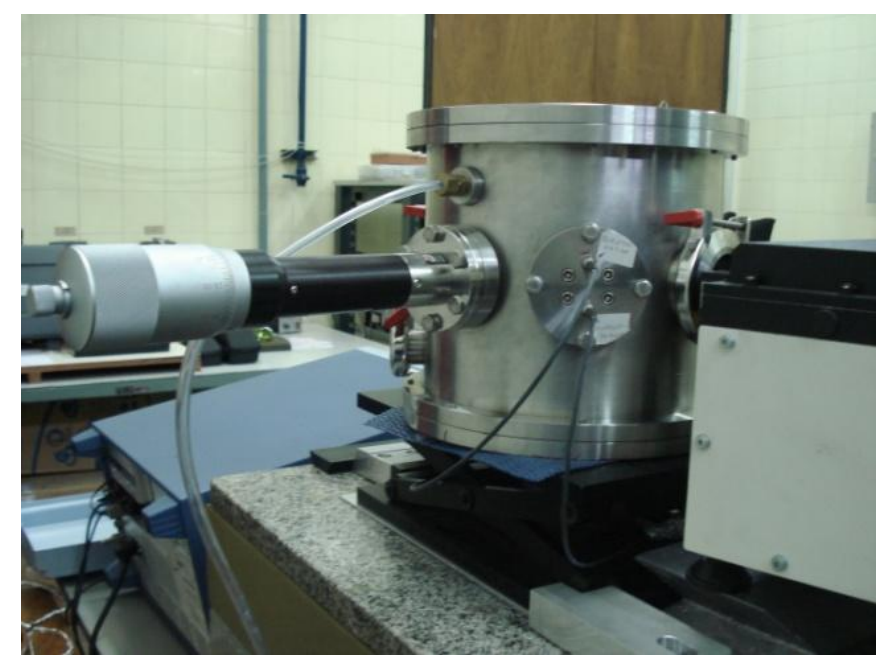

FIGURA 15 - Detalhe do parafuso micrométrico conectado ao catodo e utilizado para variar a distância entre os eletrodos. 
Para cada valor de tensão de polarização do anodo é obtida a corrente elétrica resultante. Através da curva gerada é possível observar a região de ionização, cuja corrente mantém-se aproximadamente constante (corrente de ionização primária $-I_{0}$ ), a região onde ocorre a multiplicação de cargas (corrente de avalanche $-I$ ) e a tensão de transição entre os dois regimes. Para campos elétricos uniformes, o crescimento da carga e/ou corrente coletada segue um comportamento exponencial, conforme a equação (9). O espaçamento entre os eletrodos foi mantido em 1,5 mm em todas as medidas. Desta forma, podemos determinar o primeiro coeficiente de Townsend, $\alpha$, através da relação:

$$
\alpha=\frac{1}{d} \ln \left(\frac{I}{I_{0}}\right)
$$

O nitrogênio puro tem sido um gás amplamente estudado na literatura. Por isso, a calibração do sistema e validação do método foi realizada determinando-se inicialmente $\alpha / N$ em função do campo elétrico reduzido, $E / N$, para este gás e comparando os resultados obtidos com os três conjuntos de dados disponíveis na literatura [25 - 27] para o mesmo intervalo de campo elétrico utilizado neste trabalho. Posteriormente, aplicou-se a mesma metodologia para a determinação de $\alpha / N$ para o isobutano, cujos dados presentes na literatura para campos elétricos reduzidos acima de 500 Td, além de raros, são discordantes entre si dentro do erro experimental [49 - 51]. Abaixo de $200 \mathrm{Td}$, há somente os dados determinados por Lima $[22,23]$ em seu trabalho de mestrado no Laboratório de Desenvolvimento de Detectores Gasosos. Na faixa de 200 Td e 500 Td, não há valores experimentais para o primeiro coeficiente de Townsend.

Os primeiros coeficientes de Townsend determinados para o nitrogênio e o isobutano foram comparados com valores simulados pelo Dr. Aléssio Mangiorotti [24], da Universidade de Coimbra, utilizando duas versões do programa Magboltz 2, em código FORTRAN [52, 53]. Este programa foi desenvolvido por S. Biagi para calcular os parâmetros de transporte de elétrons a partir da simulação de colisões individuais entre elétron e átomo pelo método de Monte Carlo, nos regimes estacionário e pulsado (item 3.3.5). A distribuição em energia dos elétrons gerados por colisões ionizantes é parametrizada por Opal et al. [54]. As versões 7.1 e 8.6 do programa Magboltz 2 foram escolhidas por terem sido adotadas em trabalhos anteriores do Laboratório de Desenvolvimento de Detectores Gasosos [11,23] e apresentarem conjuntos de secção de 
choque distintos para os dois gases aqui estudados. É importante ressaltar que, considerando os conjuntos de secção de choque do nitrogênio e do isobutano, nenhuma atualização foi realizada nas versões mais recentes do programa[53].

Nosso aparato está sujeito a alguns processos secundários [13]:

I - efeito de carga espacial no volume da câmara: deve-se a baixa mobilidade dos íons, que ainda estão dirigindo-se ao catodo após todos os elétrons serem coletados. Cresce com o campo elétrico e depende linearmente da intensidade do feixe de laser e de sua taxa de repetição;

II - efeito de carga espacial na avalanche individual: deve-se a densidade de carga na avalanche gerada por um único elétron. Depende somente do campo elétrico, crescendo com o aumento de $\mathrm{E} / \mathrm{N}$;

III - queda ôhmica: deve-se a diferença de potencial entre as superfícies do eletrodo resistivo. Sua dependência é análoga ao item I;

IV - recombinação volumétrica: ocorre quando o campo elétrico não é suficientemente intenso para evitar perda de cargas geradas por todas as avalanches. Depende quadraticamente da intensidade do feixe de laser e de sua taxa de repetição;

$\mathrm{V}$ - recombinação na avalanche individual: para campos elétricos menores, os portadores de carga secundários podem se recombinar muito próximo ao local aonde foram gerados. Este efeito diminui com o aumento do campo elétrico e depende quadraticamente da intensidade do feixe de laser.

Para verificar a presença destes possíveis processos secundários, o primeiro coeficiente de Townsend de ionização foi determinado para o isobutano em diferentes taxas de repetição do feixe de laser e diferentes atenuações, sendo a intensidade do feixe de laser variada interpondo até três lamínulas de vidro calibradas de $1 \mathrm{~mm}$ cada entre o laser e a janela da câmara. 


\section{RESULTADOS E DISCUSSÕES.}

\subsection{Nitrogênio}

Em condições normais de temperatura e pressão (CNTP), o nitrogênio é encontrado no estado gasoso na forma de uma molécula diatômica apolar, quimicamente inerte. Há muitos conjuntos de dados bem estabelecidos para secções de choque deste gás, cuja estrutura eletrônica é tratável computacionalmente, tornando-o quase um padrão para estudos teóricos de espalhamento em baixas energias [32]. Os parâmetros de transporte deste gás também têm sido extensivamente estudados, sendo apresentada por Raju [32] uma compilação de alguns dos dados disponíveis na literatura de velocidade de deriva e do primeiro coeficiente de Townsend, além da secção de choque. Estes estudos têm sido motivados pela aplicação deste gás em lasers $[55,56]$ e sistemas de isolamento elétrico $[25,45]$. Por isto, o nitrogênio foi escolhido para validação da técnica experimental.

As correntes elétricas para o $\mathrm{N}_{2}$ medidas com o eletrômetro analógico na saída direta do catodo em função do campo elétrico reduzido são apresentadas na TAB. 3. Foi adotada a taxa de repetição do feixe de laser de $15 \mathrm{~Hz}$. As incertezas foram determinadas considerando a precisão instrumental do eletrômetro e foram menores que 2,5\%. A temperatura e pressão médias durante a aquisição dos dados foram de $(19,0 \pm 1,0)^{\circ} \mathrm{C} \mathrm{e}$ (704 \pm 2$)$ Torr, respectivamente. 
TABELA 3 - Corrente elétrica obtida na saída direta do catodo em função do campo elétrico reduzido utilizando o nitrogênio como gás de enchimento.

\begin{tabular}{cc}
\hline $\mathbf{E} / \mathbf{N}(\mathbf{T d})$ & Corrente $(\mathbf{p A})$ \\
\hline 29 & $0,0600 \pm 0,0005$ \\
43 & $0,0620 \pm 0,0005$ \\
57 & $0,0650 \pm 0,0005$ \\
72 & $0,0750 \pm 0,0005$ \\
86 & $0,0730 \pm 0,0005$ \\
100 & $0,0950 \pm 0,0005$ \\
115 & $0,150 \pm 0,002$ \\
129 & $0,340 \pm 0,005$ \\
143 & $1,30 \pm 0,02$ \\
149 & $2,80 \pm 0,05$ \\
155 & $5,70 \pm 0,05$ \\
161 & $11,0 \pm 0,2$ \\
166 & $23,0 \pm 0,2$ \\
172 & $50,0 \pm 0,5$ \\
178 & $90 \pm 2$ \\
184 & $145 \pm 2$ \\
189 & $200 \pm 2$ \\
\hline
\end{tabular}

Observa-se um aumento significativo da corrente para campos elétricos acima de $115 \mathrm{Td}$, demonstrando a transição entre o regime de ionização e o de avalanche. O maior valor de corrente de fundo foi de $(0,00700 \pm 0,00010) \mathrm{pA}$, uma ordem de grandeza abaixo do menor valor de corrente elétrica medida, que foi de $(0,0600 \pm 0,0005) \mathrm{pA}$. Por esta razão, os valores de corrente apresentados na TAB. 3 e utilizados para a determinação do primeiro coeficiente de Townsend não foram corrigidos para a corrente de fundo.

A presença do eletrodo constituído de material de alta resistividade, neste caso o anodo ( $\rho=2 \times 10^{10} \Omega \mathrm{m}$ ), altera a configuração do campo elétrico no gás, como discutido no item 3.4.2, reduzindo o ganho em carga produzido pelas avalanches de Townsend, que é uma característica dos contadores proporcionais. A queda ôhmica foi determinada por meio da equação (34) e sua relação com a corrente medida em função do campo elétrico reduzido e da tensão de polarização do anodo é apresenta na FIG. 16. A resistência do 
vidro foi calculada considerando que a difusão dos elétrons em sua trajetória até o anodo é desprezível, de modo que a área utilizada para o cálculo é dada pela área de projeção do feixe de laser no catodo. Tomou-se como constante a resistividade do vidro, apesar de sua dependência com a temperatura, que não é controlada em nosso aparato.

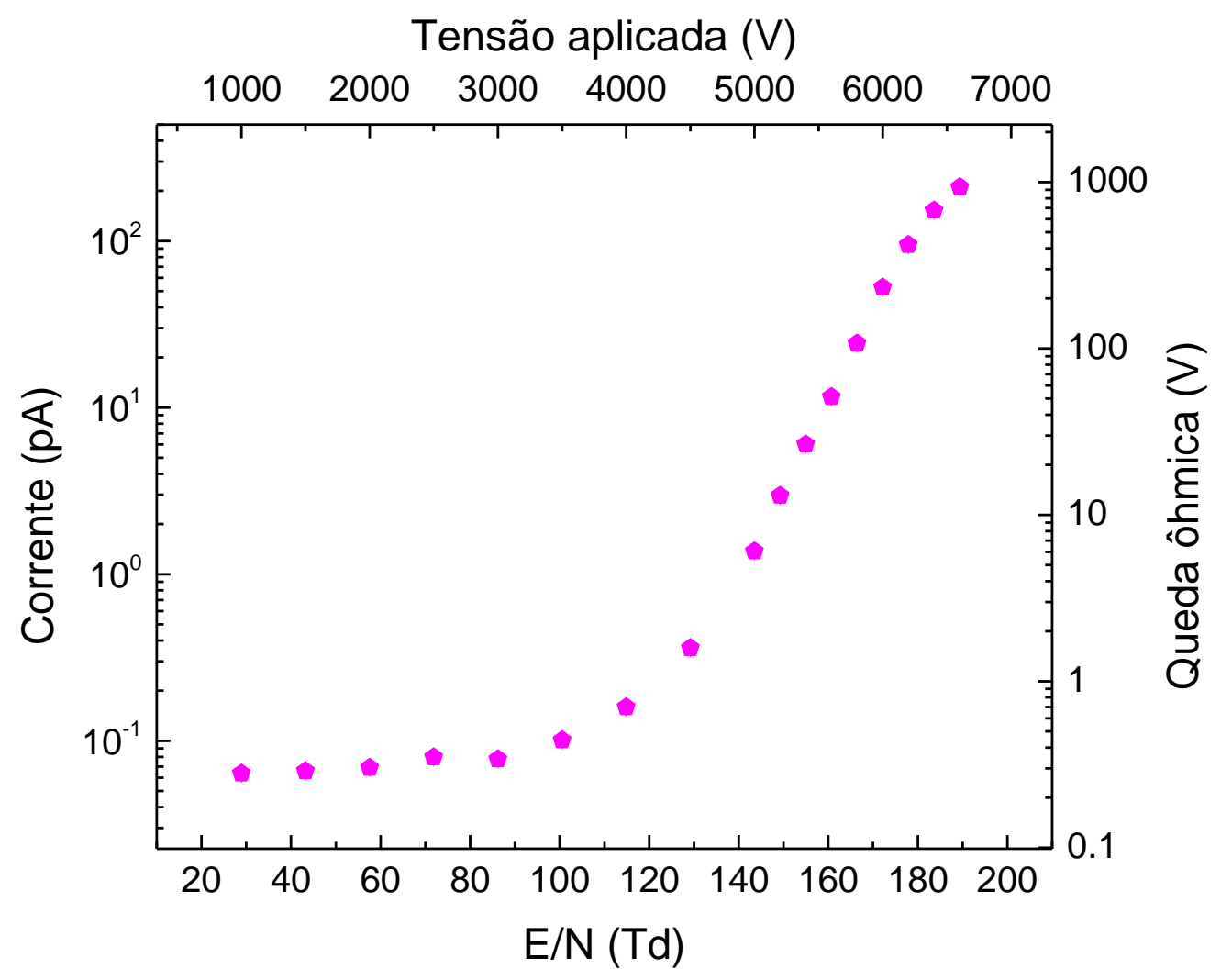

FIGURA 16 - Correspondência entre a queda ôhmica e a corrente elétrica medida para o nitrogênio.

Para baixos valores de campo elétrico reduzido, as correntes elétricas mensuradas são praticamente iguais, indicando a região de ionização. Em seguida, ocorre o crescimento significativo da corrente, característico do comportamento exponencial na região de avalanche. Na FIG. 16, é perceptível que o início da região de avalanche ocorre para $\mathrm{E} / \mathrm{N}=115 \mathrm{Td}$, assim como nota-se na $\mathrm{TAB} .3$.

A corrente de ionização primária utilizada para os cálculos dos primeiros coeficientes de Townsend foi determinada pela média dos seis valores de corrente medidos na região de ionização. Como a queda ôhmica é diretamente proporcional à corrente elétrica, ela torna-se mais significativa com o aumento da tensão de polarização e do campo elétrico reduzido, como pode ser observado na FIG. 16. 
Na TAB. 4 são apresentados os valores de campo elétrico reduzido e campo elétrico reduzido efetivo, $\mathrm{E}_{\mathrm{e}} / \mathrm{N}$, para cada valor de tensão de polarização, bem como os valores do primeiro coeficiente de Townsend. O campo elétrico reduzido efetivo no gás foi calculado utilizando a equação (35). As incertezas dos primeiros coeficientes de Townsend foram estimadas em $15 \%$ pela comparação entre os conjuntos de dados obtidos para o mesmo valor de campo elétrico reduzido [22]. Considerando somente a precisão instrumental, as incertezas do parâmetro $\alpha$ foram menores do que $2,5 \%$.

TABELA 4 - Valores do primeiro coeficiente de Townsend determinados para o $\mathrm{N}_{2}$.

\begin{tabular}{cccc}
\hline $\mathbf{V}(\mathbf{V})$ & $\mathbf{E} / \mathbf{N}(\mathbf{T d})$ & $\mathbf{E}_{\mathbf{e f} / \mathbf{N}(\mathbf{T d})}$ & $\alpha / \mathbf{N}\left(\mathbf{1 0}^{-24} \mathbf{m}^{2}\right)$ \\
\hline 4000 & 115 & 115 & $21 \pm 3$ \\
4500 & 129 & 129 & $45 \pm 7$ \\
5000 & 143 & 143 & $83 \pm 12$ \\
5200 & 149 & 149 & $105 \pm 16$ \\
5400 & 155 & 154 & $125 \pm 19$ \\
5600 & 161 & 159 & $144 \pm 22$ \\
5800 & 166 & 163 & $165 \pm 25$ \\
6000 & 172 & 165 & $188 \pm 28$ \\
6200 & 178 & 166 & $(20 \pm 3) \times 10^{1}$ \\
6400 & 184 & 164 & $(22 \pm 3) \times 10^{1}$ \\
6600 & 189 & 162 & $(23 \pm 3) \times 10^{1}$ \\
\hline
\end{tabular}

Como discutido anteriormente, para tensões de polarização maiores, a queda ôhmica é mais significativa. Isto implica que a diferença entre o campo elétrico efetivo no gás e o campo elétrico aplicado aumentará, como observado na TAB. 4. Consequentemente, pode-se atingir uma situação na qual o aumento da tensão aplicada não resulte no aumento do campo elétrico efetivo no gás, podendo até mesmo diminuí-lo, como ocorreu para $\mathrm{E} / \mathrm{N}>180 \mathrm{Td}$.

Com os dados da TAB. 4 foi construído o gráfico apresentado na FIG. 17, no qual os valores do primeiro coeficiente de Townsend são comparados com valores de $\alpha / \mathrm{N}$ presentes na literatura [25 - 27] e com curvas obtidas através de simulação utilizando o programa Magboltz 2 versões 7.1 e $8.6[52,53]$. N 2004 aniso e $\mathrm{N}_{2} 2008$ aniso2 referemse a conjuntos de secção de choque de elétrons do nitrogênio. O primeiro conjunto deve-se 
à A. V. Phelps e L. C. Pitchford [57] e o segundo é uma compilação de dados de diversos autores [53].

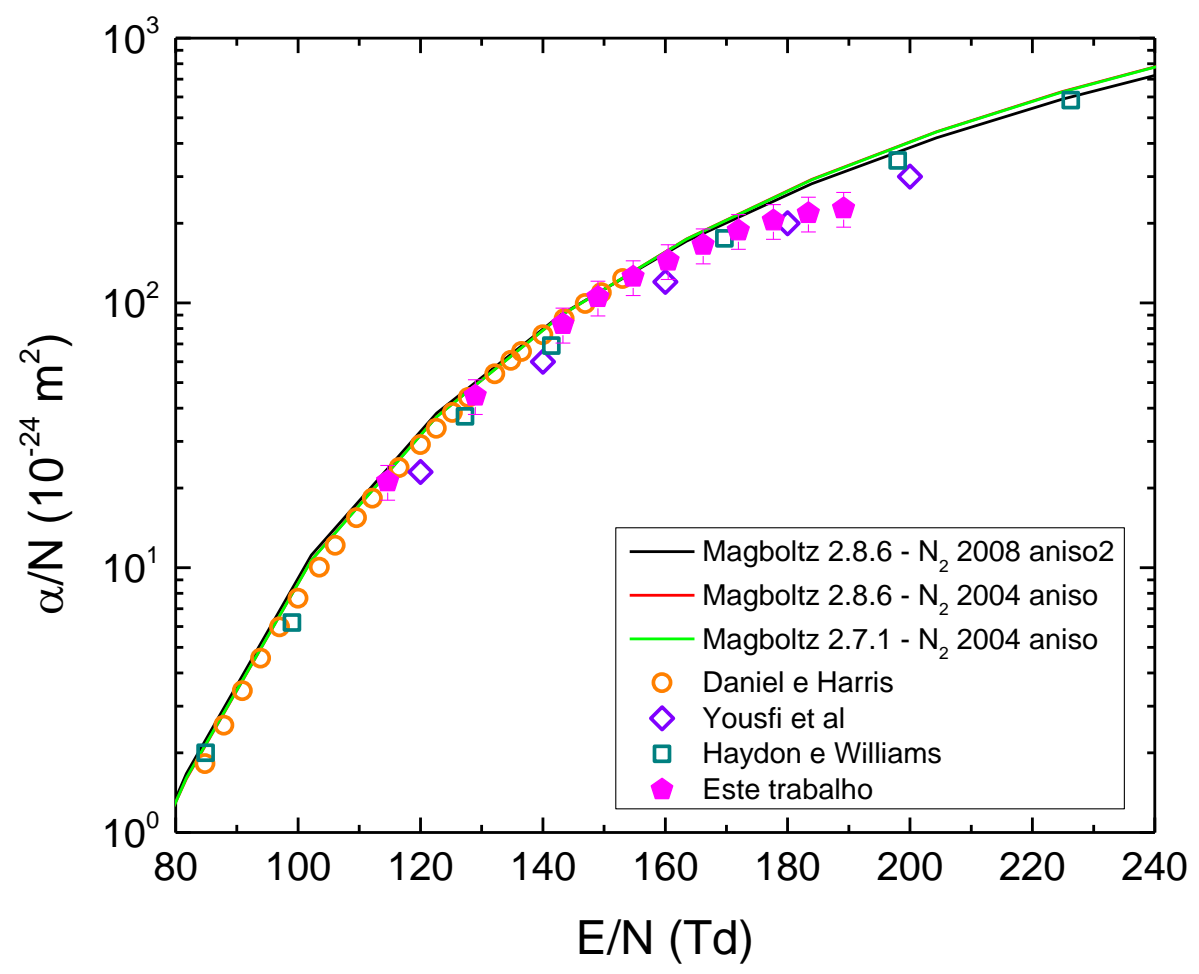

FIGURA 17 - Primeiro coeficiente de Townsend reduzido no $\mathrm{N}_{2}$ em função do campo elétrico reduzido $(15 \mathrm{~Hz})$. Os resultados obtidos neste trabalho são apresentados em simbolos fechados e possuem incerteza de 15\%. Os dados obtidos por Daniel e Harris [25], Yousfi et al. [26] e Haydon e Williams [27] estão em símbolos abertos e as curvas devem-se as simulações realizadas com o programa Magboltz 2 [53].

Observa-se que os valores de $\alpha / \mathrm{N}$ possuem comportamento compatível com os dados da literatura e apresenta boa concordância com a curva obtida por simulação. Porém, há uma tendência de saturação do primeiro coeficiente de Townsend para campos superiores a 170 Td. Na FIG. 18 são apresentados os resíduos percentuais dos nossos dados em relação às curvas simuladas normalizados para os valores simulados com a barra de incerteza experimental. 


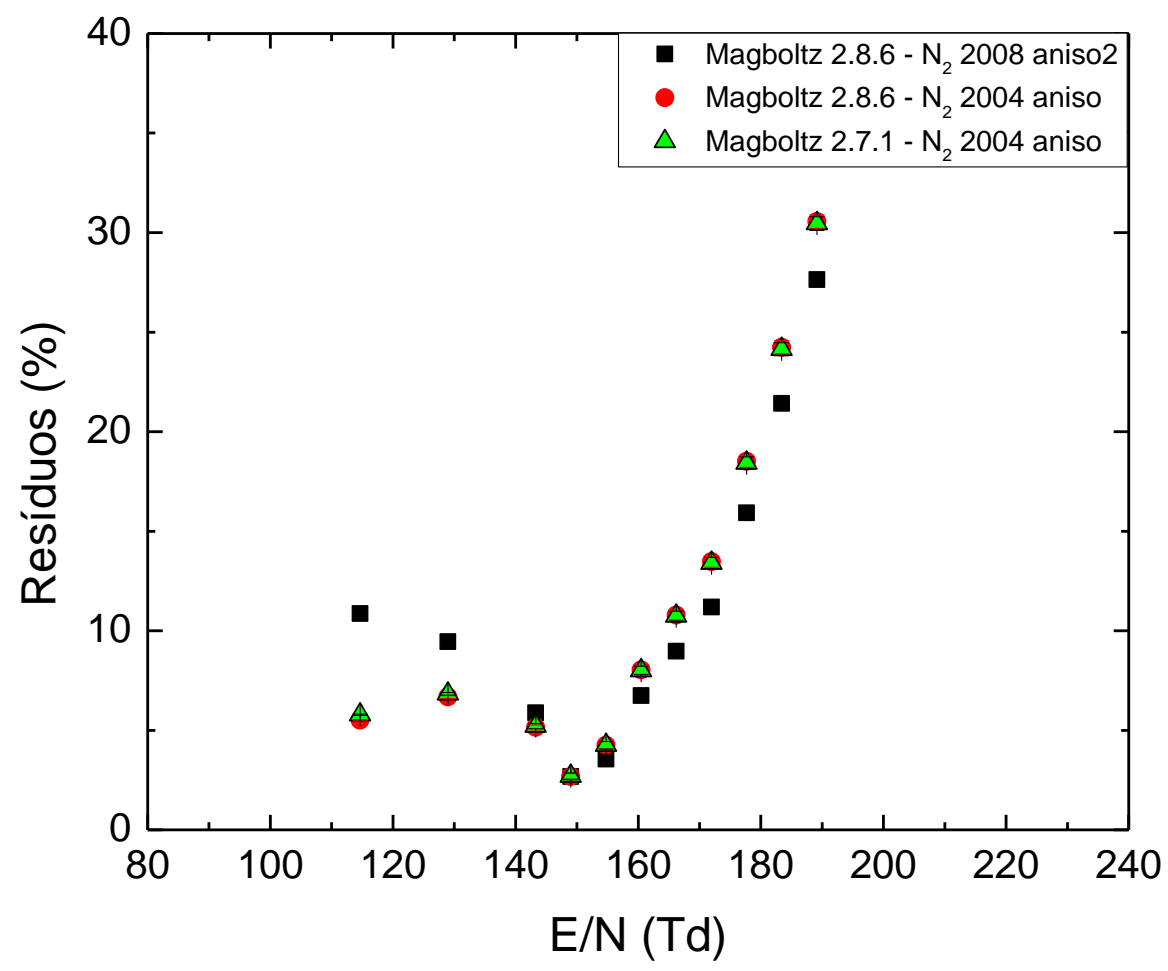

FIGURA 18 - Diferença entre os valores de primeiro coeficiente de Townsend simulados com o programa Magboltz 2 [53] e obtidos experimentalmente (FIG. 17) em função do campo elétrico reduzido.

Os resíduos aumentam significativamente para campos elétricos reduzidos acima de $160 \mathrm{Td}$, por causa da saturação dos nossos valores do $\alpha / \mathrm{N}$.

Para avaliar se o efeito de saturação deve-se à queda ôhmica, construiu-se o gráfico de comparação entre os parâmetros $\alpha / \mathrm{N}$ experimentais e simulados utilizando o campo elétrico reduzido efetivo (FIG. 19). 


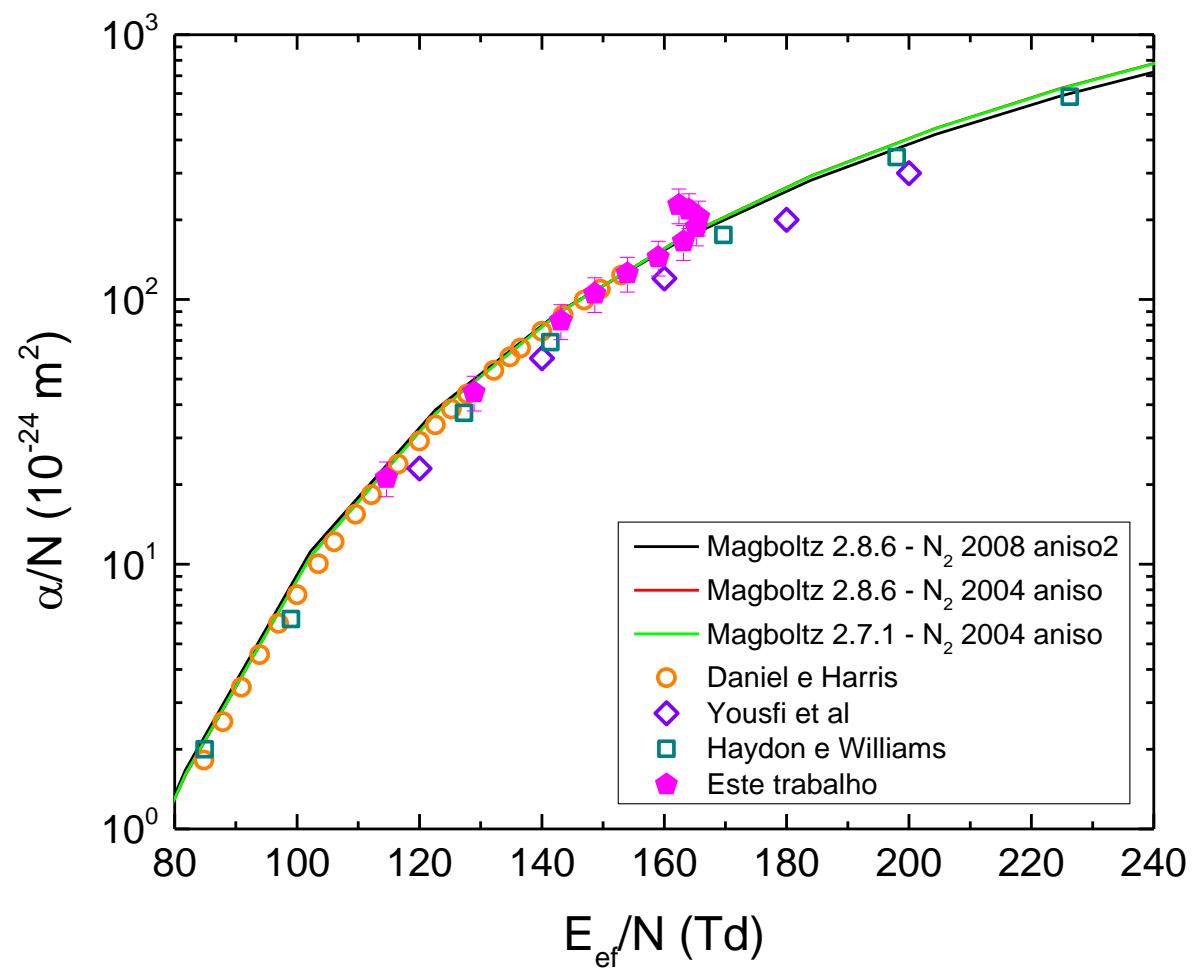

FIGURA 19 - Primeiro coeficiente de Townsend reduzido no $\mathrm{N}_{2}$ em função do campo elétrico reduzido efetivo $(15 \mathrm{~Hz})$. Os resultados obtidos neste trabalho são apresentados em símbolos fechados e possuem incerteza de 15\%. Os dados obtidos por Daniel e Harris [25], Yousfi et al. [26] e Haydon e Williams [27] estão em símbolos abertos e as curvas devem-se as simulações realizadas com o programa Magboltz 2 [53].

Ao corrigir a queda ôhmica, para E/N > $180 \mathrm{Td}$, o comportamento dos valores de $\alpha / \mathrm{N}$ não satisfaz a tendência dos dados da literatura e da curva obtida pelo programa Magboltz 2. Isto ocorre porque, nesta região, o campo elétrico reduzido efetivo no gás começa a diminuir com o aumento da tensão aplicada, como pode ser notado na TAB. 4. Para a faixa de $143 \mathrm{Td}$ - $180 \mathrm{Td}$, essa correção aumenta a concordância entre o comportamento dos valores de primeiro coeficiente de Townsend determinados neste trabalho. Os resíduos normalizados dos valores simulados do coeficiente de ionização com correção da queda ôhmica em relação às curvas obtidas por simulação são apresentados na FIG. 20 . 


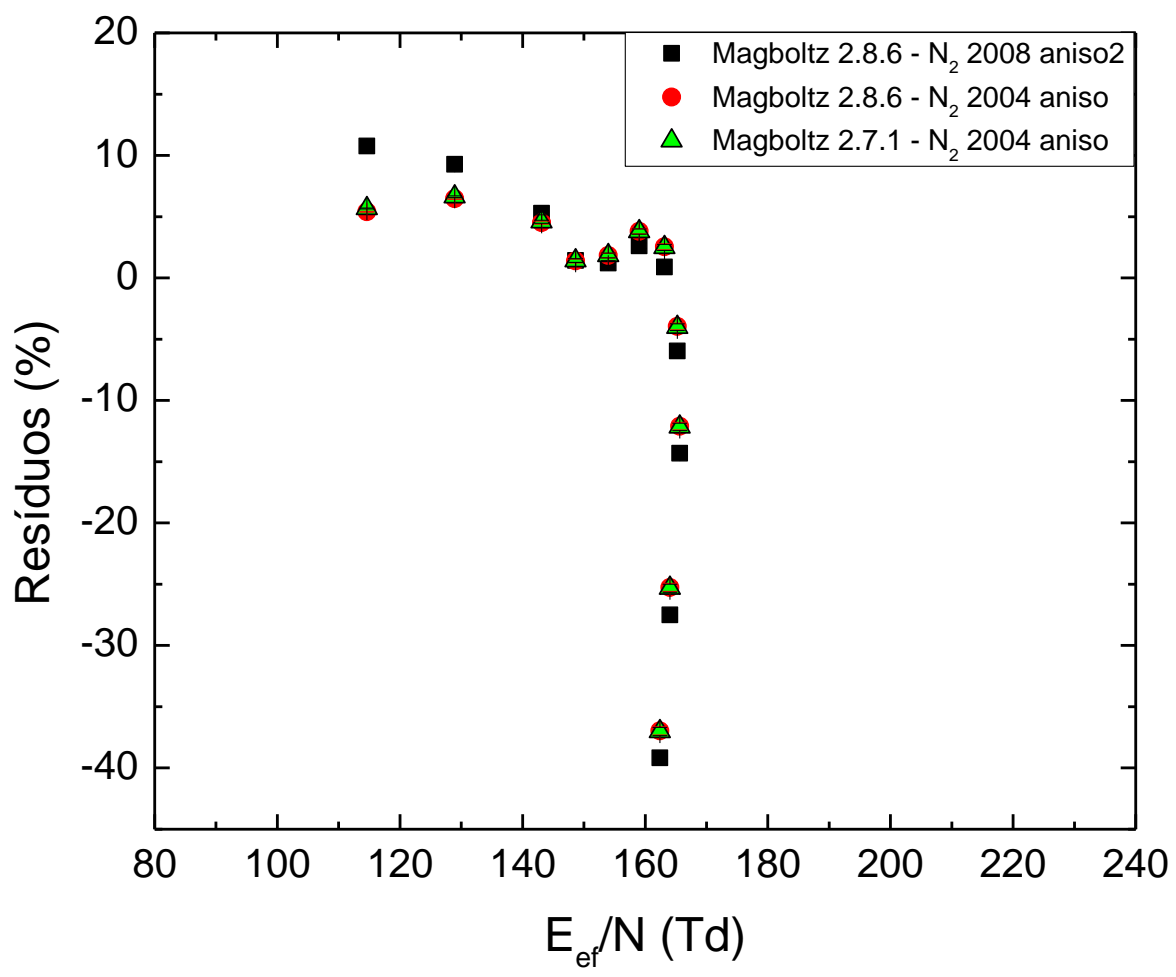

FIGURA 20 - Diferença entre os valores de primeiro coeficiente de Townsend simulados com o programa Magboltz 2 [53] e obtidos experimentalmente (FIG. 19) em função do campo elétrico reduzido efetivo.

Observa-se que apenas os quatro últimos pontos, que correspondem a E/N > $170 \mathrm{Td}$, apresentam significativos valores de resíduo. Considerando que, sem correção para queda ôhmica, o crescimento dos resíduos é relevante para E/N > $160 \mathrm{Td}$ (FIG. 18) e que, visualmente (FIG. 17 e 19) a concordância entre os dados com correção ocorreu para uma faixa de campo elétrico reduzido maior, no nosso aparato a queda ôhmica é significativa e deve ser corrigida.

Há na literatura diversos modelos que descrevem a dependência do primeiro coeficiente de Townsend reduzido com $\mathrm{E} / \mathrm{N}$, sendo alguns deles apresentados no item 3.3.1. Foram construídas as curvas $\alpha / \mathrm{N}$ em função do campo elétrico reduzido sem e com correção para queda ôhmica (FIG. 21) para a determinação experimental dos parâmetros A e B da parametrização proposta por Williams e Sara [36] (equação 11), cujos significados físicos foram discutidos no item 3.3.1. Os resíduos devido à aplicação da parametrização de Williams e Sara [36], normalizados em relação aos valores simulados, são apresentados na FIG. 22. 


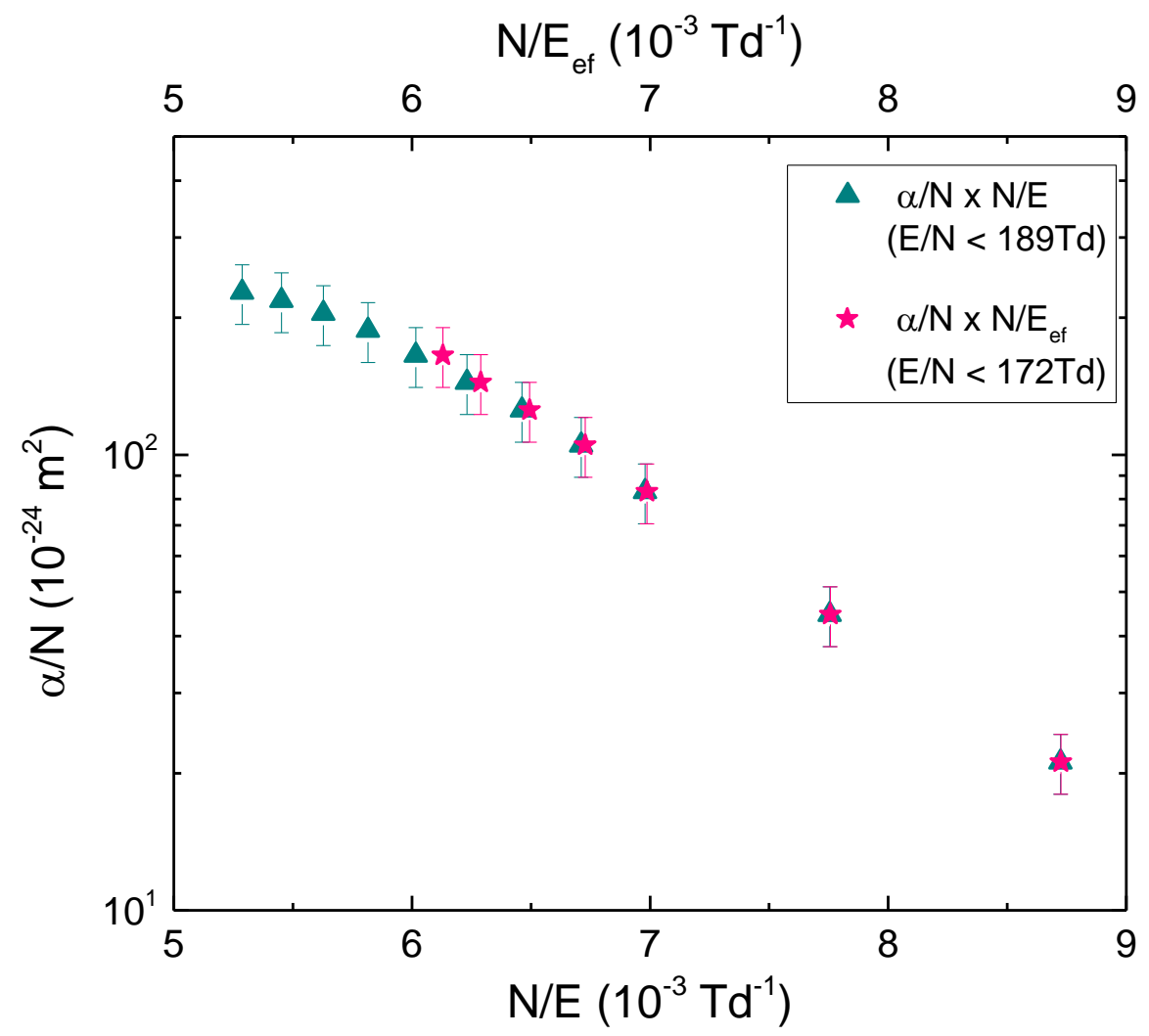

FIGURA 21 - Aplicação da parametrização de Williams e Sara [36] aos coeficientes de ionização obtidos sem e com correção da queda ôhmica para o nitrogênio.

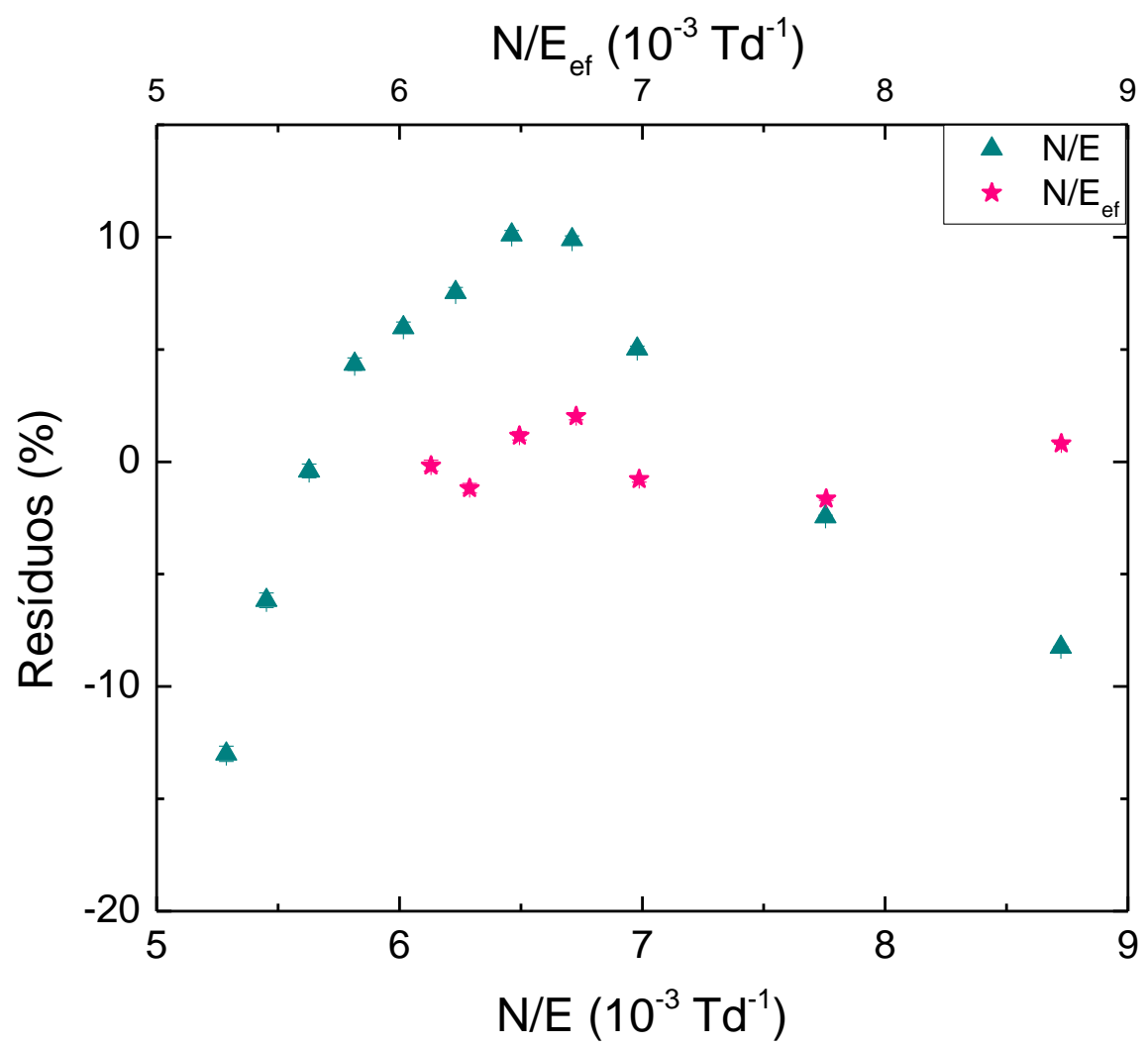

FIGURA 22 - Resíduos resultantes da aplicação da parametrização de Williams e Sara[36] aos resultados experimentais (FIG. 22). 
Com a correção para queda ôhmica, os resíduos são não-tendenciosos e aproximadamente nulos, o que indica que, para o nitrogênio, a aplicação mais adequada da parametrização é aos dados corrigidos para queda ôhmica.

Os valores de A e B obtidos são comparados com os dados apresentados na literatura [25, 27, 45] na TAB. 5. A razão B/A (equação 18) nos fornece o potencial efetivo

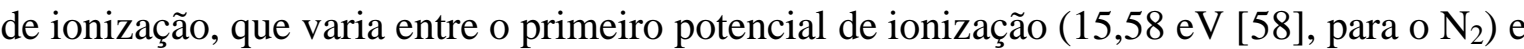
a energia média necessária para um elétron ionizar uma molécula do gás (entre 36,68 eV a 1030,38 eV, dependendo da energia do elétron incidente [59]). Sem corrigir a queda ôhmica, o coeficiente de ajuste linear $R^{2}$ foi de 0,987 e com correção, $R^{2}=0,9996$.

TABELA 5 - Parâmetros A e B, potencial de ionização efetivo $\left(\mathrm{V}_{\mathrm{i}}\right)$ para o $\mathrm{N}_{2}$ e faixa de campo elétrico, $\mathrm{E} / \mathrm{N}$, analisada.

\begin{tabular}{cccccc}
\hline & $\begin{array}{c}\text { Correção } \\
\text { para queda } \\
\text { ôhmica }\end{array}$ & $\begin{array}{c}\mathbf{A} \\
\left(\mathbf{1 0}^{-\mathbf{2 0}} \mathbf{m}^{\mathbf{2}}\right)\end{array}$ & $\begin{array}{c}\mathbf{B} \\
\mathbf{( T d )}\end{array}$ & $\mathbf{V}_{\mathbf{i}} \mathbf{( e V )}$ & $\begin{array}{c}\text { Faixa de E/N } \\
(\mathbf{T d})\end{array}$ \\
\hline $\begin{array}{c}\text { T. N. Daniel and F. M. } \\
\text { Harris [25] }\end{array}$ & $*$ & 2,33 & 802 & 34 & $85-152$ \\
$\begin{array}{c}\text { A. H. Cookson et } \\
\text { al.[45] }\end{array}$ & $*$ & 1,55 & 770 & 47 & $89-166$ \\
$\begin{array}{c}\text { S. C. Haydon and O. } \\
\text { M. Williams [27] }\end{array}$ & $*$ & 1,64 & 771 & 47 & $85-198$ \\
$\quad$ Sem & $1,09 \pm 0,17$ & $706 \pm 24$ & $65 \pm 10$ & $115-189$ \\
$\quad$ Este trabalho & Com & $2,18 \pm 0,09$ & $796 \pm 6$ & $36,5 \pm 1,5$ & $115-172$ \\
\hline
\end{tabular}

*Não se aplica, pois utilizaram eletrodos metálicos.

Os potenciais de ionização determinados sem e com correção para queda ôhmica apresentam boa concordância com os valores presentes na literatura, ressaltando que eles foram obtidos com métodos diferentes ao empregado neste trabalho. Os valores de $\mathrm{V}_{\mathrm{i}}$ calculados encontram-se dentro do intervalo de energia previsto. Portanto, o método proposto pode ser aplicado para a investigação dos primeiros coeficientes de Townsend em outros gases. 


\subsection{Isobutano}

O isobutano é um gás poliatômico comumente utilizado como gás inibidor (quenching) em detectores gasosos para operação estável em ganhos altos [21]. O mecanismo fundamental da ação dos gases quenching é o processo de dissociação molecular, como discutido no Capítulo 3. Devido a baixa energia de dissociação por impacto eletrônico desta molécula (7 eV [60]), o uso deste gás por um longo período e a uma alta taxa de radiação podem resultar no envelhecimento dos eletrodos, resultante de sua polimerização [21]. As principais aplicações deste gás em detectores já foram discutidas no Capítulo 1 e são motivadas por reduzir perdas de resposta devidas a fótons de desexcitação e à diminuição da tensão de operação do detector. Este último deve-se ao aumento dos coeficientes de ionização em gases nobres quando misturados com isobutano.

$\mathrm{O}$ primeiro coeficiente de Townsend para $\mathrm{o} \mathrm{iC}_{4} \mathrm{H}_{10}$ foi obtido utilizando a técnica validada com o nitrogênio. A corrente elétrica foi medida com os eletrômetros analógico e digital na saída direta do catodo em função do campo elétrico reduzido, sendo obtidos conjuntos de dados para diferentes taxas de repetição do pulso laser e intensidades do feixe. As incertezas dos valores de corrente foram determinadas considerando a precisão instrumental dos eletrômetros, sendo menores que 3\% para o eletrômetro analógico e $2 \%$ para o eletrômetro digital. Considerando todos os conjuntos de dados, a temperatura média foi de $(19,4 \pm 1,5)^{\circ} \mathrm{C}$ e a pressão de $(704 \pm 2)$ Torr. Para facilitar a identificação nos gráficos e tabelas dos dados obtidos para diferentes taxas de repetição com os eletrômetros analógico (Keithley ${ }^{\circledR}$ 610C) e digital (Keithley ${ }^{\circledR}$ 6517B), foram utilizadas as letras A e D, respectivamente, antes do valor de taxa de repetição. A variação da intensidade do feixe foi avaliada somente com o eletrômetro digital.

Nas TAB. 6 e 7 são apresentadas as correntes elétricas medidas com o eletrômetro analógico e digital, respectivamente, para diferentes taxas de repetição do feixe de laser. 
TABELA 6 - Corrente elétrica obtida com o eletrômetro analógico em função do E/N utilizando o isobutano como gás de enchimento.

\begin{tabular}{|c|c|c|c|}
\hline \multirow{2}{*}{$\mathbf{E} / \mathbf{N}(\mathbf{T d})$} & \multicolumn{3}{|c|}{ Corrente (pA) } \\
\hline & $A-10 H z$ & $A-15 H z$ & A - $20 \mathrm{~Hz}$ \\
\hline 57 & $0,135 \pm 0,002$ & $0,225 \pm 0,002$ & $0,235 \pm 0,002$ \\
\hline 72 & $0,135 \pm 0,002$ & $0,220 \pm 0,002$ & $0,210 \pm 0,002$ \\
\hline 86 & $0,140 \pm 0,002$ & $0,205 \pm 0,002$ & $0,230 \pm 0,002$ \\
\hline 100 & $0,150 \pm 0,002$ & $0,250 \pm 0,002$ & $0,235 \pm 0,002$ \\
\hline 115 & $0,155 \pm 0,002$ & $0,210 \pm 0,002$ & $0,220 \pm 0,002$ \\
\hline 129 & $0,170 \pm 0,002$ & $0,275 \pm 0,002$ & $0,255 \pm 0,002$ \\
\hline 143 & $0,225 \pm 0,002$ & $0,350 \pm 0,005$ & $0,400 \pm 0,005$ \\
\hline 158 & $0,400 \pm 0,005$ & $0,560 \pm 0,005$ & $0,710 \pm 0,005$ \\
\hline 172 & $1,45 \pm 0,02$ & $2,00 \pm 0,02$ & $2,40 \pm 0,02$ \\
\hline 178 & $2,80 \pm 0,05$ & $3,70 \pm 0,05$ & $4,50 \pm 0,05$ \\
\hline 184 & $6,30 \pm 0,05$ & $8,30 \pm 0,05$ & $10,0 \pm 0,2$ \\
\hline 189 & $14,0 \pm 0,2$ & $18,0 \pm 0,2$ & $20,0 \pm 0,2$ \\
\hline 195 & $29,0 \pm 0,5$ & $32,0 \pm 0,5$ & $37,0 \pm 0,5$ \\
\hline 201 & $49,0 \pm 0,5$ & $50,0 \pm 0,5$ & $61,0 \pm 0,5$ \\
\hline 207 & & $75,0 \pm 0,5$ & $86,0 \pm 0,5$ \\
\hline 212 & & $100 \pm 2$ & \\
\hline 218 & & $130 \pm 2$ & \\
\hline 224 & & $165 \pm 2$ & \\
\hline 229 & & $200 \pm 2$ & \\
\hline
\end{tabular}

As medidas realizadas com o eletrômetro analógico, para uma taxa de repetição do feixe de laser de $15 \mathrm{~Hz}$, foram realizadas para campos elétricos reduzidos mais intensos porque representa a mesma condição experimental validada com o nitrogênio. Assim, delimitou-se a região de medição para as demais condições até os primeiros valores de campos elétricos para os quais ocorreu a saturação do primeiro coeficiente de Townsend, que será discutida posteriormente. 
TABELA 7 - Corrente elétrica obtida com o eletrômetro digital em função do $\mathrm{E} / \mathrm{N}$ utilizando o isobutano como gás de enchimento.

\begin{tabular}{ccc}
\hline \multirow{2}{*}{$\mathbf{E} / \mathbf{N}(\mathbf{T d})$} & \multicolumn{2}{c}{ Corrente (pA) } \\
\cline { 2 - 3 } & $0,269 \pm 0,006$ & $\mathbf{D}-\mathbf{2 0 H z}$ \\
\hline 86 & $0,270 \pm 0,006$ & $0,456 \pm 0,008$ \\
100 & $0,293 \pm 0,006$ & $0,459 \pm 0,008$ \\
115 & $0,334 \pm 0,006$ & $0,447 \pm 0,007$ \\
129 & $0,403 \pm 0,007$ & $0,496 \pm 0,008$ \\
143 & $0,728 \pm 0,008$ & $0,665 \pm 0,007$ \\
158 & $2,51 \pm 0,03$ & $1,160 \pm 0,012$ \\
172 & $6,03 \pm 0,06$ & $4,15 \pm 0,05$ \\
179 & $14,70 \pm 0,15$ & $9,72 \pm 0,10$ \\
187 & $32,1 \pm 0,3$ & $22,30 \pm 0,23$ \\
194 & $56,1 \pm 0,6$ & $42,4 \pm 0,4$ \\
201 & & $69,5 \pm 0,7$ \\
\hline
\end{tabular}

Mesmo utilizando eletrômetros diferentes, os resultados obtidos são compatíveis entre si. Para E/N até $190 \mathrm{Td}$, a corrente elétrica para $20 \mathrm{~Hz}$ é superior à devida a taxas de repetição menores. Como a ionização primária é diretamente proporcional à energia depositada no meio, esperava-se que a razão entre as correntes no regime de ionização fosse próxima a dois, já que esta é a razão entre as taxas utilizadas, e o valor médio obtido foi de $(1,61 \pm 0,03)$ para o eletrômetro digital e $(1,62 \pm 0,04)$ para o eletrômetro analógico. No regime de avalanche, ainda há proporcionalidade entre a energia depositada e a carga elétrica total gerada no gás e essa razão manteve-se praticamente constante para E/N < 190 Td. Com o aumento da tensão aplicada, começam a surgir efeitos de não uniformidade do campo elétrico, que podem ser responsáveis pela diminuição da razão entre as correntes em campos acima de $190 \mathrm{Td}$.

Os valores de corrente elétrica medidos para cada intensidade do feixe de laser com o eletrômetro digital na saída direta do catodo são apresentados na TAB. 8. 
TABELA 8 - Corrente elétrica obtida com o eletrômetro digital em função do E/N utilizando o isobutano como gás de enchimento. Taxa de repetição do laser: $20 \mathrm{~Hz}$

\begin{tabular}{|c|c|c|c|c|}
\hline \multirow{2}{*}{$\mathbf{E} / \mathbf{N}(\mathbf{T d})$} & \multicolumn{4}{|c|}{ Corrente (pA) } \\
\hline & $100 \%$ & $87 \%$ & $76 \%$ & $66 \%$ \\
\hline 57 & $0,381 \pm 0,007$ & & $0,229 \pm 0,005$ & \\
\hline 72 & $0,383 \pm 0,007$ & & $0,246 \pm 0,005$ & \\
\hline 86 & $0,433 \pm 0,007$ & & $0,266 \pm 0,006$ & \\
\hline 100 & $0,465 \pm 0,008$ & $0,352 \pm 0,007$ & $0,282 \pm 0,006$ & $0,181 \pm 0,007$ \\
\hline 115 & $0,412 \pm 0,007$ & $0,389 \pm 0,007$ & $0,259 \pm 0,006$ & $0,195 \pm 0,007$ \\
\hline 122 & $0,482 \pm 0,008$ & $0,411 \pm 0,007$ & $0,299 \pm 0,006$ & $0,208 \pm 0,007$ \\
\hline 129 & $0,474 \pm 0,008$ & $0,413 \pm 0,007$ & $0,309 \pm 0,006$ & $0,199 \pm 0,007$ \\
\hline 136 & $0,527 \pm 0,008$ & $0,528 \pm 0,008$ & $0,338 \pm 0,006$ & $0,291 \pm 0,008$ \\
\hline 143 & $0,642 \pm 0,009$ & $0,524 \pm 0,008$ & $0,396 \pm 0,007$ & $0,292 \pm 0,008$ \\
\hline 151 & $0,813 \pm 0,008$ & $0,729 \pm 0,008$ & $0,524 \pm 0,008$ & \\
\hline 158 & $1,090 \pm 0,011$ & $0,992 \pm 0,010$ & $0,752 \pm 0,011$ & $0,539 \pm 0,010$ \\
\hline 165 & $1,980 \pm 0,020$ & $1,850 \pm 0,019$ & $1,240 \pm 0,015$ & $0,983 \pm 0,015$ \\
\hline 172 & $4,65 \pm 0,05$ & $3,46 \pm 0,04$ & $2,74 \pm 0,03$ & $1,810 \pm 0,023$ \\
\hline 178 & $8,67 \pm 0,09$ & $7,65 \pm 0,08$ & $5,36 \pm 0,06$ & $3,81 \pm 0,04$ \\
\hline 183 & $17,00 \pm 0,17$ & $14,60 \pm 0,15$ & $11,40 \pm 0,12$ & $9,07 \pm 0,10$ \\
\hline 189 & $27,7 \pm 0,3$ & $28,2 \pm 0,3$ & $15,50 \pm 0,16$ & $17,90 \pm 0,18$ \\
\hline 195 & $53,0 \pm 0,5$ & $45,3 \pm 0,5$ & $40,2 \pm 0,4$ & $31,7 \pm 0,3$ \\
\hline 201 & $77,8 \pm 0,8$ & $73,2 \pm 0,7$ & $57,8 \pm 0,6$ & $54,9 \pm 0,6$ \\
\hline
\end{tabular}

O valor de campo elétrico reduzido para os quais as correntes elétricas mensuradas cresceram significativamente foi de $143 \mathrm{Td}$ para todos os conjuntos de dados, mesmo com a variação da taxa de repetição do feixe de laser e de sua intensidade. Este valor de E/N é o limiar estimado entre o regime de ionização e de avalanche para o isobutano.

Na FIG. 23 observa-se o crescimento da corrente elétrica em função do campo elétrico aplicado nos nitrogênio e do isobutano sob as mesmas condições experimentais. 


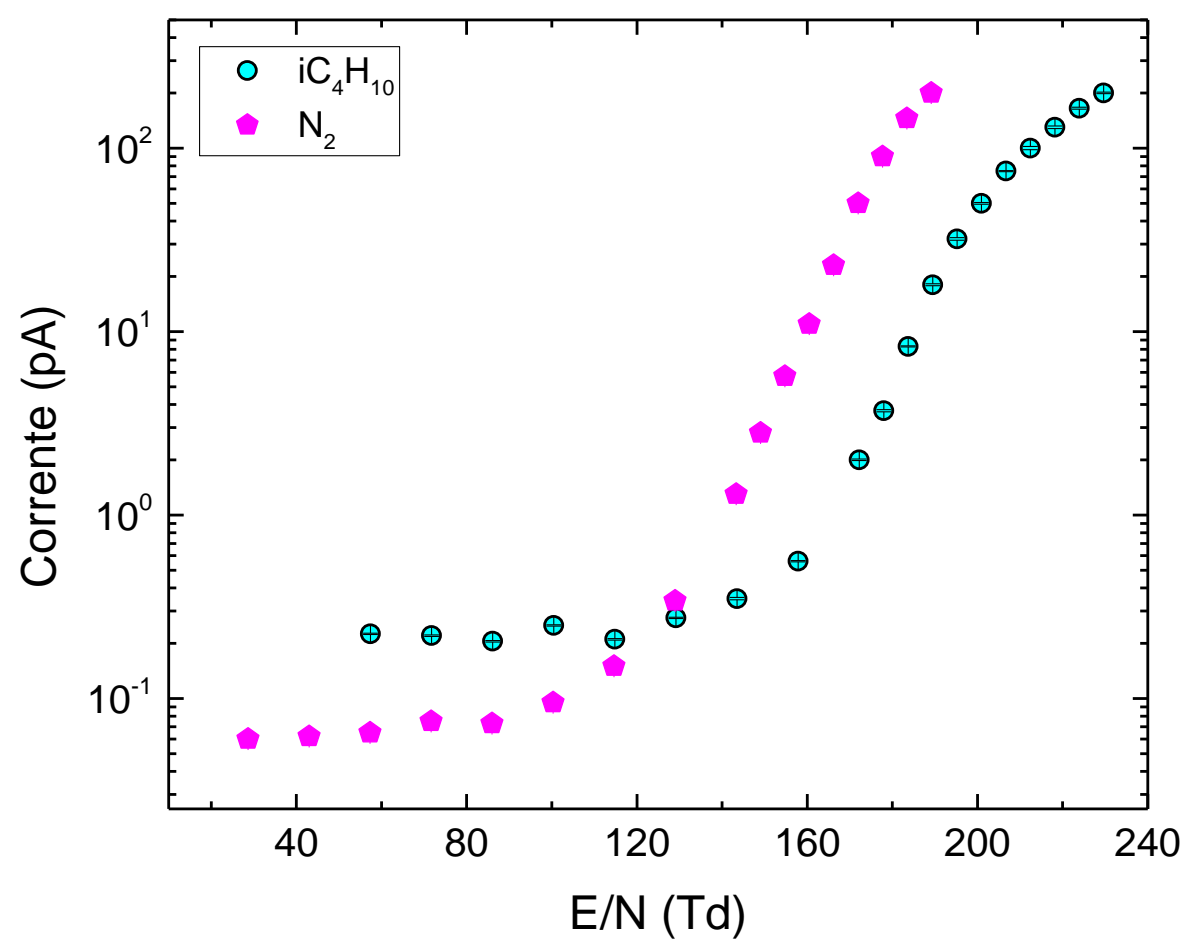

FIGURA 23 - Comportamento da corrente elétrica do isobutano e do nitrogênio medida na saída direta do catodo com o eletrômetro analógico em função do campo elétrico para uma taxa de repetição do feixe laser de $15 \mathrm{~Hz}$.

O número de estados excitados não-radiativos cresce com o número de átomos de uma molécula [21]. Por isso, o isobutano, que é um hidrocarboneto de estrutura complexa, apresenta um valor maior de campo elétrico reduzido de transição entre os regimes de ionização e de avalanche do que para o nitrogênio, que é uma molécula diatômica.

A relação entre a queda ôhmica calculada e a corrente medida em função do campo elétrico reduzido e da tensão de polarização do anodo é apresenta na FIG. 24 e 25. 


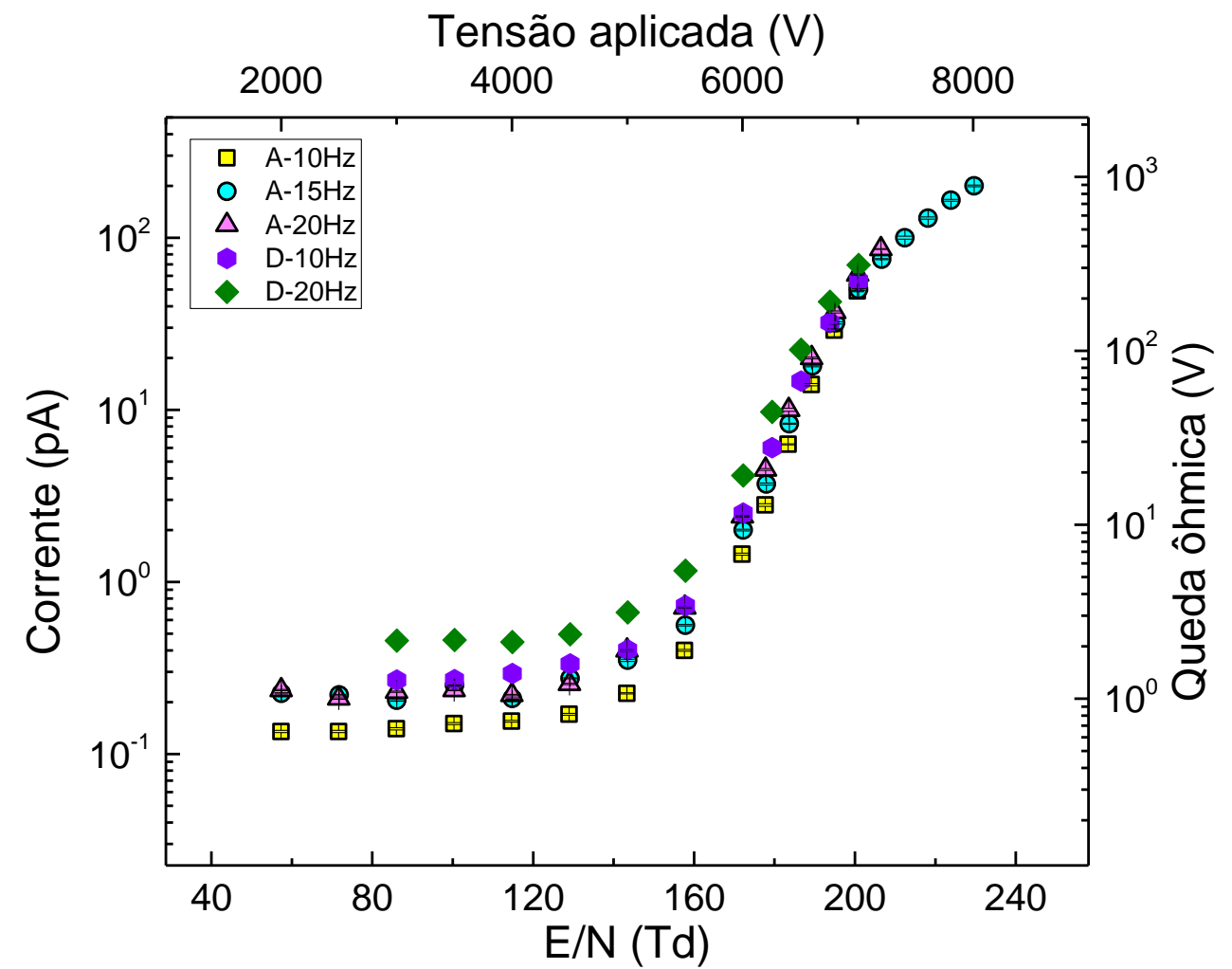

FIGURA 24 - Correspondência entre a queda ôhmica e a corrente elétrica medida para o isobutano para diferentes taxas de repetição do feixe de laser.

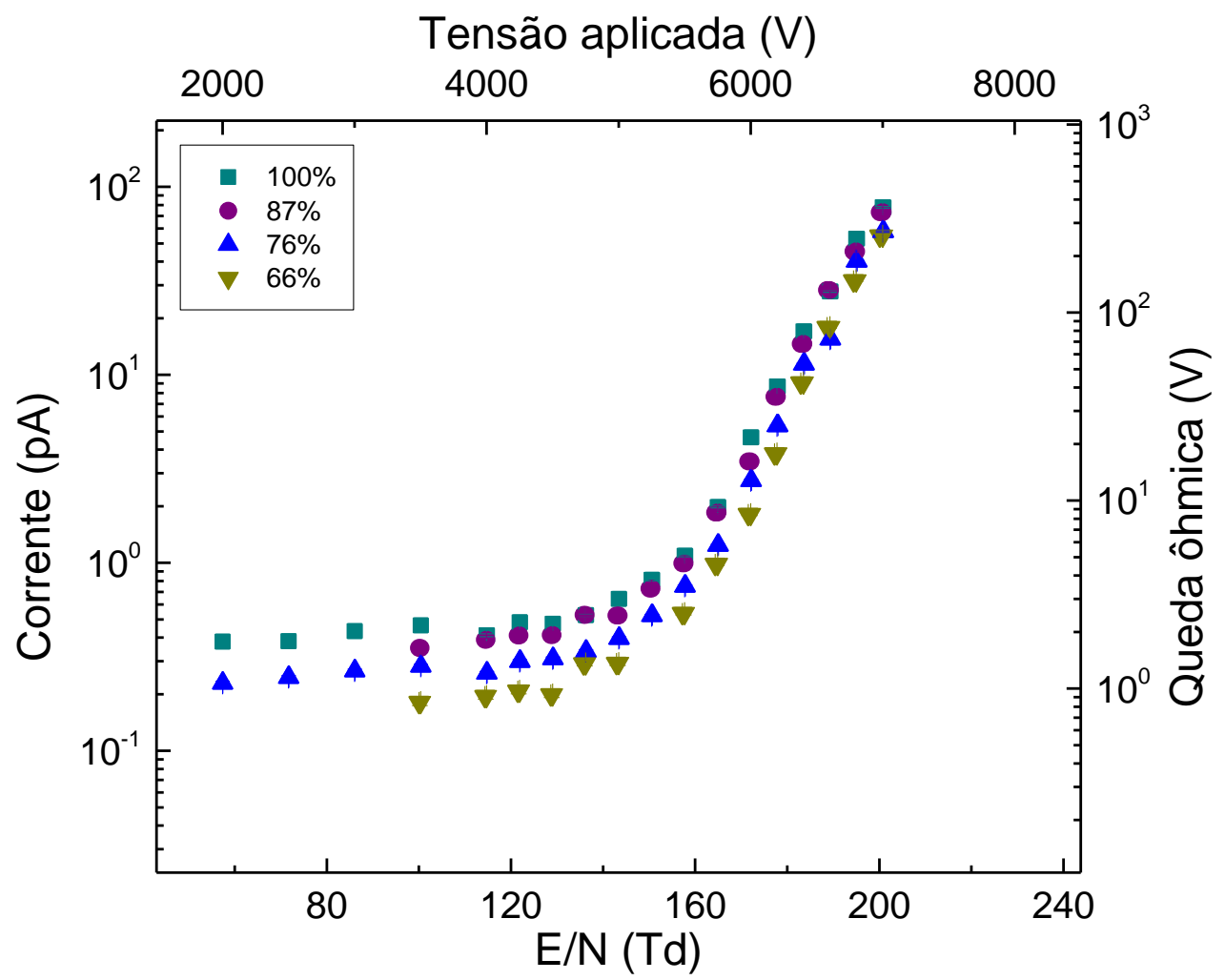

FIGURA 25 - Correspondência entre a queda ôhmica e a corrente elétrica medida para o isobutano com diferentes intensidades do feixe de laser utilizando o eletrômetro digital e taxa de repetição de $20 \mathrm{~Hz}$. 
É possível observar que o crescimento da corrente elétrica possui comportamento compatível para as diferentes intensidades do feixe e para as três taxas de repetição. Novamente, a corrente de fundo não foi descontada, pois seu maior valor foi de $(0,0060 \pm 0,0006) \mathrm{pA}$, enquanto o menor valor de corrente de ionização foi de $(0,135 \pm$ $0,002) \mathrm{pA}$.

O primeiro coeficiente de Townsend de ionização foi calculado para todos os dados experimentais obtidos (diferentes intensidades de feixe e taxas de repetição). Na TAB. 9 - 11 são apresentados os valores de campo elétrico reduzido e campo elétrico reduzido efetivo, $\mathrm{E}_{\mathrm{e}} / \mathrm{N}$, para cada valor de tensão aplicada para cada conjunto de dados, bem como os valores do primeiro coeficiente de Townsend. As incertezas foram estimadas em $15 \%$ pela comparação entre os conjuntos de dados obtidos para o mesmo valor de campo, sendo a incerteza instrumental menor de 5,5\%.

Ao contrário do que ocorreu com o nitrogênio (TAB. 4), o campo elétrico reduzido efetivo não diminuiu dentro da faixa de tensão de polarização utilizada. Porém, para os três últimos valores de E/N, correspondentes a um intervalo de 12 Td (TAB. 10 A-15Hz), o campo elétrico efetivo foi praticamente constante.

TABELA 9 - Valores do primeiro coeficiente de Townsend determinados para o iso $\mathrm{C}_{4} \mathrm{H}_{10}$ utilizando o eletrômetro digital com diferentes taxas de repetição do feixe de laser.

\begin{tabular}{cccccc}
\hline \multirow{2}{*}{$\mathbf{V}(\mathbf{V})$} & $\mathbf{E} / \mathbf{N}(\mathbf{T d})$ & \multicolumn{2}{c}{$\mathbf{D}-\mathbf{1 0 H z}$} & \multicolumn{2}{c}{$\mathbf{D}-\mathbf{2 0 H z}$} \\
\cline { 3 - 6 } & & $\begin{array}{c}\mathbf{E}_{\mathrm{e} /} / \mathbf{N} \\
(\mathbf{T d})\end{array}$ & $\begin{array}{c}\alpha / \mathbf{N} \\
\left(\mathbf{1 0}^{-24} \mathbf{m}^{2}\right)\end{array}$ & $\begin{array}{c}\mathbf{E}_{\mathrm{e}} / \mathbf{N} \\
(\mathbf{T d})\end{array}$ & $\begin{array}{c}\alpha / \mathbf{N} \\
\left(\mathbf{1 0}^{-24} \mathbf{m}^{2}\right)\end{array}$ \\
\hline 5000 & 143 & 143 & $9,3 \pm 1,4$ & 143 & $10,3 \pm 1,5$ \\
5500 & 158 & 158 & $26 \pm 4$ & 158 & $26 \pm 4$ \\
6000 & 172 & 172 & $62 \pm 9$ & 172 & $63 \pm 9$ \\
6250 & 179 & 179 & $87 \pm 13$ & 178 & $87 \pm 13$ \\
6500 & 187 & 185 & $113 \pm 17$ & 184 & $111 \pm 17$ \\
6750 & 194 & 189 & $135 \pm 20$ & 188 & $130 \pm 19$ \\
7000 & 201 & 193 & $151 \pm 23$ & 192 & $144 \pm 22$ \\
\hline
\end{tabular}


TABELA 10 - Valores do primeiro coeficiente de Townsend determinados para o iso $\mathrm{C}_{4} \mathrm{H}_{10}$ utilizando o eletrômetro analógico com diferentes taxas de repetição do feixe de laser.

\begin{tabular}{|c|c|c|c|c|c|c|c|}
\hline \multirow{2}{*}{$\mathbf{V}(\mathbf{V})$} & \multirow[b]{2}{*}{$\mathbf{E} / \mathbf{N}(\mathbf{T d})$} & \multicolumn{2}{|c|}{$\mathrm{A}-10 \mathrm{~Hz}$} & \multicolumn{2}{|c|}{$A-15 H z$} & \multicolumn{2}{|c|}{$A-20 H z$} \\
\hline & & $\begin{array}{l}\mathbf{E}_{\mathrm{ee}} / \mathbf{N} \\
(\mathbf{T d}) \\
\end{array}$ & $\begin{array}{c}\alpha / \mathbf{N} \\
\left(1^{-24} \mathbf{m}^{2}\right)\end{array}$ & $\begin{array}{l}\mathbf{E}_{\text {ef }} / \mathbf{N} \\
(\mathbf{T d}) \\
\end{array}$ & $\begin{array}{c}\alpha / \mathbf{N} \\
\left(10^{-24} \mathrm{~m}^{2}\right)\end{array}$ & $\begin{array}{l}\mathbf{E}_{\mathrm{ef} / \mathrm{N}} \\
(\mathbf{T d}) \\
\end{array}$ & $\begin{array}{c}\alpha / \mathbf{N} \\
\left(10^{-24} \mathbf{m}^{2}\right) \\
\end{array}$ \\
\hline 5000 & 143 & 143 & $13,0 \pm 1,9$ & 143 & $13,1 \pm 2,0$ & 143 & $15,8 \pm 2,4$ \\
\hline 5500 & 158 & 158 & $30 \pm 4$ & 158 & $27 \pm 4$ & 158 & $32 \pm 5$ \\
\hline 6000 & 172 & 172 & $66 \pm 10$ & 172 & $63 \pm 10$ & 172 & $67 \pm 10$ \\
\hline 6200 & 178 & 177 & $85 \pm 13$ & 177 & $81 \pm 12$ & 177 & $85 \pm 13$ \\
\hline 6400 & 184 & 183 & $108 \pm 16$ & 183 & $104 \pm 16$ & 182 & $108 \pm 16$ \\
\hline 6600 & 189 & 187 & $131 \pm 20$ & 187 & $126 \pm 19$ & 187 & $128 \pm 19$ \\
\hline 6800 & 195 & 191 & $152 \pm 23$ & 191 & $143 \pm 21$ & 190 & $146 \pm 22$ \\
\hline 7000 & 201 & 194 & $167 \pm 25$ & 194 & $156 \pm 23$ & 193 & $160 \pm 24$ \\
\hline 7200 & 207 & & & 197 & $167 \pm 25$ & 195 & $170 \pm 25$ \\
\hline 7400 & 212 & & & 199 & $175 \pm 26$ & & \\
\hline 7600 & 218 & & & 201 & $183 \pm 27$ & & \\
\hline 7800 & 224 & & & 202 & $190 \pm 28$ & & \\
\hline 8000 & 230 & & & 203 & $195 \pm 29$ & & \\
\hline
\end{tabular}

TABELA 11 - Valores do primeiro coeficiente de Townsend determinados para o iso $\mathrm{C}_{4} \mathrm{H}_{10}$ utilizando o eletrômetro digital com diferentes intensidades do feixe de laser para taxa de repetição de $20 \mathrm{~Hz}$.

\begin{tabular}{cccccccccc}
\hline \multirow{2}{*}{$\begin{array}{c}\mathbf{V} \\
(\mathbf{V})\end{array}$} & $\mathbf{E} / \mathbf{N}$ & \multicolumn{2}{c}{$\mathbf{1 0 0 \%}$} & \multicolumn{2}{c}{$\mathbf{8 7 \%}$} & \multicolumn{2}{c}{$\mathbf{7 6 \%}$} & \multicolumn{2}{c}{$\mathbf{6 6 \%}$} \\
\cline { 3 - 9 } & $(\mathbf{T d})$ & $\begin{array}{c}\mathbf{E}_{\mathrm{e} /} / \mathbf{N} \\
(\mathbf{T d})\end{array}$ & $\begin{array}{c}\alpha / \mathbf{N} \\
\left(\mathbf{1 0}^{-24} \mathbf{m}^{2}\right)\end{array}$ & $\begin{array}{c}\mathbf{E}_{\mathrm{e} /} / \mathbf{N} \\
(\mathbf{T d})\end{array}$ & $\begin{array}{c}\alpha / \mathbf{N} \\
\left(\mathbf{1 0}^{-24} \mathbf{m}^{2}\right)\end{array}$ & $\begin{array}{c}\mathbf{E}_{\mathrm{ef} / \mathbf{N}} \\
(\mathbf{T d})\end{array}$ & $\begin{array}{c}\alpha / \mathbf{N} \\
\left(\mathbf{1 0}^{-24} \mathbf{m}^{2}\right)\end{array}$ & $\begin{array}{c}\mathbf{E}_{\mathrm{eff} / \mathbf{N}}(\mathbf{N}) \\
(\mathbf{T})\end{array}$ & $\begin{array}{c}\alpha / \mathbf{N} \\
\left(\mathbf{1 0}^{-24} \mathbf{m}^{2}\right)\end{array}$ \\
\hline 5000 & 143 & 143 & $10,0 \pm 1,5$ & 143 & $8,4 \pm 1,3$ & 143 & $9,6 \pm 1,4$ & 143 & $11,4 \pm 1,7$ \\
5250 & 151 & 151 & $16,8 \pm 2,5$ & 150 & $17,8 \pm 2,7$ & 151 & $17,7 \pm 2,7$ & & \\
5500 & 158 & 158 & $25 \pm 4$ & 157 & $27 \pm 4$ & 158 & $28 \pm 4$ & 157 & $29 \pm 4$ \\
5750 & 165 & 165 & $42 \pm 6$ & 164 & $44 \pm 7$ & 165 & $42 \pm 6$ & 164 & $46 \pm 7$ \\
6000 & 172 & 172 & $67 \pm 10$ & 171 & $62 \pm 9$ & 172 & $65 \pm 10$ & 171 & $64 \pm 10$ \\
6200 & 178 & 177 & $85 \pm 13$ & 176 & $85 \pm 13$ & 177 & $84 \pm 13$ & 177 & $85 \pm 13$ \\
6400 & 183 & 181 & $104 \pm 16$ & 181 & $103 \pm 16$ & 182 & $106 \pm 16$ & 182 & $110 \pm 16$ \\
6600 & 189 & 186 & $118 \pm 18$ & 185 & $122 \pm 18$ & 187 & $115 \pm 17$ & 186 & $129 \pm 19$ \\
6800 & 195 & 188 & $137 \pm 21$ & 188 & $136 \pm 20$ & 190 & $142 \pm 21$ & 190 & $145 \pm 22$ \\
7000 & 201 & 191 & $148 \pm 22$ & 190 & $150 \pm 22$ & 193 & $153 \pm 23$ & 193 & $161 \pm 24$ \\
\hline
\end{tabular}


Com os dados das TAB. 9 - 11 foram construídas os gráficos apresentados nas FIG. 26 - 29, nos quais são comparados com valores de $\alpha / \mathrm{N}$ a simulação Magboltz 2 versões 7.1 e 8.6 [53]. Os conjuntos de secção de choque utilizados foram "ISO 1999" e "ISO 2009", respectivamente. O primeiro possui apenas o tratamento isotrópico. Além desta opção, o segundo permite escolher entre duas parametrizações para o tratamento anisotrópico do espalhamento elástico de elétrons [53]. Vale ressaltar que na faixa de campo elétrico reduzido avaliada não há dados presentes na literatura para o isobutano, a menos daqueles obtidos para $15 \mathrm{~Hz}$ sem atenuação do feixe em trabalho de Lima [22, 23].

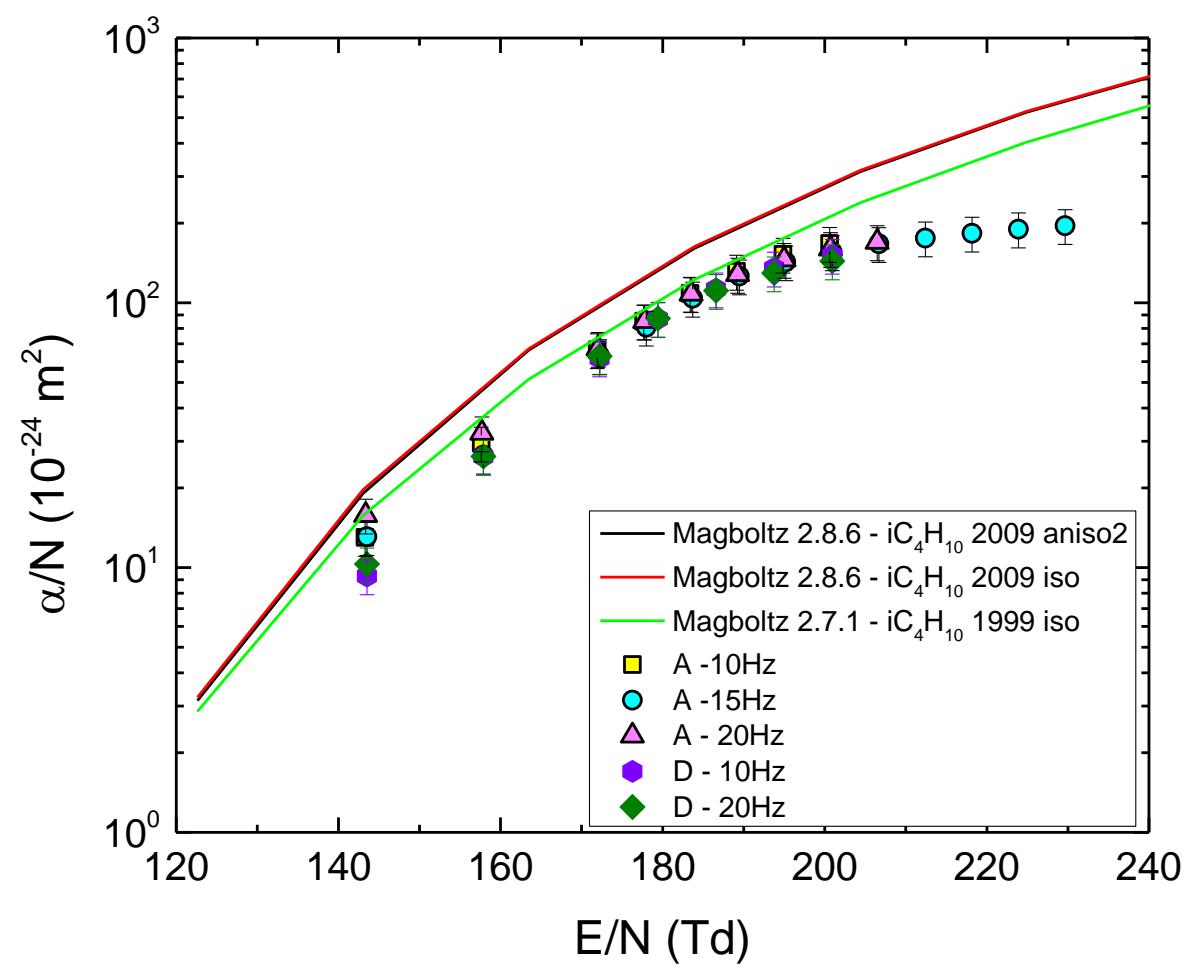

FIGURA 26 - Primeiro coeficiente de Townsend reduzido do isobutano em função do campo elétrico reduzido para diferentes taxas de repetição do feixe de laser. Resultados com incerteza de $15 \%$. As curvas representam as simulações realizadas com o programa Magboltz 2 [53]. 


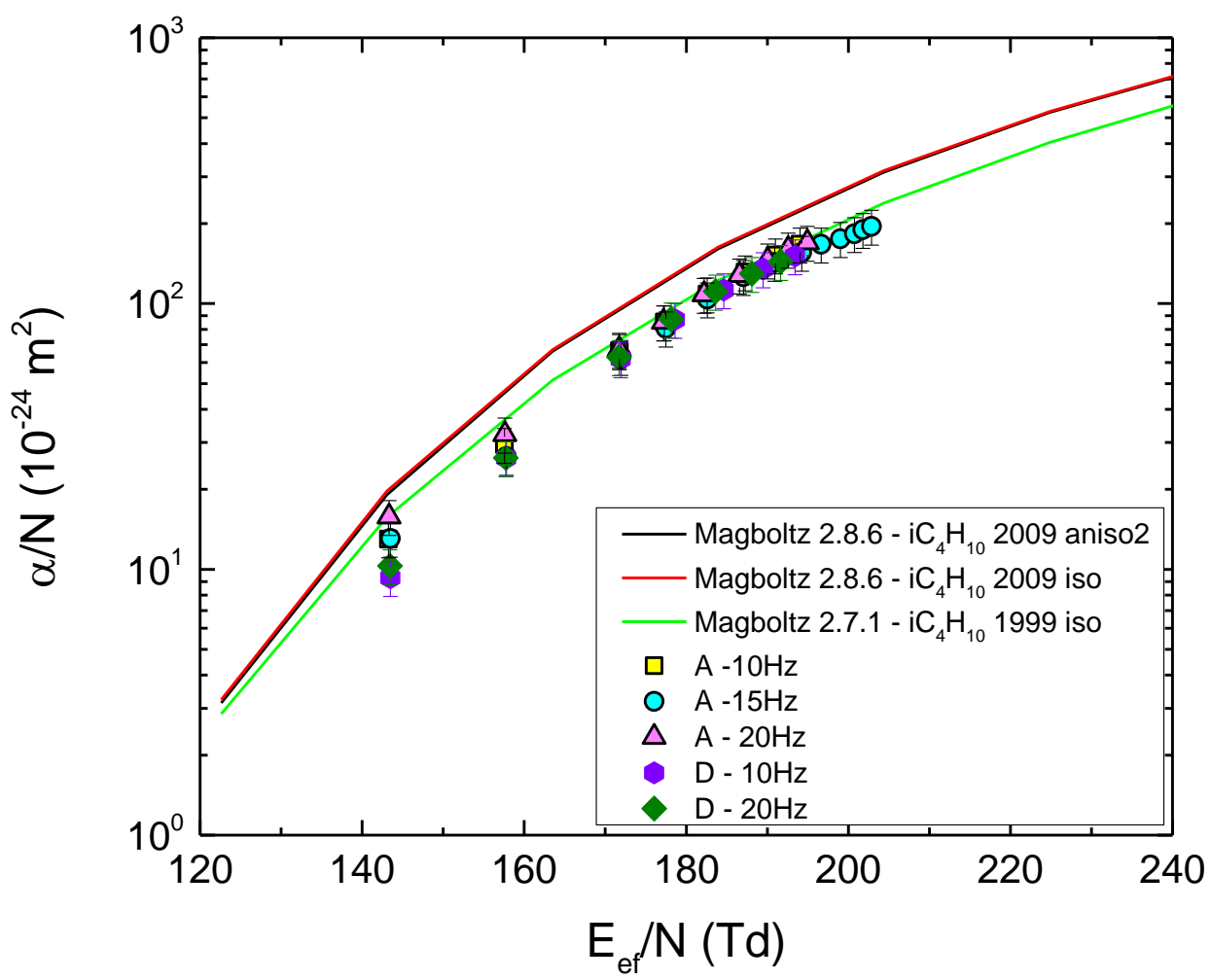

FIGURA 27 - Primeiro coeficiente de Townsend reduzido do isobutano em função do campo elétrico reduzido efetivo para diferentes taxas de repetição do feixe de laser. Resultados com incerteza de $15 \%$. As curvas representam as simulações realizadas com o programa Magboltz 2 [53].

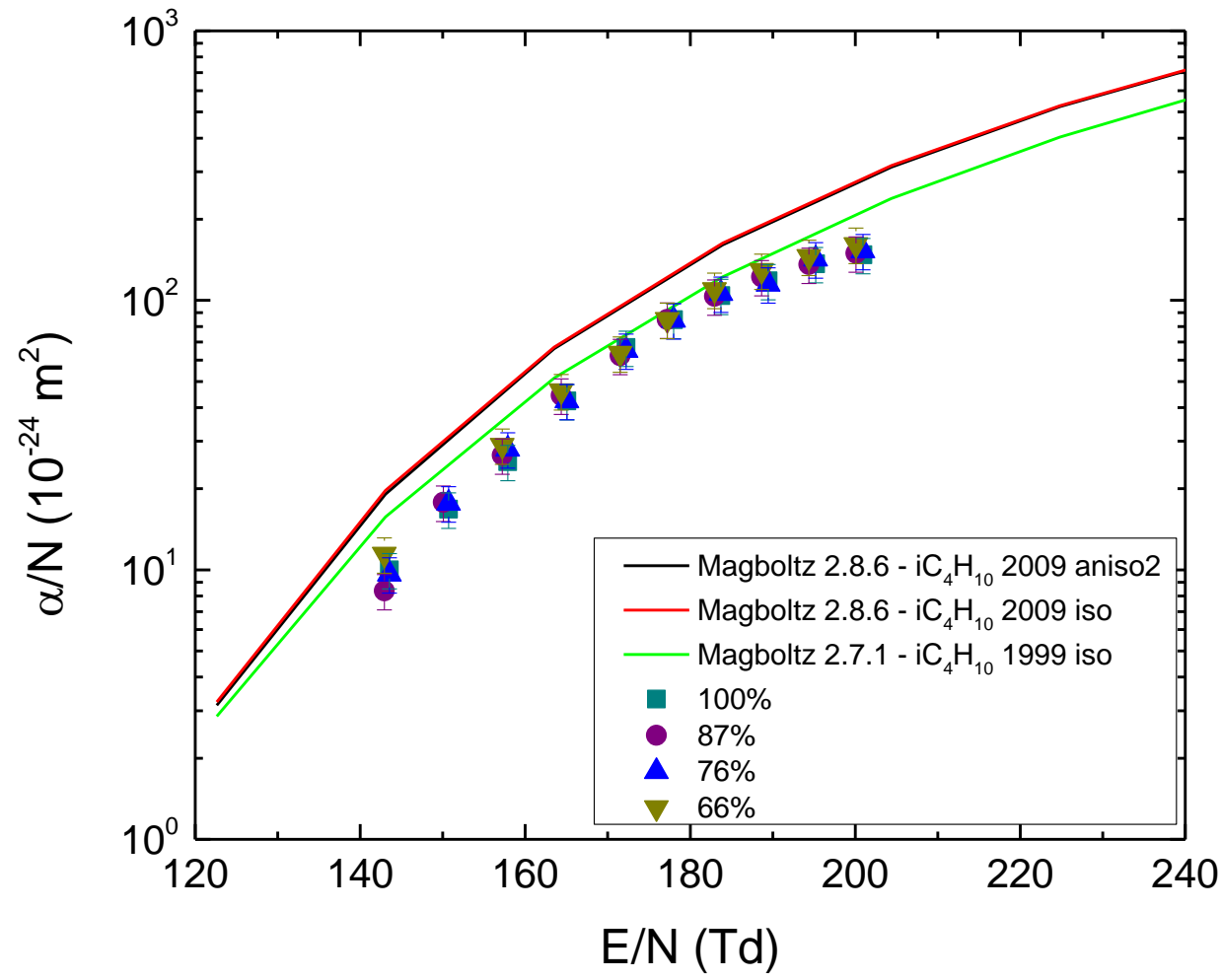

FIGURA 28 - Primeiro coeficiente de Townsend reduzido do isobutano em função do campo elétrico reduzido para diferentes intensidades do feixe de laser (20Hz). Resultados com incerteza de $15 \%$. As curvas representam as simulações realizadas com o programa Magboltz 2 [53]. 


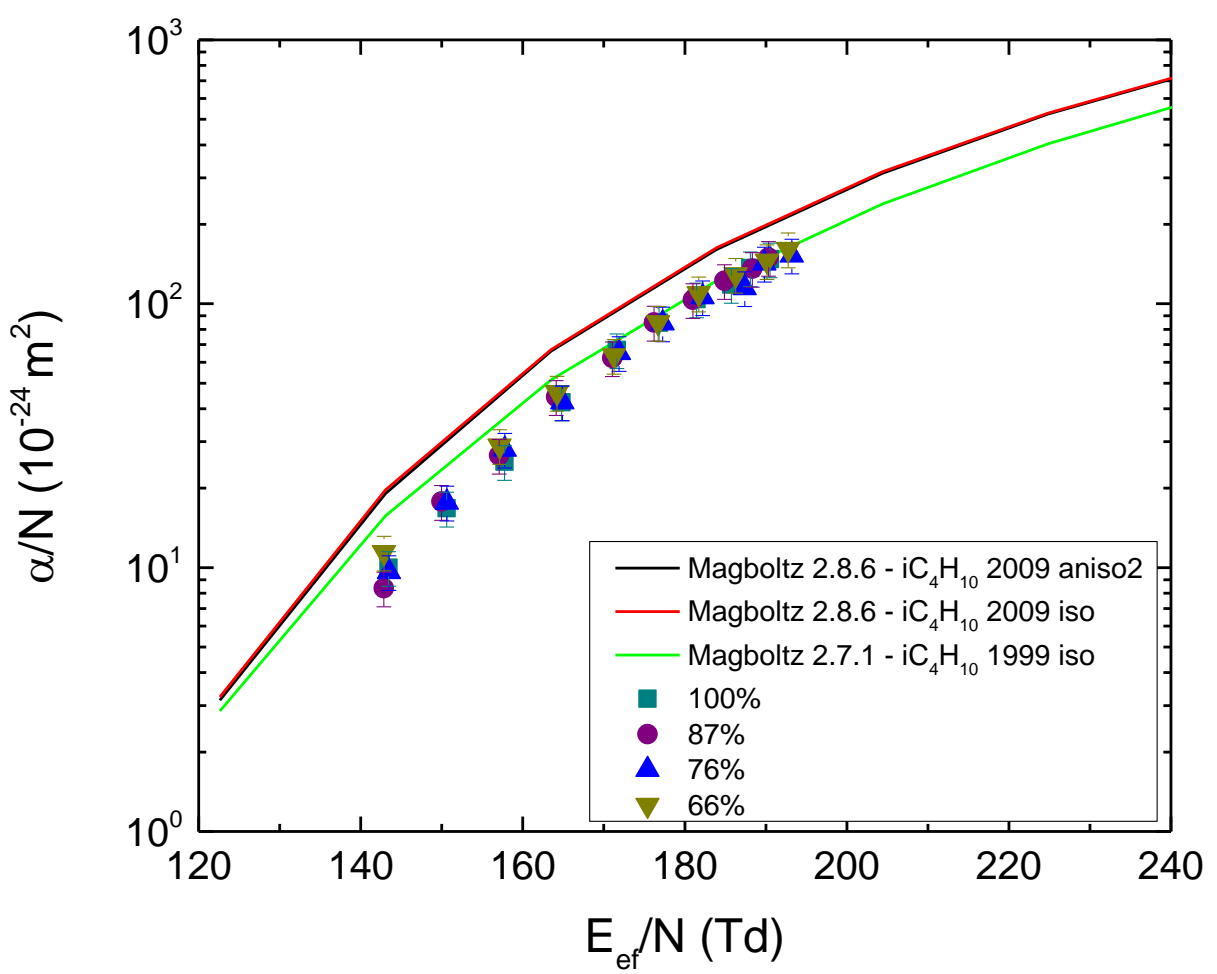

FIGURA 29 - Primeiro coeficiente de Townsend reduzido do isobutano em função do campo elétrico reduzido efetivo para diferentes intensidades do feixe de laser $(20 \mathrm{~Hz})$. Resultados com incerteza de $15 \%$. As curvas representam as simulações realizadas com o programa Magboltz 2 [53].

O comportamento do primeiro coeficiente de Townsend é compatível com as curvas simuladas pelo programa Magboltz 2, particularmente com a versão 7.1, que utiliza um conjunto de secção de choque mais antigo. Este mesmo resultado também foi obtido no trabalho de Lima et al. [23]. Observa-se a tendência de saturação no valor de $\alpha / \mathrm{N}$ para campos elétricos reduzidos acima de 200 Td (FIG. 26 e 28), nos quais a diferença entre os valores de campo com e sem correção para queda ôhmica é maior do que 5\%. Aplicando a correção aos dados, obtém-se uma boa concordância entre os dados experimentais e a curva obtida com a versão 7.1 do programa Magboltz 2 (FIG. 27 e 29).

Nas FIG. 30 - 33 são apresentados os resíduos normalizados dos valores experimentais do primeiro coeficiente de Townsend em relação à simulação realizada com a versão 7.1 do programa Magboltz 2, por esta estar em melhor acordo com nossos resultados. 


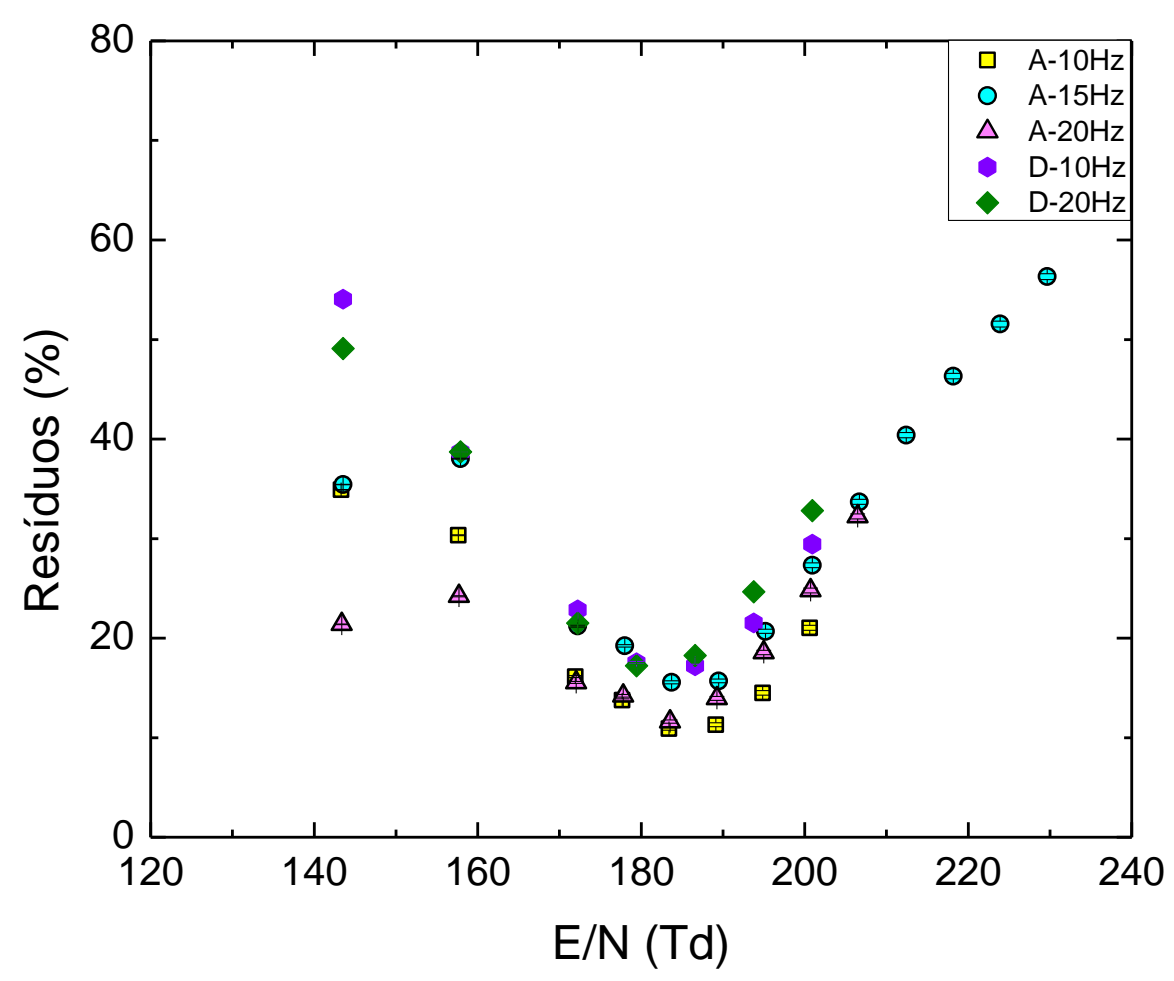

FIGURA 30 - Diferença entre os valores do primeiro coeficiente de Townsend do isobutano simulados com o programa Magboltz 2.7.1[53] e experimentais para diferentes taxas de repetição do feixe de laser (FIG. 26) em função do campo elétrico reduzido.

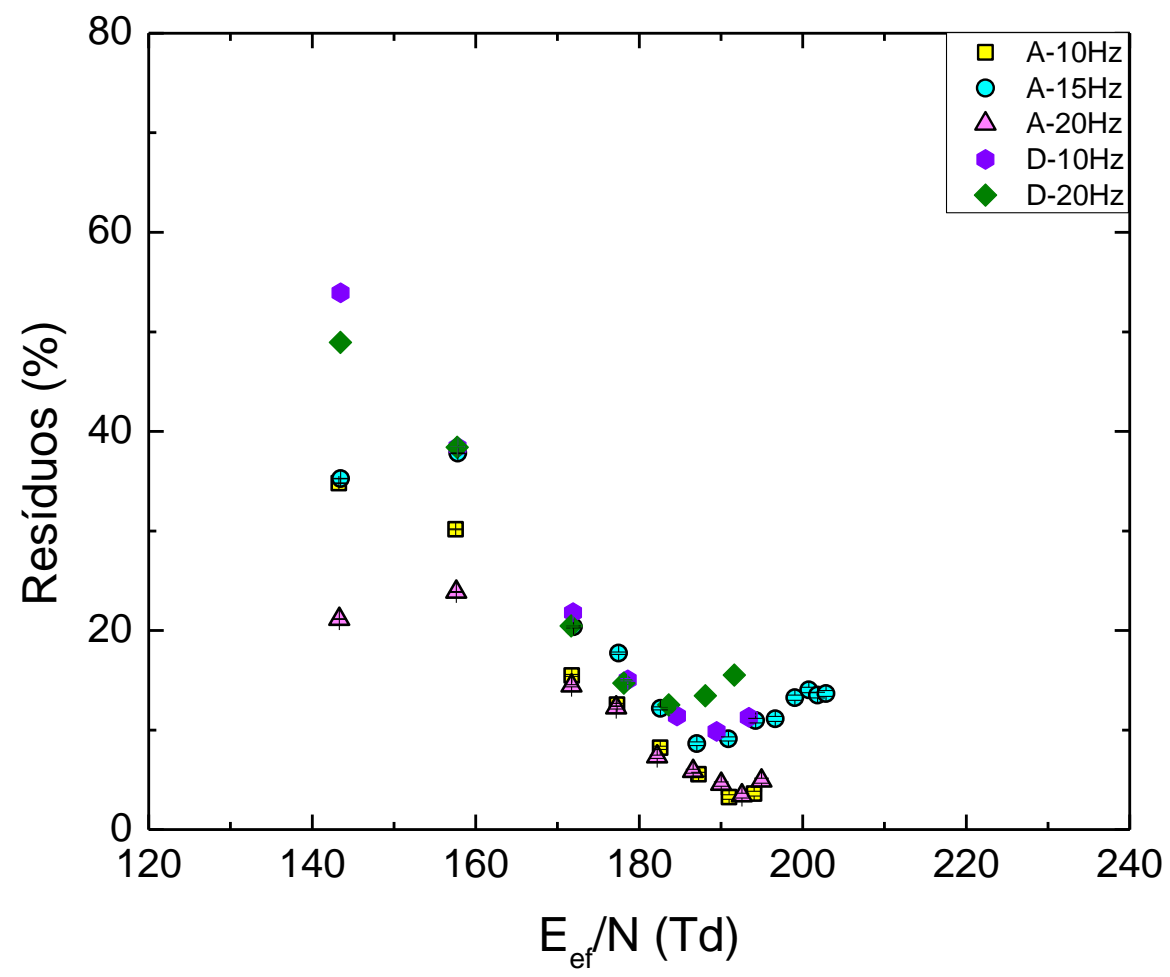

FIGURA 31 - Diferença entre os valores de primeiro coeficiente de Townsend do isobutano simulados com o programa Magboltz 2.7.1[53] e experimentais para diferentes taxas de repetição do feixe de laser (FIG. 27) em função do campo elétrico reduzido efetivo. 


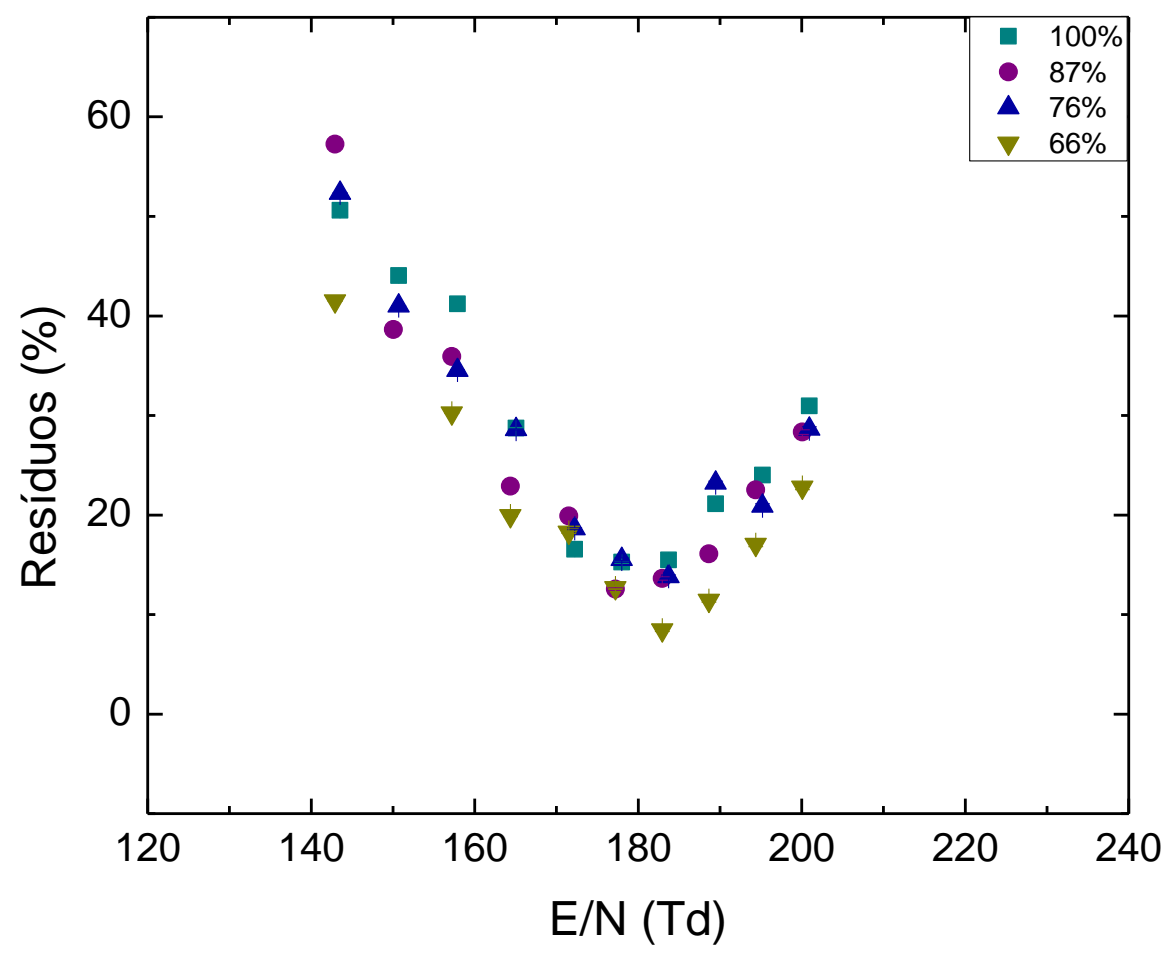

FIGURA 32 - Diferença entre os valores de primeiro coeficiente de Townsend do isobutano simulados com o programa Magboltz 2.7.1[53] e experimentais para diferentes intensidades do feixe de laser (FIG. 28) em função do campo elétrico reduzido.

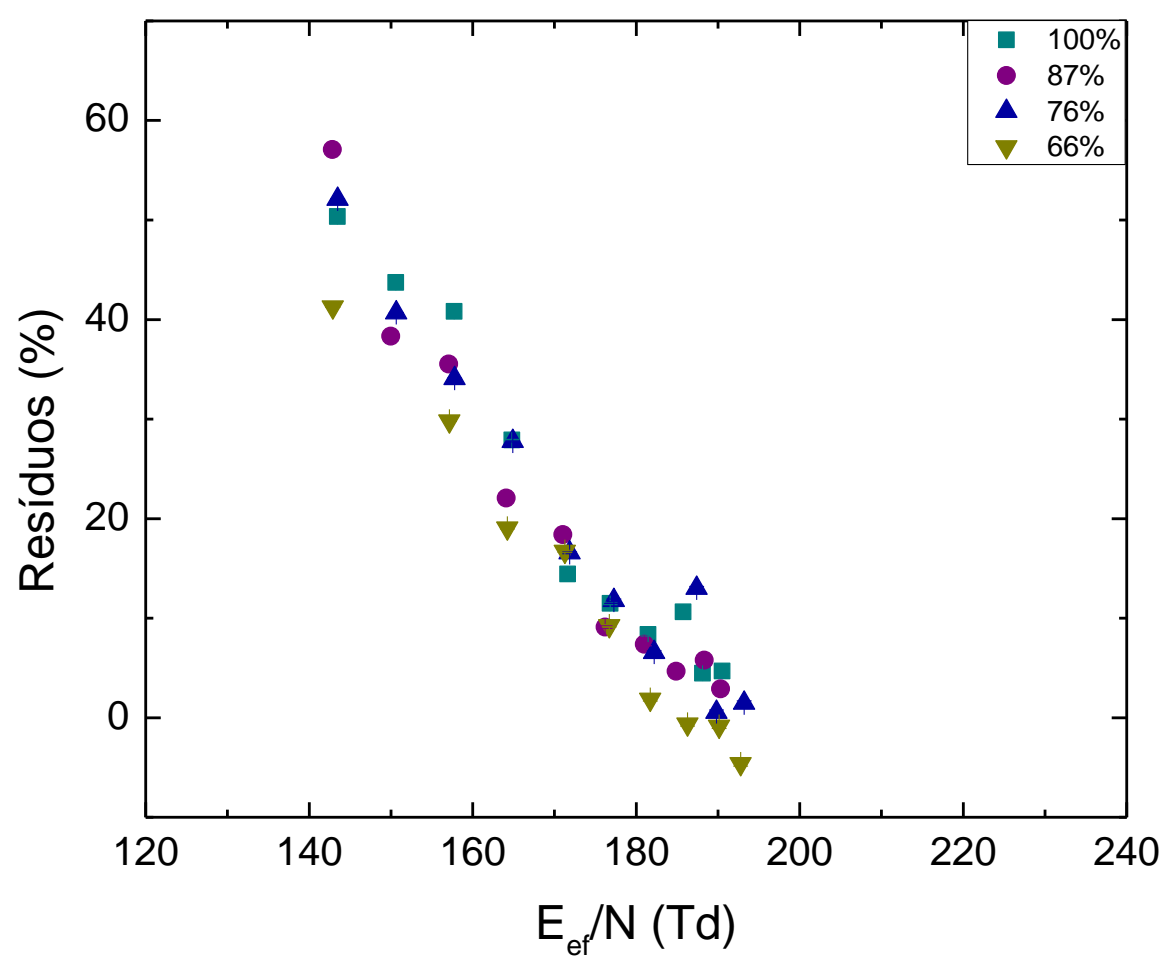

FIGURA 33 - Diferença entre os valores de primeiro coeficiente de Townsend do isobutano simulados com o programa Magboltz 2.7.1[53] e experimentais para diferentes intensidades do feixe de laser (FIG. 29) em função do campo elétrico reduzido efetivo. 
Ao aplicarmos a correção para a queda ôhmica, os resíduos dos primeiros coeficientes de Townsend diminuíram para campos elétricos reduzidos maiores que 180Td, comprovando que a concordância entre os dados experimentais e os simulados melhora.

Mesmo com a variação da intensidade do feixe de laser e da taxa de repetição dos pulsos, os valores do primeiro coeficiente de Townsend são reprodutíveis e apresentam boa concordância entre si. Nas medições de corrente utilizando a configuração semelhante à RPCs, além da queda ôhmica, podem ocorrer processos secundários, como efeito de carga espacial e recombinação. Esses efeitos dependem dos parâmetros avaliados, já discutidos no Capítulo 4, e a ausência de diferenças significativas entre os resultados obtidos exclui sua presença.

Para maior confiabilidade dos resultados obtidos para o isobutano, foram construídas as curvas $\alpha / \mathrm{N}$ em função do campo elétrico reduzido sem e com correção para queda ôhmica para as diferentes taxas de repetição e intensidade do feixe (FIG. 34 - 37) para a determinação experimental dos parâmetros A e B (equação 11). Como foi observada a saturação dos primeiros coeficientes de Townsend para E/N >200 Td na FIG. 26, em que não houve correção para queda ôhmica, a parametrização de Williams e Sara [36] foi aplicada aos dados na região de até $200 \mathrm{Td}$.

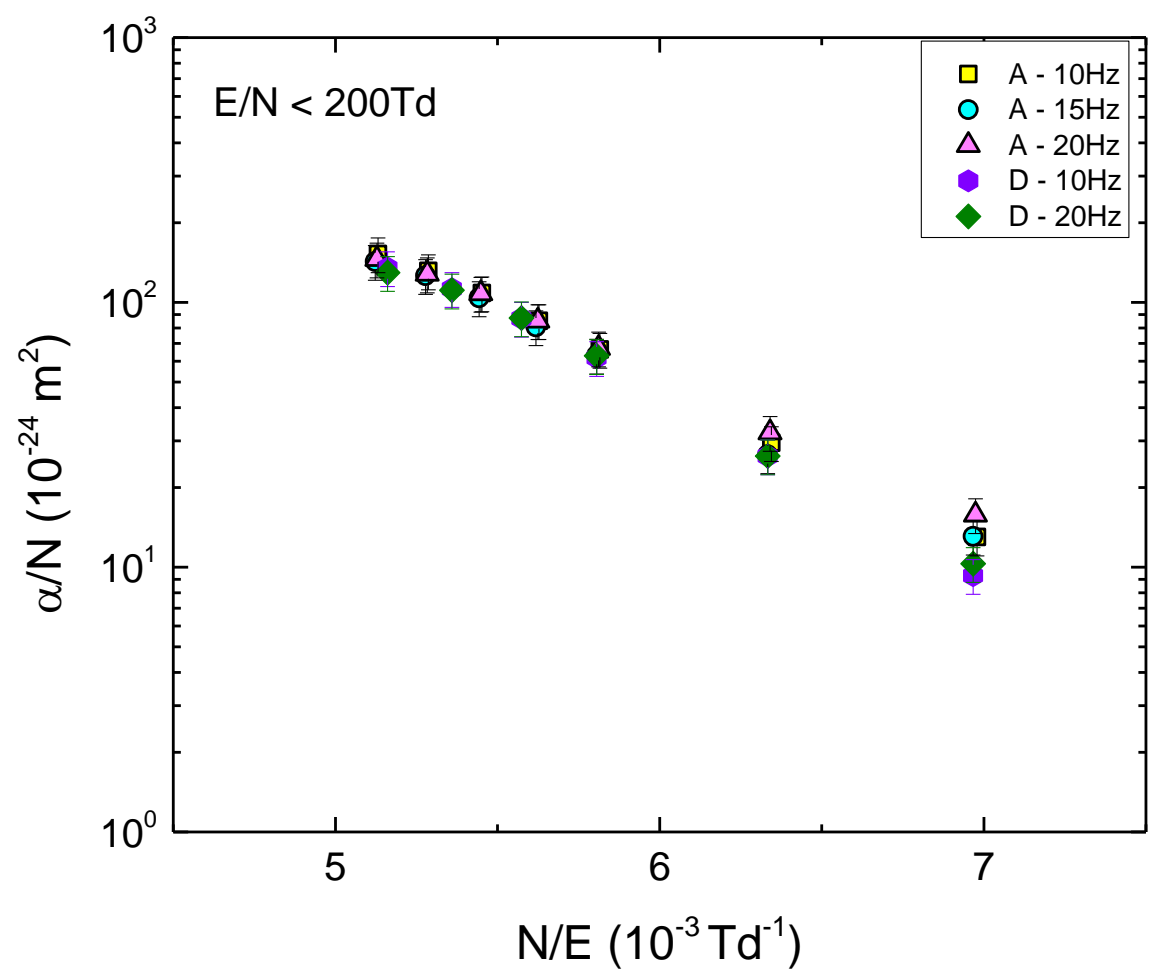

FIGURA 34 - Aplicação da parametrização de Williams e Sara [36] aos resultados obtidos para E/N <200Td sem correção da queda ôhmica para o isobutano com diferentes taxas de repetição do feixe de laser. 


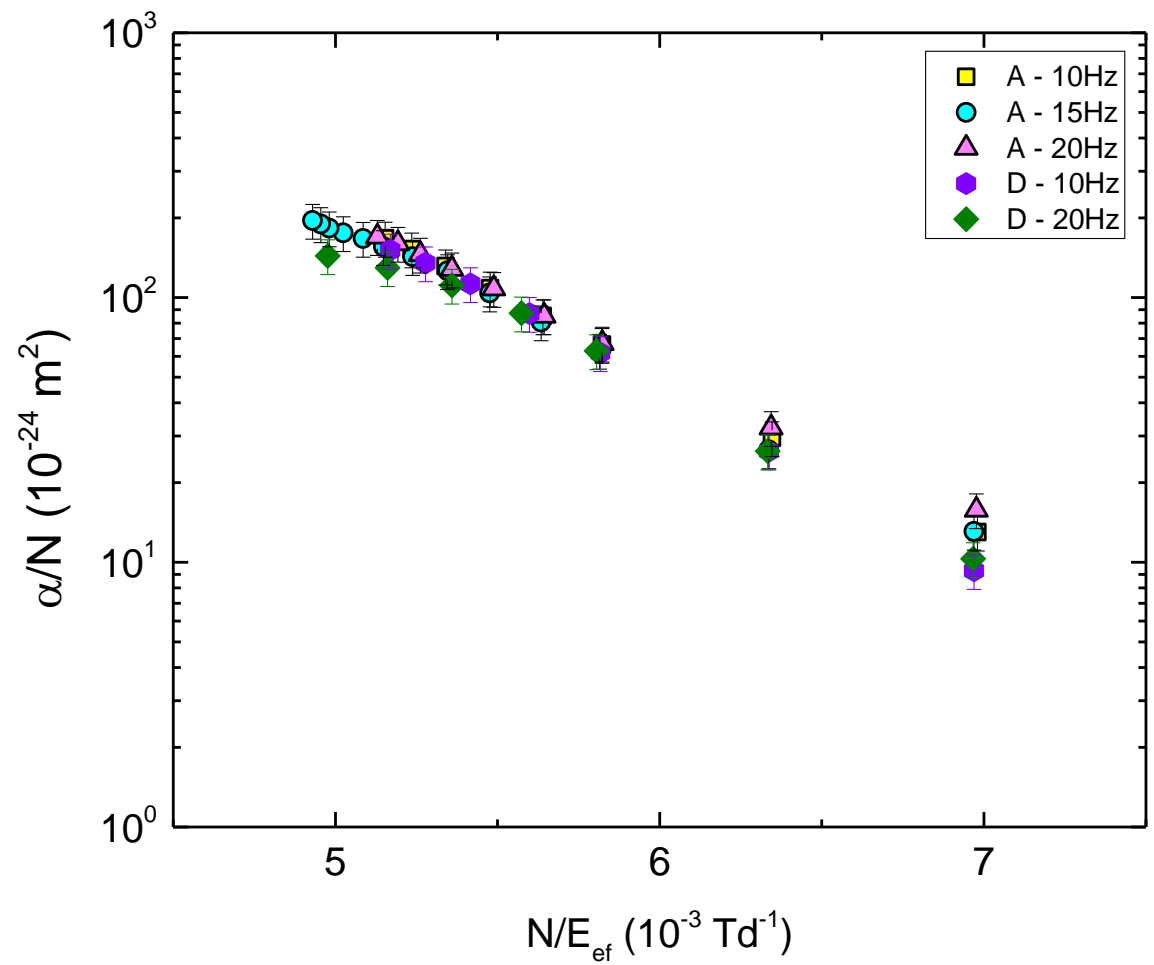

FIGURA 35 - Aplicação da parametrização de Williams e Sara [36] aos resultados obtidos com correção da queda ôhmica para o isobutano com diferentes taxas de repetição do feixe de laser.

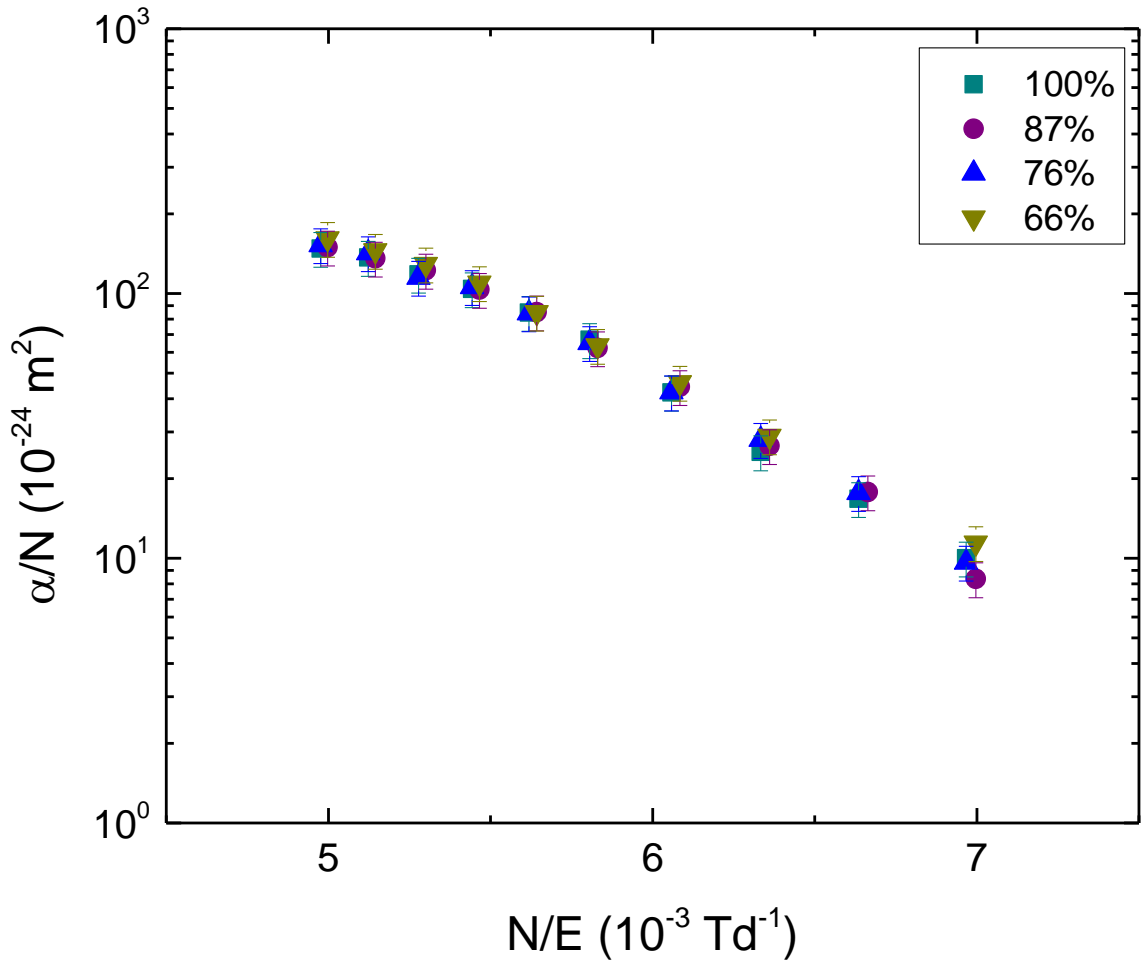

FIGURA 36 - Aplicação da parametrização de Williams e Sara [36] aos resultados obtidos sem correção da queda ôhmica para o isobutano com diferentes intensidades do feixe de laser. Taxa de repetição de $20 \mathrm{~Hz}$. 


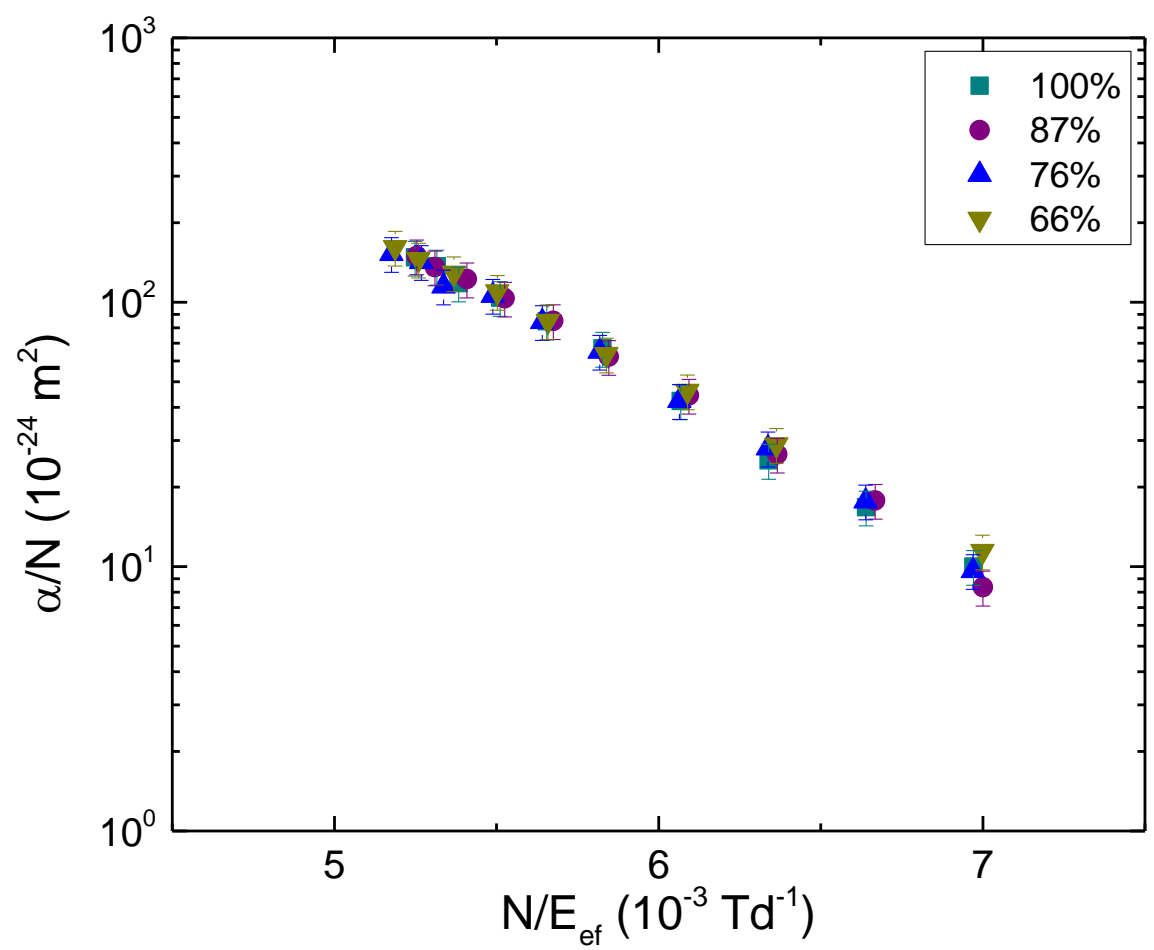

FIGURA 37 - Aplicação da parametrização de Williams e Sara [36] aos resultados obtidos com correção da queda ôhmica para o isobutano com diferentes intensidades do feixe de laser. Taxa de repetição de $20 \mathrm{~Hz}$.

Os resíduos normalizados da aplicação da parametrização de Williams e Sara [36] aos parâmetros $\alpha$ experimentais são apresentados nas FIG. 38 - 41.

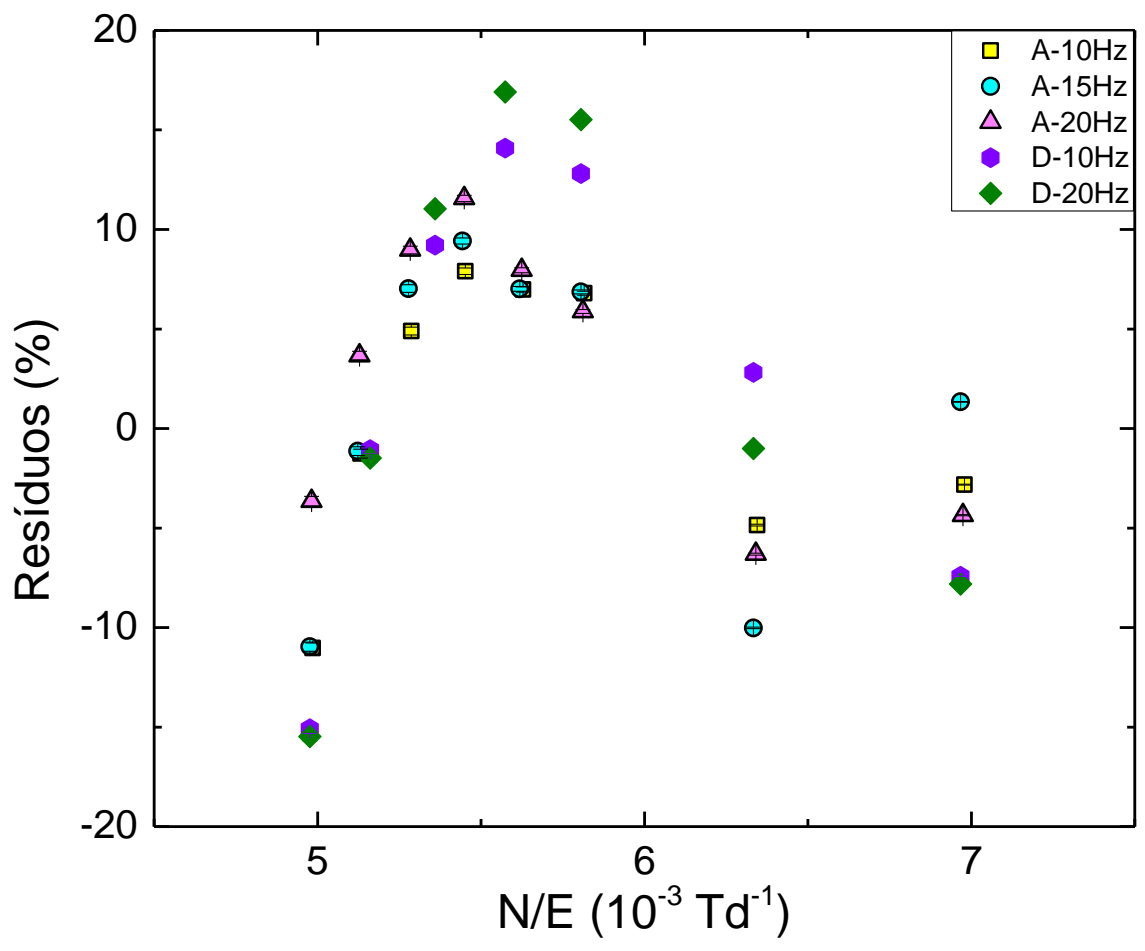

FIGURA 38 - Resíduos resultantes da aplicação da parametrização de Williams e Sara [36] aos resultados experimentais sem correção para queda ôhmica (FIG. 34). 


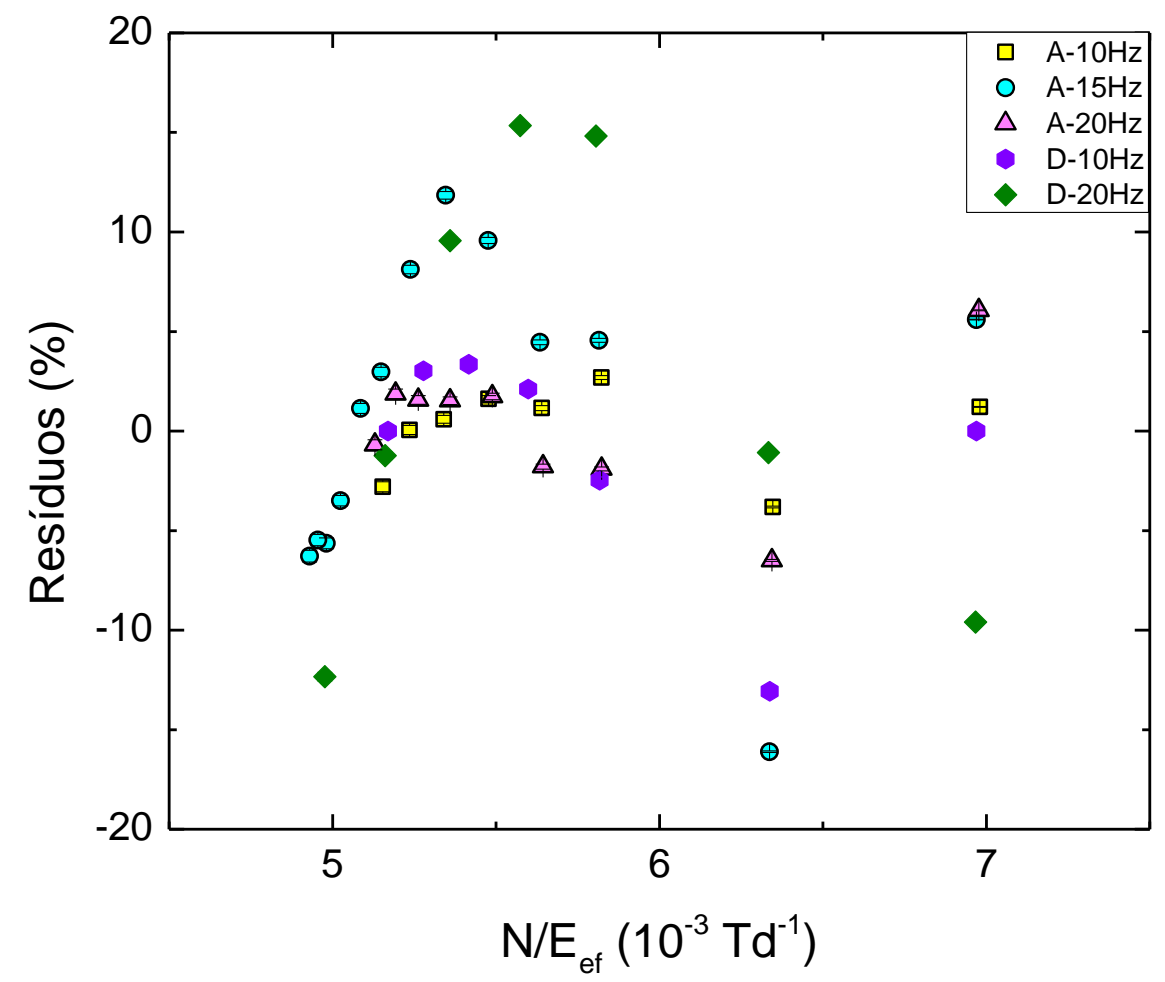

FIGURA 39 - Resíduos resultantes da aplicação da parametrização de Williams e Sara [36] aos resultados experimentais com correção para queda ôhmica (FIG. 35).

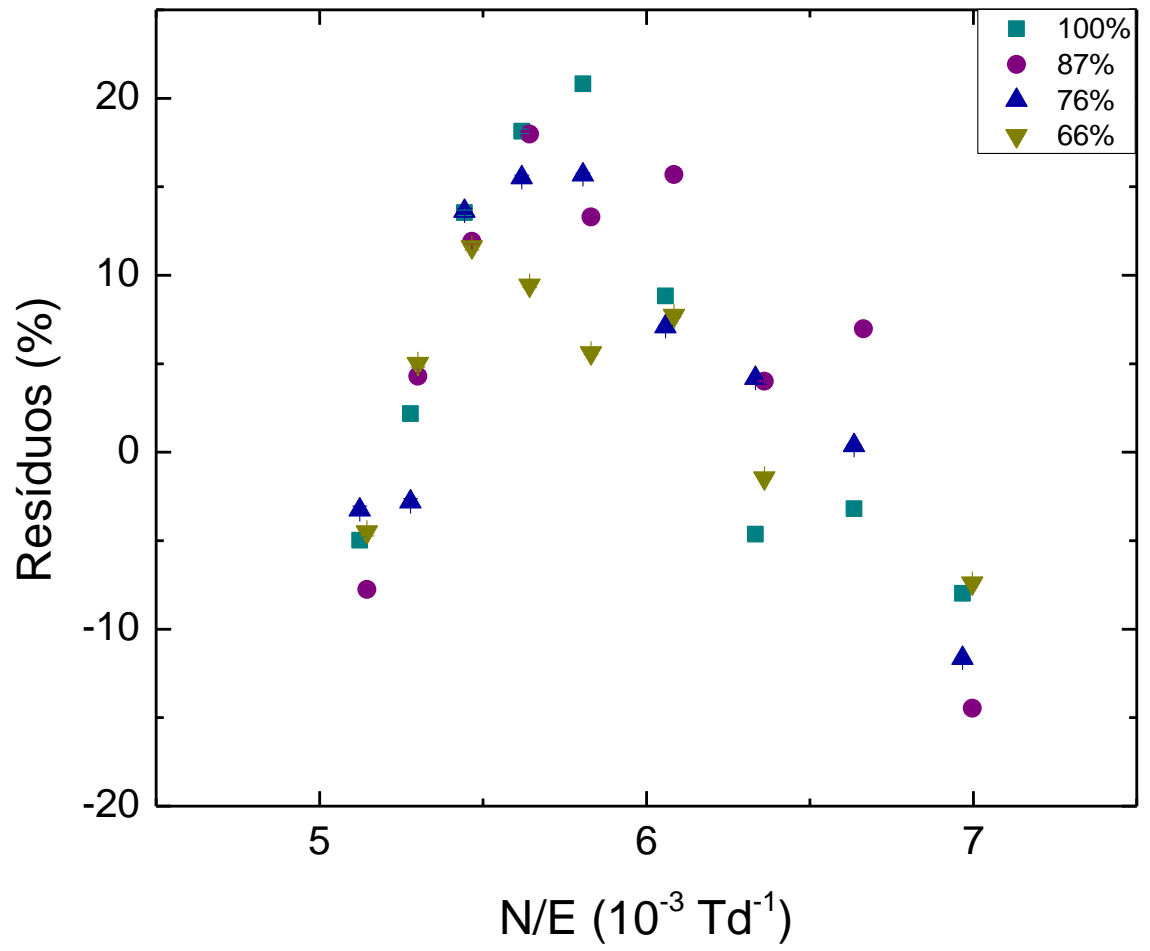

FIGURA 40 - Resíduos resultantes da aplicação da parametrização de Williams e Sara [36] aos resultados experimentais sem correção para queda ôhmica (FIG. 36). 


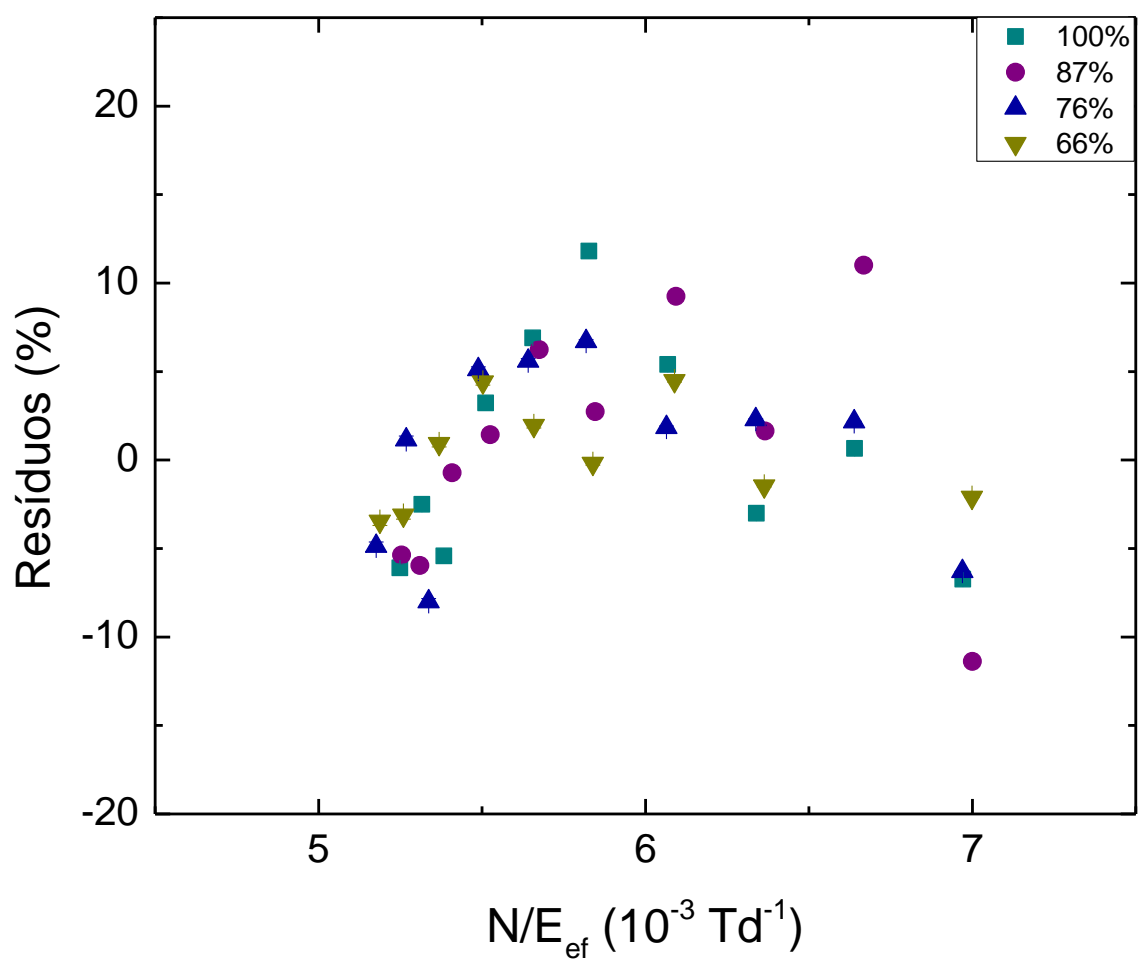

FIGURA 41 - Resíduos resultantes da aplicação da parametrização de Williams e Sara [36] aos resultados experimentais com correção para queda ôhmica (FIG. 37).

A correção para queda ôhmica diminuiu os resíduos para todos os conjuntos de dados. Porém, ao contrário do que ocorreu para o nitrogênio (FIG. 22), eles mantiveram-se tendenciosos. Por isso, os valores de A e B obtidos são comparados com os dados apresentados na literatura [49 - 51] na TAB. 12, mesmo estes sendo obtidos por métodos diferentes do aqui adotado (câmara de placas paralelas e eletrodos metálicos à baixa pressão).

A razão B/A nos fornece o potencial efetivo de ionização do isobutano (equação 18), que varia entre o primeiro potencial de ionização, que é de 10,68 eV [61], e a energia média necessária para produzir um par de íons 26,17 eV [62]. Sem corrigir a queda ôhmica, o $\mathrm{R}^{2}$ foi maior que 0,96 e com correção, $\mathrm{R}^{2}>0,99$. 
TABELA 12 - Parâmetros A e B, potencial de ionização efetivo $\left(\mathrm{V}_{\mathrm{i}}\right)$ para o $\mathrm{iC}_{4} \mathrm{H}_{10}$ e a faixa de campo elétrico, $\mathrm{E} / \mathrm{N}$, analisada.

\begin{tabular}{|c|c|c|c|c|c|}
\hline & $\begin{array}{c}\text { Correção } \\
\text { para queda } \\
\text { ôhmica } \\
\end{array}$ & $\left.\underset{\left(10^{-20}\right.}{\mathbf{A}} \mathrm{m}^{2}\right)$ & $\begin{array}{c}\mathbf{B} \\
\left(10^{-3} \mathrm{Td}\right)\end{array}$ & $\mathbf{V}_{\mathbf{i}}(\mathbf{e V})$ & $\begin{array}{l}\text { Faixa de } \\
\text { E/N (Td) }\end{array}$ \\
\hline Sharma e Sauli [49] & $*$ & 5,5 & 1,130 & 21 & $87-130$ \\
\hline Tsumaki [50] & $*$ & 7 & 1,373 & 20 & $568-1276$ \\
\hline Nakhostin et al. [51] & $*$ & 8 & 1,217 & 15 & $568-1360$ \\
\hline \multirow{2}{*}{$\mathrm{A}-10 \mathrm{~Hz}$} & Sem & $13 \pm 3$ & $1,32 \pm 0,04$ & $9,5 \pm 2,0$ & $143-201$ \\
\hline & Com & $25 \pm 9$ & $1,428 \pm 0,019$ & $5,7 \pm 2,0$ & $143-200$ \\
\hline \multirow{2}{*}{$\mathrm{A}-15 \mathrm{~Hz}$} & Sem & $12 \pm 3$ & $1,31 \pm 0,05$ & $10,9 \pm 2,8$ & $143-201$ \\
\hline & Com & $18 \pm 6$ & $1,43 \pm 0,04$ & $8,1 \pm 2,9$ & $143-230$ \\
\hline \multirow{2}{*}{$\mathrm{A}-20 \mathrm{~Hz}$} & Sem & $7,2 \pm 1,5$ & $1,21 \pm 0,04$ & $17 \pm 4$ & $143-201$ \\
\hline & Com & $14 \pm 5$ & $1,317 \pm 0,028$ & $10 \pm 3$ & $143-207$ \\
\hline \multirow{2}{*}{$\mathrm{D}-10 \mathrm{~Hz}$} & Sem & $12 \pm 6$ & $1,31 \pm 0,09$ & $11 \pm 5$ & $143-201$ \\
\hline & Com & $59 \pm 21$ & $1,594 \pm 0,023$ & $2,7 \pm 1,0$ & $143-201$ \\
\hline \multirow{2}{*}{$\mathrm{D}-20 \mathrm{~Hz}$} & Sem & $13 \pm 9$ & $1,342 \pm 0,012$ & $10 \pm 7$ & $143-201$ \\
\hline & Com & $48 \pm 17$ & $1,559 \pm 0,025$ & $3,2 \pm 1,2$ & $143-201$ \\
\hline \multirow{2}{*}{$100 \%$} & Sem & $14 \pm 6$ & $1,35 \pm 0,07$ & $9 \pm 4$ & $143-201$ \\
\hline & Com & $67 \pm 24$ & $1,589 \pm 0,028$ & $2,4 \pm 0,9$ & $143-201$ \\
\hline \multirow{2}{*}{$87 \%$} & Sem & $12 \pm 4$ & $1,31 \pm 0,06$ & $11 \pm 4$ & $143-201$ \\
\hline & Com & $88 \pm 29$ & $1,64 \pm 0,04$ & $1,9 \pm 0,7$ & $143-201$ \\
\hline \multirow{2}{*}{$76 \%$} & Sem & $12 \pm 4$ & $1,32 \pm 0,06$ & $11 \pm 4$ & $143-201$ \\
\hline & Com & $51 \pm 18$ & $1,53 \pm 0,03$ & $3,0 \pm 1,1$ & $143-201$ \\
\hline \multirow{2}{*}{$66 \%$} & Sem & $10 \pm 4$ & $1,27 \pm 0,06$ & $12 \pm 4$ & $143-201$ \\
\hline & Com & $36 \pm 13$ & $1,47 \pm 0,018$ & $4,1 \pm 1,5$ & $143-201$ \\
\hline
\end{tabular}

*Não se aplica, pois utilizaram eletrodos metálicos.

Com correção para queda ôhmica, apenas os resultados obtidos com o eletrômetro analógico para taxas de repetição dos pulsos laser de $15 \mathrm{~Hz}$ e $20 \mathrm{~Hz}$ encontramse dentro do intervalo esperado para o potencial de ionização efetivo. Sem correção, todos os valores são compatíveis com o previsto teoricamente e com os potenciais de ionização efetivo disponíveis na literatura. 


\section{CONCLUSÃO}

O sistema empregado para a medição do primeiro coeficiente de ionização de Townsend do isobutano é baseado em uma nova versão da técnica de Townsend pulsada e utiliza um detector com eletrodos em configuração semelhante à RPC. Para validação do método, foi utilizado o nitrogênio, devido aos dados bem estabelecidos na literatura para este gás.

O comportamento dos parâmetros $\alpha / \mathrm{N}$ obtidos experimentalmente foi concordante com o dos dados presentes na literatura e simulados com o programa Magboltz 2. O potencial de ionização efetivo determinado para o nitrogênio foi satisfatório, com e sem correção dos dados para queda ôhmica. Portanto, esta técnica pode ser aplicada a outros gases para a determinação dos seus valores de primeiro coeficiente de Townsend.

O primeiro coeficiente de Townsend de ionização para o isobutano foi determinado para diferentes taxas de repetição e intensidade do feixe de laser e comparado com as curvas teóricas construídas utilizando as versões 7.1 e 8.6 do programa Magboltz 2. Os valores de $\alpha / \mathrm{N}$ concordam entre si dentro do intervalo de incerteza e também com os dados das simulações, especialmente com a versão 7.1.

Os valores experimentais do parâmetro $\alpha / \mathrm{N}$ apresentam uma tendência de saturação para valores de campo elétrico reduzido acima de 200 Td. Este efeito é causado pela queda ôhmica devida ao uso de eletrodo resistivo. Ao corrigi-lo, o comportamento de $\alpha / \mathrm{N}$ se aproxima da curva do programa Magboltz 2 em toda a faixa de campo elétrico estudada. A boa concordância entre os resultados exclui a presença de efeitos de carga espacial e recombinação na montagem adotada, uma vez que esses processos dependem dos parâmetros avaliados.

Como não há dados na literatura na região de campo elétrico estudado, a menos de trabalho anterior desenvolvido no Laboratório de Desenvolvimento de Detectores Gasosos para feixe de laser sem atenuação e uma taxa de repetição de $15 \mathrm{~Hz}$, determinou-se o potencial de ionização efetivo para o isobutano aplicando a parametrização de Williams e Sara aos dados experimentais. Considerando o intervalo de $1 \sigma$, todos os valores determinados sem correção para queda ôhmica estão de acordo com o esperado. Com correção, somente os resultados obtidos para as medidas de $15 \mathrm{~Hz}$ e $20 \mathrm{~Hz}$ com o eletrômetro analógico são satisfatórios. 


\section{REFERÊNCIAS BIBLIOGRÁFICAS}

[1] TITOV, M. New developments and future perspectives of gaseous detectors. Nucl. Instr. and Meth. A, v. 581, p. 25-37, 2007.

[2] SANTONICO, R.; CARDARELLI, R. Development of Resistive Plate Chambers. Nucl. Instr. and Meth. A, v. 187, p. 377-380, 1981.

[3] AHN, S. H.; BAHK, S. Y.; HONG, B.; HONG, S. J.; ITO, M.; KANG, T. I.; KIM, B. I.; KIM, J. H.; KIM, Y. J.; KIM, Y. U.; KOO, D. G. ; LEE, H. W.; LEE, K. B.; LEE, K. S.; LEE, S. J.; LIM, J. K.; MOON, D. H.; NAM, S. K.; PARK, S.; PARK, W. J.; RHEE, J. T.; RYU, M. S. and Sim, K. S. Effects of linseed oil treatment on the forward resistive plate chamber for compact muon solenoid in the high- $\eta$ region. $\boldsymbol{J}$. Korean Phys Society, v. 46, p. 1325 - 1335, 2005.

[4] SAULI, F. Recent topics on gaseous detectors. Nucl. Instr. and Meth. A, v. 623, p. 29-34, 2010.

[5] HARTMANN, F, SHARMA, A. Multipurpose detectors for high energy physics, an introduction. Nucl. Instr. and Meth. A, v. 666, p. 1-9, 2012.

[6] FONTE, P.; PESKOV, V. High-resolution TOF with RPCs. Nucl. Instr. and Meth. $A$, v. 477, p. 17-22, 2002.

[7] SHARMA, A. Muon tracking and triggering with gaseous detectors and some applications. Nucl. Instr. and Meth. A, v. 666, p. 98-129, 2012.

[8] COUlUCCI, A.; GORINI, E.; GRANCAGNOLO, F.; PRIMAVERA, M. Measurement of drift velocity and amplification coefficient in $\mathrm{C} 2 \mathrm{H} 2 \mathrm{~F} 4$-isobutane mixtures for avalanche operated resistive-plate counters. Nucl. Instr. and Meth. A, v. 425, p. 84 - 91, 1999.

[9] BRONIC, I.K.; GROSSWENDT, B. Townsend ionization coefficient of some argon based mixtures in strong nonuniform electric fields. J. Appl. Phys., v. 88, n. 11, p. $6192-6200,2000$. 
[10] ALISOY, H. Z.; YESIL, A.; KOSEOGLU, M; UNAL, I. An approach for unipolar corona discharge in $\mathrm{N} 2 / \mathrm{O} 2$ gas mixture by considering townsend conditions. Journal of Electrostatics, v. 69, p. $284-290,2011$.

[11] FONTE, P.; MANGIAROTTI, A.; BOTELHO, S.; GONÇALVES, J.A.C.; RIDENTI, M. A.; BUENO, C.C. A dedicated setup for the measurements of the electron transport parameters in gases at large electric fields. Nucl. Instr. and Meth. $A$, v. 613, p. 40-45, 2010.

[12] SMIRNOV, B. M. Modeling of gas discharge plasma. Physics - Uspekhi, v. 52, n. 6, p. $559-571,2009$.

[13] RAETHER, H. Electron avalanches and breakdown in gases. London: Butterworth, 1964.

[14] LANGEN, K. M.; BINNS, P.J.; LENNOX, A.J.; KROC, T.K.; DeLUCA Jr.; P.M. Pileup correction of microdosimetric spectra. Nucl. Instr. and Meth. A, v. 484, p. 595-612, 2002.

[15] PISACANE, V. L.; DOLECEK, Q. E.; MALAK, H.; DICELLO, J. F. End-to-end system test for solid-state microdosemeters. Rad. Protec. Dosim., v. 151, n. 1, p. 117-128, 2011.

[16] BAUMGART, R; GRUPEN, C; MEYER, H. J.; SCHÄFER, U. Test of an iron/streamer tube calorimeter with electrons and pions of energy between 1 and $100 \mathrm{GeV}$. Nucl. Instr. Meth. A, v. 268, p. 105 - 111, 1988.

[17] DAVYDOV, Y.; OPENSHAW, R. Self-quenching streamer mode in quenching gases initiated by alpha particles. IEEE transactions on nuclear science, v. 56, n. 5, p. $2880-2884,2009$.

[18] GRUPEN, C. Particle Detectors. $2^{\text {nd }}$ ed. Cambridge, UK: Cambridge University Press, 2008.

[19] LEE, K. S. Six-gap resistive plate chambers for high-rate muon triggers. Nucl. Instr. and Meth. A, v. 661, p. S90-S93, 2012.

[20] PARK, S. K. et al. Test of a four-gap resistive plate chamber with cosmic muons and high-rate gamma-rays. Nucl. Instr. and Meth. A, v. 680, p. 134-138, 2012. 
[21] SAULI, F. Principles of Operation of Multiwire Proportional and Drift Chambers. Report CERN 77-09. Geneva (Switzerland): CERN European Organization for Nuclear Research. 1977.

[22] LIMA, I. B. Medidas do coeficiente de multiplicação gasosa do isobutano puro. 2010. Dissertação (Mestrado) - Instituto de Pesquisas Energéticas e Nucleares, São Paulo.

[23] LIMA, I. B.; MANGIAROTTI, A.; VIVALDINI, T.C.; GONÇALVES, J.A.C.; BOTELHO, S.; FONTE, F.; TAKAHASHI, J.; TARELHO, L.V.; BUENO, C.C. Experimental investigations on the first Townsend coefficient in pure isobutane. Nucl. Instr. and Meth. A, v. 670, p. 55-60, 2012.

[24] MANGIAROTTI, A.; LIMA, I.B.; VIVALDINI, T.C.; GONÇALVES, J.A.C.; PETRI, A.R.; BOTELHO, S.; FONTE, P.; BUENO, C.C. Secondary effects on electron multiplication in pure isobutane. Nucl. Instr. and Meth. A, v. 694, p. $162-$ 166, 2012.

[25] DANIEL, T. N.; HARRIS, F.M. The spatial growth of ionization current in nitrogen at voltages up to 500kV. J. Phys. B.: Atom. Molec. Phys. v.3, p.363-368, 1970.

[26] YOUSFI, M.; URQUIJO, J.; JUÁREZ, A.; BASURTO, E.; HERNÁNDEZ-ÁVILA, J. L. Electron Swarm Coefficients in CO2-N2 e Co2-O2 mixtures. IEEE Transactions on Plasma Science, vol. 37, n. 6, p. 764-772, 2009.

[27] HAYDON, S.C.; WILlIAMS, O.M. Combined spatial and temporal studies of ionization growth in nitrogen:II. J. Phys. D: Appl. Phys.,v. 9, p. 523-536, 1976.

[28] LLEWELLYN-JONES, F. Ionization and Breakdown in Gases. London, UK: Methuen \& Co LTD, 1966.

[29] MEEK, J. M.; CRAGGS, J. D. Electrical breakdown of gases. Oxford, UK: Clarendon Press, 1953.

[30] LEE, J. D. Química Inorgânica. Tradução: J. H. Maar. São Paulo: Editora Edgard Blücher LTDA, 1980.

[31] KNOLL, G. F. Radiation Detection and Measurement. $3^{\circ}$ edition. Hoboken, USA: John Wiley \& Sons, 2001. 
[32] RAJU, G. G. Gaseous Electronics. Boca Raton, USA: Taylor \& Francis Group, 2006.

[33] SMIRNOV, B. M. Physics of ionized gases. Nova York: John Wiley \& Sons, 2001.

[34] CHARLES, M. W. Gas gain measurements in proportional counters. J. Phys. E: Scientific Instruments. v. 5, p. 95 - 100, 1972.

[35] BRONIC, I. K.; GROSSWENDT, B. Gas amplification and ionization coefficients in isobutane and argon-isobutane mixtures at low gas pressures. Nucl. Instr. and Meth. B. v. 142, p. 219-244, 1998.

[36] WILlIAMS, A.; SARA, R. I. Parameters affecting the resolution of a proportional counter. Int. J. Appl. Radiat. Isotopes. v.13, p. 229-238, 1962.

[37] BUENO, C. C.; FRAGA, M. M.; GONÇALVES, J. A. C.; MARQUES, R. F.; POLICARPO, A. J. P. L.; SANTOS, M. D.S. Rate effects in a proportional counter with resistive cathode. Nucl. Instr. Meth. A, v. 408, p. 496-502, 1998.

[38] FRAGA, M. M.; MARQUES, R. F.; POLICARPO, A. J. P. L.; BUENO, C. C.; GONÇALVES, J. A. C.; SANTOS, M. D. S. Influence of resistive electrodes on detector performance. Scientifica Acta Quaderni Del Dottorato v. XIII , n. 2 , p. 1-9, 1998.

[39] SAKAI,Y; TAGASHIRA, H.; SAKAMOTO, S. The development of electron avalanches in argon at high E/N values: I. Monte Carlo simulation. J. Phys. D: Appl. Phys., v. 10, p. 1035 - 1049, 1977.

[40] SAKAI, Y; SAWADA, S.; Tagashira, H. Effect of Penning ionisation on the Townsend first ionisation coefficient of pulsed and STEADY-state Townsend experiments in Ar /Ne mixtures. J. Phys. D: Appl. Phys., v. 19, p. 2393-2400, 1986.

[41] TAGASHIRA, H; SAKAI, Y.; SAKAMOTO, S. The development of electron avalanches in argon at high E/N values: II. Boltzmann equation analysis. J. Phys. D: Appl. Phys., v. 10, p. 1051 - 1063, 1977.

[42] GAllagher, J. W.; BEATY, E. C.; DUTTON, J.; PITCHFORD, L. C. An annotated compilation and appraisal of electron swarm data in electronegative gases. J. Chem. Phys Ref. Data, v. 12, n. 1, p. $109-152,1983$. 
[43] HUNTER, S. R.; CARTER, J. G.; CHRISTOPHOROU, L. G. Electron transport measurements in methane using an improved pulsed Townsend technique. J. Appl. Phys. v. 60, p. $24-3,1986$.

[44] URQUIJO, J.; ALVAREZ, I.; BASURTO, E.; CISNEROS, C. Measurement of ionization and electron transport in methane-argon mixtures. J. Phys. D: Appl. Phys.,v. 32, p. 1646-1649, 1999.

[45] COOKSON, A. H.; WARD, B. W.; LEWIS, T. J. Townsend' s first ionization coefficient for methane and nitrogen. Brit. J. Phys. v. 17, p. 891-903, 1966.

[46] SUGAWARA, H.; SAKAI, Y.; TAGASHIRA, H. Analyses of electron swarms in gases under steady-state Townsend conditions. J. Phys. D Appl. Phys., v. 27, p. 9094, 1994.

[47] TOWNSEND, J. S. The theory of ionization of gases by collision. London, UK: Constable \& Company LTD, 1910.

[48] ABBRESCIA, M. The dynamic behaviour of Resistive Plate Chambers. Nucl. Instr. and Meth. A, v. 533, p. 7-10, 2004.

[49] SHARMA, A., SAULI, F. First Townsend coefficient measured in argon based mixtures at high fields. Nucl. Instr. and Meth. A, v. 334, p. 420-424, 1993.

[50] TSUMAKI, K. Determination of the Townsend primary ionization coefficient using a parallel plate avalanche counter. Jap. Jour. Appl. Phys. v. 27, p. 393-396, 1988.

[51] NAKHOSTIN, M.; BABA, M.; OHTSUKI, T.; OISHI, T.; ITOGA, T. Precise measurements of first Townsend coefficient, using parallel plate avalanche chamber. Nucl. Instr. and Meth. A. v. 572, p. 999 - 1003, 2007.

[52] BIAGI, S. F. Monte Carlo simulation of electron drift and diffusion in counting gases under the influence of electric and magnetic fields. Nucl. Instr. Meth. A, v. 421, p. 234 - 240,1999.

[53] BIAGI, S. F. Magboltz, The Fortran source code of the stand-alone version is freely downloadable from <http://consult.cern.ch/writeup/magboltz/> (2011). 
[54] OPAL, C. B.; PETERSON, W. K.; BEATY, E. C. Measurements of secondaryelectron spectra produced by electron impact ionization of a number of simple gases. J. Chem. Phys., v. 55, p. 4100 - 4106, 1971.

[55] HAYDON, S. C.; WILlIAMS, O. M. Experimental investigations of ionization growth in nitrogen : II. J. Phys. B: At. Mol. Phys. v.6, p. 227 - 231, 1973.

[56] NAKAMURA, Y. Drift velocity and longitudinal diffusion coefficient of electrons in nitrogen and carbon monoxide. J. Phys. D: Appl. Phys., v. 20, p. 933 - 938, 1987.

[57] PHELPS, A. V.; PITCHFORD, L. C. Anisotropic scattering of electrons by N2 and its effect on electron transport. Physical Review A, v. 31, n. 5, p. 2932 - 2949, 1985.

[58] NATIONAL INSTITUTE OF STANDARDS AND TECHNOLOGY - NIST <http://physics.nist.gov/cgi-bin/Ionization/table.pl?ionization=N2> Acesso em: 26 out. 2012.

[59] COMBECHER, D. Measurements of W values of low-energy electrons in several gases. Radiat. Res. v. 84, p. 189-218, 1980.

[60] VA' VRA, J. Physics and chemistry of aging - early developments. Nucl. Instr. And Meth. A. v. 515, p. 1 - 14, 2003.

[61] NATIONAL INSTITUTE OF STANDARDS AND TECHNOLOGY - NIST <http://webbook.nist.gov/cgi/cbook.cgi?ID=C75285\&Units=SI>. Acesso em 26 out. 2012.

[62] KLOTS, C. E. Energy-partition parameters in radiation studies of molecular gases. J. Chem. Phys. v. 44, p. 2715-2718, 1966. 